\title{
Seizures following a first cerebral infarct : risk factors and prognosis
}

Citation for published version (APA):

van Raak, E. P. M. (1996). Seizures following a first cerebral infarct : risk factors and prognosis. [Doctoral Thesis, Maastricht University]. Rijksuniversiteit Limburg. https://doi.org/10.26481/dis.19960307er

Document status and date:

Published: 01/01/1996

DOI:

10.26481/dis.19960307er

Document Version:

Publisher's PDF, also known as Version of record

\section{Please check the document version of this publication:}

- A submitted manuscript is the version of the article upon submission and before peer-review. There can be important differences between the submitted version and the official published version of record.

People interested in the research are advised to contact the author for the final version of the publication, or visit the DOI to the publisher's website.

- The final author version and the galley proof are versions of the publication after peer review.

- The final published version features the final layout of the paper including the volume, issue and page numbers.

Link to publication

\footnotetext{
General rights rights.

- You may freely distribute the URL identifying the publication in the public portal. please follow below link for the End User Agreement:

www.umlib.nl/taverne-license

Take down policy

If you believe that this document breaches copyright please contact us at:

repository@maastrichtuniversity.nl

providing details and we will investigate your claim.
}

Copyright and moral rights for the publications made accessible in the public portal are retained by the authors and/or other copyright owners and it is a condition of accessing publications that users recognise and abide by the legal requirements associated with these

- Users may download and print one copy of any publication from the public portal for the purpose of private study or research.

- You may not further distribute the material or use it for any profit-making activity or commercial gain

If the publication is distributed under the terms of Article $25 \mathrm{fa}$ of the Dutch Copyright Act, indicated by the "Taverne" license above, 
Seizures following a first

cerebral infaret

Risk factors and prognosis

door Lisette Heuts - van Raak geboren te Hilvarenbeek op

18 juni 1965

1977 - 1983

Gymnasium-B, Rijksscholengemeenschap Koning Willem II. Tilburg

1983 - 1989

Geneeskunde, Rijksuniversiteit Limburg, Maastricht

1986 - 1989

student-assistent, afdeling

Neurologie, Academisch Ziekenhuis

Maastricht, begeleider:

Dr. J. Lodder

$1989-1994$

assistent in opleiding, afdeling Neurologie, Rijksuniversiteit Limburg, Maastricht, begeleider: Dr. J. Lodder

1994 - heden arts-onderzoeker, afdeling Neurologie, Academisch Ziekenhuis Maastricht, afdelingshoofd:

Prof. Dr. J. Troost 
Seizures following a first cerebral infarct

Risk factors and prognosis 


\title{
CIP-DATA KONINKLIJKE BIBLIOTHEEK, DEN HAAG
}

\author{
Heuts-van Raak, Elisabeth Petronella Maria
}

Seizures following a first cerebral infaret : risk factors and prognosis /

Elisabeth Petronella Maria Heuts-van Raak. - [S.l. : s.n.]

Thesis Rijksuniversiteit Limburg, Maastricht. - With ref. - With summary in Dutch. ISBN 90-9009220-X

NUGI 742

Subject headings: ischaemic stroke / epileptic seizures / cerebral infarct.

Produktic en layout: Profiel Prepress. Biest-Houtakker

Omslagontwerp: Hans Heuts, ECS-Maastrichi

Copyright 1996. E.P.M. Heuts-van Raak. Maastricht. The Netherlands

All rights are reserved, whether the whole or part of the material is concerned. No part of this publication may be reproduced, stored in a retrieval system, or transmitted in any form of by any means. electronic. mechanical. photocopying, recording or otherwise, without written permission from the copyright owner. 


\title{
SEIZURES FOLLOWING A FIRST CEREBRAL INFARCT
}

\author{
Risk factors and prognosis
}

\section{PROEFSCHRIFT}

ter verkrijging van de graad van doctor

aan de Rijksuniversiteit Limburg te Maastricht, op gezag van de Rector Magnificus, Prof. Mr. M.J. Cohen, volgens het besluit van het College van Dekanen, in het openbaar te verdedigen op donderdag 7 maart 1996 om 16.00 uur

door

\section{Elisabeth Petronella Maria Heuts-van Raak}

geboren te Hilvarenbeek op 18 juni 1965 
Promotor

Prof. Dr. J. Troost

\section{Co-promotor}

Dr. J. Lodder

\section{Beoordelingscommissie}

Prof. Dr. J.A. Knottnerus (voorzitter)

Prof. Dr. J. De Reuck (Universitair Ziekenhuis Gent, België)

Prof. Dr. H. Meinardi (Katholieke Universiteit Nijmegen)

Prof. Dr. H.A.J. Struijker Boudier

Dr. H.W.M. Steinbusch

This thesis was prepared at the Department of Neurology.

University Hospital Maastricht, The Netherlands. 
No matter how much you think you want or ne'd it.

the past has to remain just that, the past....

Phil Collins, Both Sides 



\section{TABLE OF CONTENTS}

\section{List of abbreviations}

\section{Chapter 1}

General introduction

\section{Chapter 2}

Supratentorial brain infarcts in adult-onset seizures

The Maastricht Epilepsy Case Register

\section{Chapter 3}

Demographic determinants of occurrence and prognosis of epileptic seizures following a first-ever supratentorial brain infarct

Data from an ongoing prospective register

\section{Chapter 4}

Risk factors for developing epileptic seizures after a

first-ever supratentorial brain infarct

\section{Chapter 5}

Brain infarct lesion location and the risk of seizures

Can specific epileptogenic cortical gyri be identified?

\section{Chapter 6}

Seizure risk and peri-stroke medication use

\section{Chapter 7}

General discussion

Can seizures following a first cerebral infarct be predicted, and should high risk brain infarct patients be treated prophylactically with anti-epileptic drugs?

\section{Chapter 8}

Summary

Samenvatting

Appendix

References 


$\begin{array}{ll}\text { ACA } & \text { Anterior cerebral artery } \\ \text { ACE } & \text { Angiotensin converting enzyme } \\ \text { ADL } & \text { Activities of daily life } \\ \text { AED } & \text { Anti-epileptic drug } \\ \text { ATP } & \text { Adenosine triphosphate } \\ \text { BBB } & \text { Blood-brain barrier } \\ \text { BDZ } & \text { Benzodiazepine(s) } \\ \text { CE } & \text { Cardioembolic (territorial infarct or source of embolism) } \\ \text { CI } & \text { Confidence interval } \\ \text { CNS } & \text { Central nervous system } \\ \text { COPD } & \text { Chronic obstructive pulmonary disease } \\ \text { CT } & \text { Computed tomography } \\ \text { CVD } & \text { Cerebrovascular disease } \\ \text { DM } & \text { Diabetes mellitus } \\ \text { EAA } & \text { Excitatory amino acid(s) } \\ \text { ECG } & \text { Electrocardiography } \\ \text { EEG } & \text { Electroencephalogram } \\ \text { GABA } & \text { y-aminobutyric acid } \\ \text { HR } & \text { Hazard Ratio } \\ \text { IF } & \text { Inferior frontal gyrus } \\ \text { IHD } & \text { Ischaemic heart disease } \\ \text { IRR } & \text { Incidence Rate Ratio } \\ \text { LACI } & \text { Lacunar infarct } \\ \text { MCA } & \text { Middle cerebral artery } \\ \text { Md } & \text { Median } \\ \text { MECR } & \text { Maastricht Epilepsy Case Register } \\ \text { MF } & \text { Middle frontal gyrus } \\ \text { MRI } & \text { Magnetic resonance imaging } \\ \text { MT } & \text { Middle temporal gyrus } \\ \text { N } & \text { Number } \\ \text { OR } & \text { Odds Ratio } \\ \text { PC } & \text { Post-central gyrus } \\ \text { PCA } & \text { Posterior cerebral artery } \\ \text { PSE } & \text { Post-stroke epilepsy } \\ \text { PSS } & \text { Post-stroke seizurels) } \\ \text { RI } & \text { Remaining territorial infarcts } \\ \text { SAH } & \text { Subarachnoid Haemorrhage } \\ \text { seiz } & \text { seizure(s) } \\ \text { SM } & \text { Supramarginal gyrus } \\ \text { SNPR } & \text { Substantia nigra pars reticulata } \\ \text { ST } & \text { Superior temporal gyrus } \\ \text { theo } & \text { theophylline } \\ \text { TIA } & \text { Transient ischaemic attack } \\ \text { vS } & \text { versus } \\ & \end{array}$




\section{CHAPTER 1}

General introduction 
Stroke ranks third as cause of death in the western world. ${ }^{63,86,93,198}$ It is also one of the most important causes of lasting disability in older adults. ${ }^{63.86 .198}$ Some stroke patients will additionalily be handicapped by the occurrence of epileptic seizures. Developing epilepsy is an alarming event with a consequent decline in the quality of life, especially in patients who already experience a reduced quality of life as a result of the persistent neurological impairment due to a stroke.

Stroke is a highly prevalent disease, and its occurrence is directly related to age. 63.86 .198 The annual incidence of first-ever stroke in the general population in the Netherlands is approximately $150 / 100.000$; in patients $65-74$ years it is almost 700/100,000 and in patients older than 75 years even $1,600 / 100,000.86$ Because of the ageing of our population and the increasing survival-rate after a stroke, ${ }^{86,93,131,148}$ the number of people at risk for developing stroke, and consequently those with post-stroke epilepsy probably will increase.

Post-stroke epilepsy is not a modern concept. The relationship between cerebrovascular discase (CVD) and seizures has been recognized since 1864 , when John Hughlings Jackson reported partial seizures complicating embolic stroke: "It is not very uncommon to find when a patient has recovered or is recovering from hemiplegia, the result of embolism of the middle cerebral artery. or of some branch of this vessel, that he is attacked by convulsion beginning in some part of the paralyzed region." "I7 In 1885 William Gowers, in his book on epilepsy and other chronic convulsive diseases, even entitled one of the chapters "Posthemiplegic Epilepsy". ${ }^{77}$ Therefore. it is rather puzzling that there are still so many questions about post-stroke epilepsy, and that the subject of epileptic seizures and acute stroke has received relatively little attention in the literature.

In the literature the problem of post-stroke epilepsy is addressed in two different ways. Firstly, patients with so-called "late onset epilepsy" have been studied to find out if they ever had a stroke which then might be the cause for their epileptic seizures $2.6 .21,44,51.53,59.61 .76,85.88,99.111 .112,115,128,149,150.160 .162 .167 .172 .173,175,181.200$ Such studies resulted in figures between 11 and $54 \%$ of adult epilepsy patients in whom a prior "stroke" was the presumable cause for their seizures. $6.44 .53 .59 .85,88.112$. 115.150.167.172 However, the results varied widely, and are difficult to compare because of greatly varying study methods. The definition of so-called "late onset epilepsy" varies between studies from the first epileptic seizure after the age of 20 , to the first seizure after the age of 40.50 or even 60 . Many studies were done before the advent of CT. Furthermore, the possible causes of the epileptic seizures were not uniformly assessed. Some studies clearly referred to strokes as the cause of the seizures, whereas many studies included "cerebrovascular disease" as underlying cause, which not necessarily means the same. Besides, nearly all studies failed to detect the cause of epilepsy in every patient: the percentage "unknown cause" varied from zero to $75 \%$. Nevertheless, despite these difficulties in interpretation. it is now generally accepted that "cerebrovascular disease" (including stroke) is the most frequent cause of late onset epilepsy, especially in adults above the age of 60 . in whom in almost $40 \%$ 
cerebrovascular disease can be detected as the most probable cause for their epilepsy. ${ }^{44.51 .88 .111 .115 .173,175}$ As approximately $30 \%$ of all new epilepsy patients are 60 years or older, $82.111,114,181,182$ "post-stroke epilepsy" is the cause for their epileptic seizures in almost $12 \%$ of all new epilepsy patients.

A different approach to study the relationship between stroke and epilepsy is to

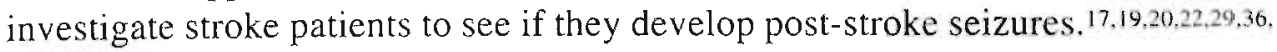
$37,43,45-47,49,54,55,58,60.61,69,80,83,88,90,92,100-102,104,107,113.118,124-127,135-137,140-142,146,152,154-156,166$, 168,174,176,188,193 The frequency of post-stroke epilepsy varies between such studies from zero to more than $50 \%$. 17.19,20.29,36,37.45-47.54,55, $\$ 8,69.83,88.90,100,102.104 .113,118,124,123$. 136,137,140-142,146.154-156.166.168.174.188.193 Unfortunately, most studies were retrospective, whereas they should have been prospective with follow-up at least until the first seizure occurred. Again, studies are difficult to compare due to differences in study methods: type of stroke studied, patient inclusion criteria, duration of follow-up, and definition of what post-stroke epilepsy signified. Many studies were based on small numbers, used unclear selection criteria and an insufficient ascertainment of the type of stroke, especially in the pre-CT era. Some investigators included patients with a prior history of epilepsy, whereas others excluded patients who only had one single post-stroke seizure. Besides the reported differences in the frequency of post-stroke epilepsy, risk factors for developing seizures also differed between studies. Some authors reported the highest risk of post-stroke seizures in patients with cerebral haemorrhage, 5 , $69,100.127$ whereas others found that haemorrhagic infarction, $8,45,100,104,107,127$ or embolic stroke had the highest risk. $45,90.107,118,124,127,146$ Some reported that not stroketype but large infarct size, $80.100 .104,137,152$ or cortical involvement of the lesion $17.20,22,29.45,53,55,80,92,100,101.104 .107 .118 .127 .137 .140,146,152,174,193$ increased the risk of seizures. Opinions on seizure recurrences also diverged. Some reported recurrent seizures to be less frequent if the initial seizure occurred early after stroke. ${ }^{80.113 .114}$ The effectiveness of anti-epileptic drug (AED) therapy also varicd largely between studies. As early as 1967 Fine considered prophylactic treatment with AED's in stroke patients when he wrote: "The question of prophylactic anticonvulsants must be seriously considered in cases of hemiplegia secondary to cerebrovascular disease. It will in due course be necessary to have extensive trials in order to discover whether such an approach could prevent unnecessary invalidism and hospitalization." 60 Until now such trials have not been performed.

In conclusion: despite many reports on post-stroke epilepsy (PSE), due to the above mentioned discrepancies in the literature, many questions on PSE remain still unanswered, whereas PSE is an important health care problem that will likely increase in the future, as the number of stroke victims will rise.

The incidence of epileptic seizures following stroke is probably not very high, most authors agree on 6-8\%. However, these figures have a greater impact when one takes into consideration that cerebrovascular diseases are highly prevalent and that they constitute one of the most frequent causes of epilepsy in the elderly. In addition, epilepsy among the elderly is even more hazardous than 
among the young because many elderly patients live alone. making the postictal states especially dangerous. Besides, seizures increase the risk of bone fractures due to concomitant osteoporosis. Furthermore, cognitive impairment related to seizures or anti-epileptic medication ${ }^{89,108,144,147}$ may superimpose on previous intellectual deterioration leading to severe cognitive dysfunction and functional dependency. Epileptic seizures may also lead to a transient or persistent worsening of neurological deficit due to a stroke. because of a direct effect of the seizure itself on the infarcted area, possibly by an excessive release of excitatory amino acids. 24.81 .124 All this implicates that seizure control is a major priority in the management of patients with stroke, not only to prevent the known complications of seizures, but also to prevent persistent neurological sequelae.

All these considerations emphasize the need for more extensive investigations and careful treatment of patients with epilepsy following a stroke. Prospective series of well-defined stroke patient subgroups could give more insight into the impact of different factors involved in the development of post-stroke epilepsy. and could also lead to identify high risk patients, in whom prophylactic antiepileptic drug treatment may be considered, not only to prevent seizures, but possibly also to lower the chance of the development of a persistent epileptic brain focus. Therefore. we decided to study the occurrence of and risk factors for epileptic seizures in a prospective register of all adult patients presenting with a first-ever-in-a-lifetime symptomatic supratentorial brain infarct. Brain infarct patients were chosen. because they make up approximately $80 \%$ of all stroke patients, ${ }^{14.23,63.86}$ and they have a relatively favourable survival rate, and consequently a relatively high risk to develop post-stroke seizures. We assumed that infarcts in the cerebellum or brain stem (approximately $15 \%$ of all brain infarcts) were not often associated with seizures. and therefore only patients with a supratentorial brain infarct were included. The results of this prospective study are described from chapter 3 of this thesis.

In chapter 2 the contribution of supratentorial brain infarction to the occurrence of late onset epilepsy is studied in epileptic patients. registered in the Matstricht Epilepsy Case Register, who had experienced their first epileptic seizure after the age of twenty. The following questions are answered: what is the contribution of supratentorial brain infarction to the occurrence of adult-onset epilepsy: what is the time-course of seizure development in such paticnts: do such patients sustain territorial infarcts more often than lacunar infircts: can "specific epileptogenic" cortical gyri be identified?

In chapter 3 the "Patients and methods" of the prospective stroke register study are described extensively and demographic data are reported. To study the relationship between brain infirct and epileptic seizures most accurately, only patients with a firs: symptomatic supratentorial brain infarct were included and followid. Any seizure occurring after this first cerebral infarct was regarded as a pust-stroke scizure, despite the simultaneous presence of another possible cause for the seizure, like metabolic disturbances or recurrent stroke. The frequency of 
post-stroke seizures and seizure delay are described. The influence of age and sex as possible risk factors is investigated, and the prognosis of post-stroke seizures is described, both with regard to seizure recurrences and survival.

In chapters $\mathbf{4}$ and $\mathbf{5}$ risk factors for the development of post-stroke seizures are explored in order to identify a high risk group of patients that will benefit from anti-epileptic drug treatment after stroke to prevent the occurrence of post-stroke seizures. In chapter 4 general risk factors are explored in all patients. In chapter 5 only the patients with a first-ever CT-confirmed symptomatic territorial brain infarct involving the cortex are studied for the possible existence of specific epileptogenic cortical areas.

In chapter 6 the influence of medication, other than anti-epileptic drugs, on the occurrence of post-stroke seizures is explored. The results of this chapter may not only be helpful in defining high risk groups more accurately, but also indicate what drugs should especially be avoided in stroke patients to lower the risk of post-stroke seizures.

Finally, in chapter 7 the characteristics of high risk patients are described, and some practical guide-lines to lower the risk of post-stroke seizures are provided.

\section{In summary the purposes of this thesis are:}

- to establish the frequency and prognosis of post-stroke epilepsy in a prospective series of a well-defined stroke patient subgroup: patients with a first symptomatic cerebral infarct

- to identify clinical and CT-scan features involved in the development of poststroke suizures following a first cerebral infarct

- based on this data. to provide rational guide-lines for the treatment of patients with a first-ever symptomatic cerebral infarct to lower the risk of post-stroke seizures 



\section{CHAPTER 2}

Supratentorial brain infarcts in adult-onset seizures The Maastricht Epilepsy Case Register

Adapted from:

Heuts-van Raak EPM, Boellaard A, de Krom MCTFM, Lodder J.

Supratentorial brain infarcts in adult-onset seizures;

the Maastricht Epilepsy Case Register.

Seizure 1993: 2: 221-227. 
As described in the general introduction in 11 to $54 \%$ of adult epilepsy patients a prior stroke is the probable cause for their epileptic seizures. $6.44,53.59,85.88 .112 .115$. 150.167.172 Besides differences in study methods and patient inclusion criteria (especially age), this large variation may in part relate to differences between studies in the number of patients with different stroke subtypes, especially in the era before the advent of computed tomographic head scanning, as the risk of developing post-stroke seizures may vary with the type of stroke. ${ }^{90,100,137.146}$

Therefore, the contribution of the most frequent stroke subtype (supratentorial brain infarction) to the occurrence of adult-onset epilepsy was retrospectively studied in 680 epileptic patients, registered in the Maastricht Epilepsy Case Register (MECR), who had experienced their first epileptic seizure after the age of twenty. In addition the following questions were studied: is the contribution of symptomatic supratentorial brain infarction to the occurrence of epilepsy in adults related to age; what is the time-course of seizure development in such patients; do such patients sustain territorial infarcts more often than lacunar infarcts: can "specific epileptogenic" cortical gyri be identified, using a detailed topographical brain atlas?

\section{Patients and methods}

Patients had been registered in the Maastricht Epilepsy Case Register (MECR). The MECR started in 1983, aiming to register all patients with epilepsy living in a geographically well-defined area in the southern part of the Netherlands (ZuidLimburg). Patients are registered by neurologists, paediatricians, and psychiatrists, working in private practice, hospitals or other health care institutes. On registration a standardized intake form is filled out including among others the patients' sex, date of birth, date of first seizure, number of seizures, seizure type (according to the international classification of epileptic seizures ${ }^{39}$ ), presumed cause for the epileptic seizures, date of starting antiepileptic medication. number of seizures before medication, type of medication, electroencephalogram (EEG) abnormalities, as well as some items related to socioeconomic status and occupation. The included presumed causes of epilepsy are: birth-trauma: meningoencephalitis: metabolic encephalopathy; stroke or cerihral atherosclerosis: head trauma: cerebral tumour: aneurysm; any other specific cause; unknown causc. Patients are only registered after informed consent: all information is handled in a strictly confidential manner, monitored by the MECR monitoring commitlec. A follow-up form is filled out on each follow-up contact. This form registers among others the number and type of seizurs since latest follow-up, and any change in medication. All forms are sent to the central office in Maastricht where they are checked for completeness, and stured in the data bank. We estimated that at the time of the present study the number of patients registered with the MECR was not complete. Therefore, and in the absence of a population census, we decided that the MECR was not yet fit 
for proper epidemiological study on post-stroke epilepsy, although patients most likely missing were those under the age of twenty, because of minimal patient attribution to the MECR by paediatricians so far. However, in our opinion, the MECR was yet suited to estimate the frequency of epilepsy following a brain infarct relative to all causes.

For practical reasons, one of which was that at the time of the study most of the patients in some parts of the study area would not have had CT, the study was limited to two of the major hospitals' adherent populations, Heerlen and Maastricht. For the aim of the study the query was restricted further to those MECR patients who had experienced their first seizure after the age of twenty; 680 patients fulfilled this requirement, of whom 101 had "stroke or cerebral atherosclerosis" listed as presumed cause of epilepsy. We considered "postinfarct epilepsy" as one or more epileptic seizures at any time following a symptomatic (with clinical signs and symptoms) supratentorial brain infarct, without any other cause than the sustained stroke, in a patient not already suffering from scizures before this stroke. CT either showed evidence of a sustained territorial, lacunar, or striatocapsular infarction, or was without a specific lesion. After studying the medical records of the 101 patients with "stroke or cerebral atherosclerosis", 65 patients met our inclusion criteria. Of these patients the following data were collected: sex. stroke-date and age at the time of stroke, time between stroke and last follow-up or death, age at first seizure. time between stroke and first seizure. number of seizures, if and when patients received anti-epileptic treatment, and time between stroke and CT. Cerebral CT scans were reviewed and in territorial lesions on CT the affected cortical gyri were identified according to Bories' method. ${ }^{27}$ Five patients experienced a recurrent stroke before the first seizure; in three of them the recurrent stroke was considered most likely to be related to the occurrence of the seizures, because of the rather long time-interval between first stroke and first seizure. In the two remaining patients the first stroke was used as the index event.

\section{Results}

Of the 65 patients with post-infarct epilepsy registered in the MECR, 46 were men $(71 \%)$ and 19 were women $(29 \%)$. Median follow-up (time between stroke and last contact or death) was 5.5 years (range 117 days - 17.2 years). The distribution (in decades) of age at the time of the first seizure of all 680 patients, and those suffering from post-infarct epilepsy is shown in table 2.1. Median age in the post-infarct epilepsy group was 65 (range 33-90) years. In seven patients the exact stroke date was unknown; in five of them CT was performed, a lesion compatible with sustained infarction was seen in four. In the remaining 58 patients the median delay between stroke and the first post-stroke seizure was 7.5 months (range 0 days -8 years). 
Table 2.1: Age at first seizure in patients registered in the MECR

\begin{tabular}{lrrrrrrr}
\hline $\begin{array}{l}\text { Age in } \\
\text { years }\end{array}$ & All patients (\%) & $\begin{array}{c}\text { Patients with post- } \\
\text { infarct epilepsy }(\%)\end{array}$ & $\begin{array}{c}\text { Percentage of } \\
\text { post-infarct } \\
\text { epilepsy }\end{array}$ & \multicolumn{2}{c}{$\begin{array}{c}\text { Patients with } \\
\text { other causes }(\%)\end{array}$} \\
\hline $20-29$ & 209 & $(31)$ & 0 & $(0)$ & $0 \%$ & 209 & $(34)$ \\
$30-39$ & 138 & $(20)$ & 4 & $(6)$ & $3 \%$ & 134 & $(22)$ \\
$40-49$ & 86 & $(13)$ & 6 & $(9)$ & $7 \%$ & 80 & $(13)$ \\
$50-59$ & 96 & $(14)$ & 13 & $(20)$ & $14 \%$ & 83 & $(13)$ \\
$60-69$ & 82 & $(12)$ & 21 & $(32)$ & $26 \%$ & 61 & $(10)$ \\
$70-79$ & 64 & $(9)$ & 16 & $(25)$ & $25 \%$ & 48 & $(8)$ \\
$\geq 80$ & 5 & $(1)$ & 5 & $(8)$ & $100 \%$ & 0 & $(0)$ \\
\hline Total & 680 & $(100)$ & 65 & $(100)$ & $10 \%$ & 615 & $(100)$ \\
\hline
\end{tabular}

Table 2.2: Time between symptomatic supratentorial brain infarct and first seizure in 58 of 65 patients with post-infarct epilepsy, registered in the MECR (in seven patients time of stroke not certified)

\begin{tabular}{lcc}
\hline Seizure delay & Number of patients & Percentage \\
\hline $0-24$ hours & 9 & 15 \\
1 day $-\leq 2$ weeks & 5 & 9 \\
$>2$ weeks $-\leq 1$ year & 22 & 38 \\
$>1$ year $-\leq 2$ years & 11 & 19 \\
$>2$ years & 11 & 19 \\
\hline
\end{tabular}

"Ear/y" and "late" seizures

Nine patients had their first seizure at stroke onset. Early seizures were never single. Table 2.2 shows seizure delay in more detail. If wi consider "early" ( $\leq 2$ weeks) and "late" ( $>2$ weeks) seizures. then half of the late seizures developed within the first year post-stroke, whereas $25 \%$ developed later than two years post-stroke. All of the fourteen patients with early seizures received anti-epileptic treatment. that was started after a median of two (range 1-6) seizures. and continued at the time of the study in all patients. Eight of these 14 patients $(57 \%)$ experienced one or more recurrent seizures despite anti-epileptic treatment. Three of the 44 patients $(7 \%)$ with late seizures received no antiepileptic treatment at all following their first seizure. and were without recurrences during a median follow-up of 18 months. The remaining 41 patients with late seizures received anti-epileptic treatment. which was started after a median of two (range 1-6) seizures. and continued at the time of the study in 37 pattients. Twenty-eight of these 41 patients $(68 \%)$ experienced one or more recurrent seizures despite anti-epileptic treatment. 


\section{Single and multiple seizures}

Eight patients (12\%) experienced a single, late seizure, after a median of 2.1 years (range 34 days -7 years) following stroke. Five of them were treated with anti-epileptic drugs, three not. Their median age at the time of stroke was 70 (range 52-84) years. Fifty-seven patients (88\%) had two or more epileptic seizures following stroke, in fourteen of whom $(25 \%)$ the first seizure had occurred early (early seizures were never single). Median delay between stroke and first seizure in these patients with multiple seizures was 6.9 months (range 0 days -8 years), median age at the time of stroke was 63 (range 33-90) years. All were treated with anti-epileptic drugs and thirteen (23\%) experienced no more seizures after initiation of the treatment.

\section{CT-findings}

Fifty-two patients $(80 \%)$ had one or more CT scans. Of 41 patients $(79 \%)$ the scans were available for the study. Median delay between stroke and CT was 15 days (range 0 days -11 years). Thirty-eight scans showed at least one lesion compatible with sustained infarction. Table 2.3 shows the number of patients with different infarct types on their CT. Table 2.4 shows the affected gyri in the middle cerebral artery (MCA) territory infarcts involving the cortex $(\mathrm{N}=26)$ according to Bories' templates. ${ }^{27}$ Either one of the three most frequently affected gyri was involved in all of these 26 patients. The affected gyri in the posterior cerebral artery (PCA) territory $(\mathrm{N}=9)$ are also shown in table 2.4.

Table 2.3: Infarct types on CT in 38 patients with post-brain-infarct epilepsy

\begin{tabular}{lrr}
\hline Infarct type & Number of patients & Percentage \\
\hline Cortical infarct(s) only & 28 & 74 \\
Lacunar infarct(s) only & 6 & 16 \\
Cortical and lacunar infarct & 2 & 5 \\
Cortical and striatocapsular infarct & 1 & 3 \\
Cortical and watershed infarct & 1 & 3 \\
\hline
\end{tabular}

1) Six had two infarets: 2) Three had two infarets, one had seven infarets 
Table 2.4: Frequency of affected cortical gyri in 23 post-infarct epilepsy patients with MCA infarct, 6 with PCA infarct, and 3 with infarcts in both territories

\begin{tabular}{lrrlrr}
\hline \multicolumn{1}{c}{ MCA (26 patients) } & & & PCA 19 patients) \\
Gyrus & $\mathrm{N}$ & $\%$ & Gyrus & N & $\%$ \\
\hline Orbital & 2 & 8 & Parahippocampal & 2 & 22 \\
Superior temporal & 15 & 58 & Fusiform & 3 & 33 \\
Middle temporal & 16 & 62 & Uncus & 0 & 0 \\
Inferior temporal & 3 & 12 & Occipital lobe & 4 & 44 \\
Middle frontal & 4 & 15 & Cingulate & 1 & 11 \\
Inferior frontal & 7 & 27 & Lingual & 5 & 56 \\
Precentral & 16 & 62 & Cuneus & 2 & 22 \\
Post-central & 12 & 46 & Precuneus & 0 & 0 \\
Supramarginal & 20 & 77 & & & \\
Angular & 12 & 46 & & & \\
Occipital lobe & 2 & 8 & & & \\
Superior parietal lobule & 3 & 12 & & & \\
\hline
\end{tabular}

\section{Discussion}

At the time of the present study approximately 60 per cent of all adult patients with epilepsy in our study area had been registered with the MECR. This estimation is based on data from the study by Hauser and Kurland $\$ 2$ who found an overall epilepsy prevalence rate of $1: 185(0.54 \%)$, data from a recent Dutch prevalence rate estimate of $1: 196(0.51 \%)$ by Van de Lisdonk et al. ${ }^{109}$ and data from demographic figures acquired from the Dutch Central Statistical Office. By assuming that an overall prevalence rate of $0.54 \%$ is similar to a rate of $0.51 \%$, and that the age-distribution of the total population in Rochester corresponds with that of the adlerent populations of Hecrlen and Maastricht, we found the population based study by Hausicr and Kurland\$2 suited for comparison with our adherent populations. Therefore the age-specific prevalence rates from the study by Hauser and Kurland were applied to the age-specific population figures of our study arcil (alcyuired from the Dutch Central Statistical Office) and for each agegroup the number of patients that would have been registered if all the patients with epilepsy in our study area would have been included in the MECR was determined. By comparing thes expected figures with the actually registered patients. it appeared that the children between 0 and 9 years were severely underreported. whereas of the patients with epilepsy over the age of twenty 61 per cent of the expected number had becn registered.

We were primarily interested in the question how much ischaemic stroke, that 
makes up approximately 80 per cent of all strokes, ${ }^{14,23,63.86}$ contributed to the occurrence of epilepsy in adults related to age. Our overall percentage of 10 (95\% CI: 8-12) is low compared to similar studies. . $^{4.44,53.59,85.88 .112,115,150.167 .172}$ The fact that only patients with a clear history of stroke most likely due to a supratentorial brain infarct, with compatible CT, were included, probably accounts for this difference. Moreover, patients with cerebral haemorrhage, those with vertebrobasilar stroke, and those with the rather vague description of "cerebral atherosclerosis", a presumed diagnosis often applied when elderly patients suffer seizures without apparent cause, were excluded. Nevertheless, some of our patients without CT and some with CT performed later than two weeks following stroke, still might have suffered small cerebral haemorrhage, as sustained infarction cannot always fully reliably be differentiated from a scar left from haemorrhage, ${ }^{64}$ as CT scanning later than approximately two weeks following stroke may not differentiate reliably between infarction and haemorrhage. ${ }^{48}$ However, if so, we expect this number to be low, probably not biasing our final results. Table 2.1 shows that with increasing age at first seizure, brain infarction as the presumed cause of epilepsy increases as well, undoubtedly reflecting increasing frequency of stroke with increasing age. Thus, almost one quarter of epilepsy patients with first seizure after the age of 50 sustained a prior brain infarct accounting for their epilepsy.

Sixty-two per cent of our patients experienced their first seizure within one year (24 per cent even within two weeks), and 81 per cent within two years following brain infarction. This differs from other studies that found $38-100$ (median 73) per cent within one year, and 75 - 100 (median 100) per cent within two years following brain infarction. $36,46,49,60,80,90,137,1+0.1+6,176$ The longer period before first seizure in our series is possibly related to the prolonged follow-up with a median duration of 5.5 years, and to the above mentioned differences in study methods. Time between stroke and first seizure in hospital series is likely to be shorter compared with a register as ours, because hospital series likely include patients with seizures at stroke onset more often, as well as patients who develop seizures and eventually die following stroke. Compared with earlier series our study might also have registered more patients with late onset post-stroke epilepsy because of increasing stroke survival over the past decades. ${ }^{86,93.131 .148}$

There is no consensus in the literature about what the term "post-stroke epilepsy" significs. Most authors do not provide a clear definition, whereas some ${ }^{174}$ suggest the term should be restricted to indicate recurrent seizures following a stroke, but not in the early phase, which is often arbitrarily set at the first two weeks post-stroke. However. the occurrence of late seizures is undoubtedly influenced by anti-epileptic treatment in patients with early seizures. Such treatment is most likely to be initiated in cases with multiple early seizures, as was the case in our study. Therefore, we adopted a pragmatic approach in describing different aspects of post-brain infarct seizures rather than adhere to an arbitrary definition of post-stroke epilepsy. Early seizures may indicate an increased risk of seizure recurrences (post-stroke epilepsy). ${ }^{101}$ Fifty-seven per 
cent of our patients with early seizures had seizure recurrences, and could be considered to have developed epilepsy, the more so because seizures recurred despite anti-epileptic treatment. The size of the stroke population our patients stem from is unknown. However, considering that the NINDS Stroke Data Bank $^{29}$ found subsequent seizures in only 6.5 per cent of their stroke patients. our 44 patients that developed late seizures likely represent a very low percentage of all stroke patients without early seizures. This supports the assumption that stroke patients with early seizures are more likely to develop "post-stroke epilepsy" than those without. Prospective stroke register data, however, could more reliably confirm such association. Such data are analysed in the following chapters of this thesis.

Our patients with multiple seizures were younger than those with a single seizure, whereas the delay between stroke and first seizure was shorter in those with recurrent scizures. Although the numbers are small. our data may indicate that younger age at stroke is related to earlier, recurrent seizures.

Lacunar infarcts are considered an unlikely cause of post-stroke epilepsy, $\$ 2$ but not by all authors.9.141.176 Among our patients with an infarct on CT twenty eight had territorial infarct(s) only, four had either lacunar or large subcortical infarcts as well, whereas six had lacunar infarcts only. Should lacunar infarcts cause seizures as often as territorial infarcts do, we would have expected to find lacunar infarcts in our series in a similar proportion as they cause supratentorially located brain infarcts, which is approximately 40 per cent. ${ }^{25}$ Instead we found ( 6 of 38) 16 per cent. Therefore we consider lacunar infarcts an unlikely, although a not proven impossible cause of post-stroke scizures. Lacunar infarction might merely reflect more severe generalized cerebral small vessel disease, or more widespread cerebral vascular disease, 9.52.53.141.150.160.167.176 that could lead to epilepsy in some cases by more generalized rather than focal disturbances, such as: decreased activity of the enzyme ATP-ase, damage to calcium channels, the GABA-ergic inhibitory system. or to receptors involved in excitatory brain activity, disturbing the delicate balance between excitatory and inhibitory neural mechanisms in favour of excitation. 3.84 .121 .129 .163 Still, some parts of the brain may be particularly susceptible to the development of epileptic activity, like the hippocampi and the sensorimotor cortex." Using a detailed topographic brain atlas 27 we found that some gyri, especially those louated in the MCA territory, were more often affected than others. The finding that in 77 per cent of our MCA territory infarct patients the supramarginal gyrus was affected might indicate that this gyrus is especially associated with the development of scizures, as was shown in patients with traumatic brain damage for the central parietal region. 33,116,129,196,197 However, overall we failed to identify "specific epileptogenic" gyri. That some gyri located in the MCA territory were more often affected than others might merely reflect the high frequency of infarction in this brain vascular territory: a possibility that can only be studied from comparing stroke patients developing seizures with those who do not, as was pursued in chapter 5 of this thesis. On the other hand. complete destruction of an 
area with a low seizure threshold might "protect" against epileptic activity. The fact that large cortical infarcts with persisting paresis cause epilepsy more often than small ones ${ }^{137}$ could be due to more frequent involvement of the supramarginal gyrus, but also to the more extended cortical damage in such infarcts.

Prospective series of well-defined stroke patient subgroups could give more insight into the importance of different factors involved in the development of post-stroke seizures, and could also lead to identify high risk patients, in whom prophylactic anti-epileptic drug treatment could be considered, not only to prevent seizures, but possibly also to lower the chance of development of a persistent epileptic brain focus following stroke. In the next chapters of this thesis such a prospective study is analysed.

So far, from this retrospective study we may conclude the following: 1) Brain infarction as the presumed cause of epilepsy increases with increasing age at first seizure. 2) In approximately one quarter of epilepsy patients with the first epileptic seizure after the age of 50, epilepsy relates to sustained symptomatic brain infarction. 3) Eighty one per cent of the patients with seizures following a brain infarct experienced their first seizure within two years following brain infarction. 4) First seizures that occur early following supratentorial brain infarction in relatively young stroke patients seem to have a high recurrence rate despite anti-epileptic drug treatment. 5) Stroke patients with early seizures are more likely to develop late seizures (post-stroke epilepsy) than those without. 6) Seizures following a brain infarct are associated mainly but not exclusively with infarcts involving the cortex. 7) Although some cortical gyri were frequently affected, especially the supramarginal, precentral, middle temporal and superior temporal gyrus, no cortical area emerged convincingly as "specific epileptogenic". 



\section{CHAPTER 3}

Demographic determinants of occurrence and prognosis

of epileptic seizures following a first-ever supratentorial brain infarct

Data from an ongoing prospective register 
As stated in the general introduction the frequency of so-called post-stroke epilepsy varies between studies from zero to more than $50 \%$.17.19.20,29.36.37.45$47,54,55,58,69,83,88,90,100,102,104,113,118,124,127,136,137,140-142,146,154-156,166,168,174,188.193$ This large variability probably reflects differences in selection of populations studied, in duration of follow-up, and in the definition of what post-stroke epilepsy signifies. Most studies were retrospective, and many were performed prior to the CT-scan era, or based on small numbers. Some investigators included also patients with a prior history of epilepsy, whereas others excluded patients with a single post-stroke seizure. Some studied only seizures occurring during the first weeks after stroke, whereals others studied seizures occurring later than one month. The distinction between such "early" and "late" seizures following a stroke was not uniform, varying from a cut off point at one week to one month post-stroke, to no distinction at all. The cut off point was often arbitrarily set at two weeks post-stroke. ${ }^{46,50.107 .113}$ However, this distinction may be important, as early seizures may be caused by a disarrangement of several non-cerebral factors, such as electrolyte imbalance, acid-base disturbances, etc, whereas late seizures may be regarded as "real" post-stroke epilepsy primarily due to "scar formation". $43.45,46,53,61.80 .92 .107,113.152 .176$ Besides this difference in pathogenesis, early and late seizures may also differ in prognosis, and early seizures may predict the occurrence of late seizures, ${ }^{101}$ justifying the distinction between early and late seizures.

Which particular factors influence the occurrence of epileptic seizures following a stroke is still unknown. Whether seizures relate to stroke subtype remains uncertain. due to the difficulty in distinguishing embolic from thrombotic stroke. to the small number of patients in most series, and to the fact that location, size and type of stroke on CT scan have scarcely been studied. Some authors noted a higher incidence of seizures in patients with cerebral haemorrhage. ${ }^{55,69.100 .127}$ or with hatemorrhagic infarction, $\$ .+5,100.104 .127$ or with embolic stroke. $90.107 .118 .124 .127 .1+6$ Others reported similar frequencies in patients with thrombotic and embolic stroke. $45,92,100,125,166$ Large infarct size was reported to increase the risk of seizures, $80.100 .104 .137,152$ as was cortical involvement. $17.20,22.29 .45,53.55 .80 .92 .100 .101,104$. 118.127.137, 140.146,152,174 However, seizures are also reported in patients with lacunar infarcts. $9.52 .141,150.160 .167 .176$ Some investigators found a clear predominance of males in developing post-stroke seizures (PSS), ${ }^{45.69 .137}$ whereas others found a female predominance ${ }^{102}$ or similar frequencies in the two sexes. ${ }^{101.10+}$ Data on the age-distribution of patients with and without PSS have scarcely been reported. However, the authors who did provide information on age, found no differences in age-distribution between patients with early PSS and those without. ${ }^{459}$ nor between patients with early or late PSS and those without seizures. ${ }^{10+1}$.

The prognosis of post-stroke seizures, concerning mortality and seizure recurrence, is not clear. Although a higher mortality in patients with seizures has been described.20 most investigators found that early seizures were not associated with a higher mortality or worse functional outcome. ${ }^{17.19 .45 .100 .101}$ With 
regard to seizure recurrences opinions are controversial: some found that patients with early seizures are less likely to develop recurrent seizures than patients presenting with late seizures, $55.107 .113 .115,124,166$ whereas others reported a high risk of seizure recurrence in patients with early seizures. ${ }^{80,83,101,173}$ However, the current opinion is that chronic epilepsy develops more often among patients with a first late seizure than among those with a first early seizure. ${ }^{61,92,102,113,115,176}$ The indication for anticonvulsant drugs in patients with post-stroke seizures remains controversial, and the efficacy of anti-epileptic drug (AED) therapy in post-stroke epilepsy has not been established yet. Some reported that early seizures usually resolve spontaneously and that AED's are not indicated. 100.166 Others found that early seizures are readily controlled with AED's, ${ }^{101}$ whereas I.nuis et al. "1: found that early seizures were "refractory to medication but fortunately resolved spontaneously". Most authors reported that late seizures were easily controlled with AED's, $80,113,156$ but others found that up to 60 per cent of treated patients continued to have seizures despite "adequate" AED treatment. Because of the above mentioned discrepancies in the literature it remains uncertain what factors influence the occurrence of seizures following a stroke. Therefore we decided to study the occurrence of epileptic scizures in a prospective register of all adult patients presenting with a first-ever-in-a-lifictime symptomatic supratentorial brain infarct. In this chapter the "Patients and methods" are described and demographic data reported.

\section{Patients and methods}

Patients were registered between I July 1987 and I July 1992 in an ongoing prospective register at the University Hospital Maastricht, that includes all adult patients admitted to the Neurological Department or seen at the outpatients' clinic, with a first-ever symptomatic supratentorial brain infarct with symptoms lasting longer than 24 hours. The University Hospital is the only hospital in the Maastricht region and has an adherent population of approximately 190,000 people.

The prospective rigister: patient-selection, data recorded and definitions used

Patients with a history of former stroke, those with cerebellar or brainstem stroke. primary intracerebral haemorrhage, subarachnoid haemorrhage, or brain tumour were not included. Brain infarction was defined as the rapid onset of clinical signs of focal cerebral function disturbance. lasting longer than 24 hours or leading to death. with no other apparent cause than that of vascular origin. with normal CT or CT showing an area of low attenuation compatible with the clinical signs and symptoms, or autopsy revealing an infarct compatible with the clinical signs and symptoms. ${ }^{11,12.86}$ When neither CT nor autopsy were available, 
we used the Guy's Hospital Stroke Diagnostic Score (Allen score) ${ }^{5}$ to determine the probability that the stroke was due to infarction. Patients with an Allen score less than four, i.e. with a probability of 90 per cent or more that their stroke was due to infarction, were included in the register.5.11

All patients were examined as soon as possible after hospitalization or at the first outpatients' clinic visit. In addition to personal data, such as age and sex, clinical infarct syndromes were recorded.11.62.110 A distinction between lacunar and cortical syndrome was made. We distinguished four lacunar syndromes: pure motor syndrome, sensorimotor syndrome, pure sensory syndrome, and dysurthria-clumsy hand syndrome/ataxic hemiparesis cases.11.62 Cortical syndrome was recognized in patients with signs of cortical dysfunction (aphasia, visual field deficit, visuospatial problems, apraxia, neglect, forced gaze, agnosia) alone or in combination with unilateral motor and/or sensory deficit. The degree of handicap at first examination was measured using the modified Rankin scale (sce Appendix).13.1+.131.143.179 Medication taken at the time of stroke was noted and the patient's medical history was reviewed with special attention to prior signs and symptoms of stroke or brain tumour (exclusion criteria), a history of epileptic seizures, chronic obstructive pulmonary disease (COPD), and vascular risk factors such as hypertension, diabetes mellitus, and ischaemic heart disease. Definitions for these vascular risk factors are given in chapter 4 . The occurrence of epileptic seizures during hospitalization was noted.

Patients had routine investigations including standard blood and urine tests, electrocardiography (ECG), chest radiography, non-invasive carotid studies (Duplex scanning, multigated pulse Doppler with spectral frequency analysis, or continuous wave Doppler), and cerebral CT scan. Echocardiography, 24 hour electrocardio-graphic monitoring (Holter) and cerebral angiography were performed in selected patients. Not all patients had non-invasive carotid studies: those who were too ill to cooperate. who had major cognitive defects that did not allow reliable examination. or who died before the test could be performed. In some patients however. the examination was not performed without specific reason.

Cerebral CT scans were independently reviewed by two neurologists without knowledge of the clinical data, except that the patient was in the register. CT delay, number and type of abnormalities and affected hemisphere were noted. For every infarct visible on CT, infarct type (lacunar, striatocapsular or territorial), size, location, and whether it was haemorrhagic were determined. The presence of leukoaraiosis was also noted. In case of disagreement on the presence of an infarct or leukoaraiosis CT was regarded as negative for this particular item. A lacunar infarct was defined as a subcortical. small, sharply marginated hypodense lesion in the paraventricular centrum semiovale. the internal capsule or basal ganglia. .5 with a diameter of less than $20 \mathrm{~mm}$ on CT, most likely due to occlusion of one single perforating artery." a striatocapsular infarct as an infarct with a diameter greater than $20 \mathrm{~mm}$ on CT. not involving the cortex and not compatible with occlusion of one single perforating artery, and a 
territorial infarct as a hypodense lesion compatible with a territory supplied by the main stem, or the cortical or medullary branches of one of the three large cerebral arteries. Definitions for infarct-size and infarct-location are given in chapter 5 .

\section{Classification of patients in four infarct sub-groups}

After reviewing the CT scans, for every patient CT findings were combined with clinical data to delermine which infarct on CT was the symptomatic one. An infarct was considered symptomatic if located in the clinically affected hemisphere, in an area that could account for the neurological signs and symptoms, whereas the radiologically estimated age was consistent with the time of clinical symptoms of the index stroke (old lesions being more hypodense. more sharply delineated, or showing signs of retraction of brain structures towards the lesion site). All other visible infarcts not complying with this definition were considered to be "silent" brain infarcts.

Subsequently, patients were assigned to one of four infarct sub-groups. First, patients with a "rare" stroke-cause, such as vasculitis, fibromuscular dysplasia, arterial dissection. coronary bypass surgery with complications, haematologic disorders, etc, were assigned to the infarct with a rare cause group, regardless clinical syndrome and CT features. Then, of the remaining patients, all patients with one of the four lacunar syndromes without CT or in whom CT showed a symptomatic lacunar infarct, or no specific lesion, were assigned to the lacunar infarct group, regardless the presence of a potential cardiac source of embolism or carotid stenosis. Patients with a cortical syndrome but a symptomatic lacunar infarct on CT were also assigned to the lacunar infarct group. Patients with a cortical syndrome without CT or with CT showing a symptomatic territorial or striatocapsular infirct. or no specific lesion. were assigned to the territorial infarct group. as were patients with a lacunar syndrome in whom CT showed a symptomatic territorial or striatocapsular infarct. Striatocapsular or large subcortical infarcts were included in the territorial infarct group, because of the similarity in clinical features and pathogenesis. These territorial infarcts were further divided according to their presumed cause: a cardioembolic territorial infarct (CE) was defined in patients who had one of the following potential cardiac sources of embolism in their medical history, on ECG, or echocardiography: chronic or intermittent ECG confirnted atrial fibrillation; left ventricular myocardial infarction within six wechs preceding stroke; left ventricular or atrial thrombus; left ventricular aneurysm; left ventricular akinetic segment: cardiomyopathy; mitral or aortic valve abnormalities (endocarditis, mitral stenosis, prosthetic aortic or mitral valves); and in young patients without any other specific stroke cause: atrial septal defect, ventricle septal defect. The remaining patients with a non-cardiocmbolic symptomatic territorial infarct (presumably large vessel disease. i.e. atherothrombosis or artery-to-artery embolism 
whether or not confirmed by non-invasive carotid studies) were considered as one group and assigned to the remaining territorial infarcts group $(R I)$.

\section{Follow-up}

Follow-up was aimed at every 3 to 6 months. On every follow-up handicap was measured using the modified Rankin scale. Special attention was paid to stroke recurrences, and the occurrence of epileptic seizures. ${ }^{39}$ Any seizure occurring after the first symptomatic supratentorial brain infarct was regarded as a poststroke seizure. As we felt that different seizure types could not always reliably be ascertained, no subdivision as to seizure type was pursued. In case of an epileptic seizure (both during hospitalization and following discharge), date, delay between stroke and first seizure, description of the clinical signs and symptoms, anti-epileptic treatment, and possible causes for the seizure (metabolic or electrolyte disturbances, hypoxia or respiratory insufficiency, drug-induced, head trauma, subdural haematoma, recurrent stroke) were recorded. With regard to the number of seizures we only distinguished between single and multiple epileptic seizures. A status epilepticus ${ }^{16.55}$ was classified as multiple seizures, notwithstanding the fact that some patients in whom the first seizure developed into a status epilepticus experienced no more seizures.

Information on patients discharged 10 nursing homes was collected by visiting the nursing homes every 6 to 12 months. Information on patients unable or unwilling to visit the neurological outpatients' clinic. was collected by telephone from the patient or a close relative. from the attending general practitioner, and from reviewing their hospital files. During the first six months of 1993 of every patient still alive final follow-up data were gathered, aiming at a follow-up of at least six months for every patient still alive. Of the patients who had died date and cause of death were noted. Duration of follow-up was defined as number of days between stroke and final follow-up contact for the patients still alive, and as number of days between stroke and death for deceased patients. Exposure time, expressed as number of days that the patient was at risk for developing poststroke seizures, was equal to follow-up time for those who did not develop seizures, and was defined as number of days between stroke and first epileptic seizure for the patients who developed post-stroke seizures.

\section{Statistical methods}

The aim of this chapter is to describe demographic data such as age and sex by simply counting the number of patients with seizures in different agc- and sexgroups, and comparing the percentages of patients with seizures in the different subgroups. The frequencics of epileptic seizures and the features of the patients who diveloped scizures are described. Differences in male/female ratio. age- 
distribution. median follow-up times, and seizure delay were analysed using the distribution-fice. nonparametric Mann-Whitney Test. ${ }^{133}$ In this follow-up study with varying lengths of exposure times and a time dependent outcome variable (the occurrence of seizures following a cerebral infarct) the Odds Ratio (OR $)^{42.159}$ cannot be used to estimate the relative risk and describe the difference between risk factor subgroups, but the Incidence Rate Ratio (IRR) has to be used instead. 151 The IRR is a statistical method that accounts for differences in exposure time. Therefore, differences between the different risk factor subgroups were analysed using IRR's with $95 \%$ confidence intervals $(\mathrm{CI})$ and two-tailed p-values. Besides age and sex, delay between stroke and first epileptic seizure, the number of seizures, treatment with anti-epileptic drugs, the occurrence of late seizures following early seizures, and survival of patients with and without seizures were noted. The contribution of post-stroke seizures to mortality after stroke was statistically adjusted for interaction of other prognostic variables by means of a Cox regression analysis (proportional hazards model), a specific regression model for survival data, able to handle censored data (incomplete observations) and varying lengths of follow-up, and consequently varying lengths of exposure times. 42.119 .134 The Cox regression procedure estimates proportional hazard regression models for time-constant covariates. However, seizures do not occur at the same delay following stroke for every patient, whereas the patient is at risk only from the moment of his first seizure. Therefore. the contribution of post-stroke seizures to mortality is timedependent. Consequently. the Time-Dependent Cox Regression Analysis was used. ${ }^{134}$ This procedure analyzes proportional hazards models containing a covariate whose values change during the course of the study.

\section{Results}

During the intake-period of five years. 816 patients with a first-ever supratentorial brain infarct were registered. However, thirteen patients $(1.6 \%)$ with epileptic seizures before this first strnke were not at risk for developing a first post-stroke seizure, and were thercfure excluded from the study. Two patients $(0.2 \%)$ were lost to follow-up after 20 and 72 days respectively. As the remaining patients were all followed till final follow-up visit or prior death these two patients were excluded. Finally, there were 31 patients $(3.8 \%)$ who suffered an infarct with a rare stroke cause. Since these patients constitute a rather heterogeneous group. we decided to exclude them, leaving 770 patients $(94.4 \%)$ at risk for developing post-stroke seizures. This thesis describes the findings in these 770 patients. 


\section{General features}

There were 402 males (52\%) and 368 females (48\%) with a median age at the time of stroke of 72 (range 26-96) years. Median follow-up for all patients was 618 (range 1-1998) days, with a median number of 3 (range 1-20) follow-up visits per patient. However, during follow-up 293 patients (38\%; 95\% CI: 35-42) died after a median of 172 (range 1-1897) days; they had had 2 (range 1-14) follow-ups, $48 \%$ were male and the median age at the time of stroke was 78 (range 39-96) years. The 477 patients (62\%: 95\% CI: 58-65) still alive at the end of this study were followed for 863 (range 195-1998) days: they had had a median of 5 (range I-20) follow-up visits per patient, 55\% were male and the median age at the time of stroke was 68 (range 26-92) years. As expected. patients who died were significantly older and their length of follow-up was significantly shorter (Mann-Whitney test $p=0.000$ for both variables). However, there were no differences in male/female ratio between the patients who died and those who were still alive (Mann-Whitney test $p=0.054$ ). Table 3.1 shows that the intake of the 770 patients was rather constant during the five study years, as was the percentage of patients that developed first post-stroke seizures every year.

\section{Frequency of post-stroke seizures (PSS)}

During follow-up 84 patients (11\%; 95\% CI: 9-13) experienced one or more epileptic seizures after a median of 149 (range 0-1848) days. In seven of the 84 patients with PSS the first epileptic seizure developed into a status epilepticus. According to our definition they were assigned to the multiple seizures group, notwithstanding the fact that four of them (all treated with AED's) experienced no more seizures after this first event. Twenty-four patients with seizures (29\%; 95\% CI: 19-38) had an additional potential cause for their seizure(s), which was: head trauma in two patients (in one with subdural haematoma); drug-induced in 17 patients (they used theophylline); poor condition due to pneumonia, fever, apneas and electrolyte disturbances in four patients: and severe hypoglycaemia of $1.5 \mathrm{mmol} / \mathrm{l}$, due to disregulated diabetes mellitus, in one patient. However, following our pragmatic definition, these 24 patients were not excluded from the analyses. Likewise, in some patients. the occurrence of a recurrent stroke could have been another additional potential cause for the development of epileptic seizures. One-hundred-and-fifteen patients (15\%; $95 \% \mathrm{CI}$ : 12-18) had one or more recurrent strokes during follow-up, of whom 22 developed PSS. However, in half of thesc 22 patients the recurrent stroke occurred after the first epileptic seizure. Consequently these eleven patients belong to the group without recurrent strokic before the first epileptic seizure. The remaining 11 patients developed PSS (11\%: 95\% Cl: 5-17) after a recurrent stroke, whereas 73 patients of 666 patients without recurrent stroke developed PSS (11\%:95\% CI: 9-13). 
Table 3.1: Intake over the 5 study-years and percentage with first post-stroke seizures (percentages between parentheses)

\begin{tabular}{ccccccc}
\hline Intake year & Number of patients & \multicolumn{2}{c}{ Number with PSS } & \multicolumn{2}{c}{$\%$ with PSS $(95 \%$ CI) } \\
\hline 1 & 124 & $(16)$ & 14 & $(17)$ & 11 & $(6-17)$ \\
2 & 142 & $(18)$ & 18 & $(21)$ & 13 & $(7-18)$ \\
3 & 151 & $(20)$ & 19 & $(23)$ & 13 & $(7-18)$ \\
4 & 180 & $(23)$ & 18 & $(21)$ & 10 & $(6-14)$ \\
5 & 173 & $(23)$ & 15 & $(18)$ & 9 & $(5-13)$ \\
\hline \multirow{2}{*}{ Total 5 years } & 770 & $(100)$ & 84 & $(100)$ & 11 & $(9-13)$ \\
\hline
\end{tabular}

Table 3.2: General features of patients with and those without seizures following a first cerebral infarct

\begin{tabular}{lrrrrr}
\hline All patients N=770 & With seizures & Without seizures & $\begin{array}{c}\text { Mann-Whitney } \\
\text { test p-value }\end{array}$ \\
\hline Number of patients (\% of total) & 84 & $(11)$ & 686 & $(89)$ & \\
Males (\% in group) & 44 & $(52)$ & 358 & $(52)$ & 0.9732 \\
Median age (range) in vears & 76 & $(40-88)$ & 71 & $(26-96)$ & 0.0221 \\
Md seizure delay (range) in days & 149 & $(0-1848)$ & & & \\
Md follow-up (range) in days & 734 & $(8-1897)$ & 617 & $(1-1998)$ & 0.7970 \\
Deaths (\% of group) & 40 & $(48)$ & 253 & $(37)$ & 0.0559 \\
Md death-delay (range) in days & 225 & $(8-1897)$ & 170 & $(1-1781)$ & 0.2453 \\
\hline
\end{tabular}

\begin{tabular}{lrrrrr}
\hline Patients with seizures $\mathrm{N}=84$ & \multicolumn{2}{c}{$\begin{array}{c}\text { With early-onset } \\
\text { seizures }\end{array}$} & $\begin{array}{c}\text { With late-onset } \\
\text { seizures }\end{array}$ & $\begin{array}{c}\text { Mann-Whitney } \\
\text { test } p \text {-value }\end{array}$ \\
\hline Number of patients (\% of total) & 28 & $(33)$ & 56 & $(67)$ & \\
Males (\% in group) & 15 & $(54)$ & 29 & $(52)$ & 0.8780 \\
Median age (range) in years & 81 & $(65-88)$ & 73 & $(40-87)$ & 0.0004 \\
Md seizure delay (range) in days & 1 & $(0-14)$ & 261 & $(18-1848)$ & 0.0000 \\
Md follow-up (range) in days & 377 & $(8-1614)$ & 972 & $(21-1897)$ & 0.0006 \\
Deaths (\% of group) & 17 & $(61)$ & 23 & $(41)$ & 0.0912 \\
Md death-delay (range) in days & 18 & $(8-1068)$ & 484 & $(21-1897)$ & 0.0002 \\
\hline
\end{tabular}


Table 3.3: Age-distribution and male/female ratio of all patients, and of those who developed post-stroke seizures PSS (percentages between parentheses)

\begin{tabular}{|c|c|c|c|c|c|c|c|c|c|c|}
\hline \multirow{2}{*}{$\begin{array}{l}\text { Age } \\
26 \cdot 39\end{array}$} & \multicolumn{2}{|c|}{$\begin{array}{c}\text { Total number } \\
\text { of patients }\end{array}$} & \multicolumn{2}{|c|}{$\begin{array}{l}\text { Number } \\
\text { with PSS }\end{array}$} & \multirow{2}{*}{$\begin{array}{c}\text { Males } \\
\text { total N } \\
4\end{array}$} & \multicolumn{2}{|c|}{$\begin{array}{l}\text { Number } \\
\text { with PSS }\end{array}$} & \multirow{2}{*}{$\begin{array}{c}\text { Females } \\
\text { total } N \\
7\end{array}$} & \multicolumn{2}{|c|}{$\begin{array}{l}\text { Number } \\
\text { with PSS }\end{array}$} \\
\hline & 11 & (1) & 0 & & & 0 & & & 0 & \\
\hline $40-44$ & 11 & (1) & 2 & (18) & 9 & 1 & (11) & 2 & 1 & (50) \\
\hline $45-49$ & 24 & (3) & 3 & (13) & 10 & 1 & (10) & 14 & 2 & (14) \\
\hline $50-54$ & 23 & (3) & 4 & $(17)$ & 20 & 4 & $(20)$ & 3 & 0 & \\
\hline $55-59$ & 51 & (7) & 4 & (8) & 36 & 2 & (6) & 15 & 2 & (13) \\
\hline $60-64$ & 70 & (9) & 1 & (1) & 49 & 1 & (2) & 21 & 0 & \\
\hline $65-69$ & 121 & (16) & 12 & $(10)$ & 71 & 8 & (11) & 50 & 4 & (8) \\
\hline $70-74$ & 146 & (19) & 10 & (7) & 84 & 8 & $(10)$ & 62 & 2 & (3) \\
\hline $75-79$ & 125 & (16) & 21 & (17) & 53 & 8 & (15) & 72 & 13 & (18) \\
\hline $80-84$ & 106 & (14) & 19 & $(18)$ & 40 & 8 & $(20)$ & 66 & 11 & (17) \\
\hline $85-89$ & 67 & (9) & 8 & $(12)$ & 21 & 3 & (14) & 46 & 5 & (11) \\
\hline $90-96$ & 15 & (2) & 0 & & 5 & 0 & & 10 & 0 & \\
\hline Total & 770 & $(100)$ & 84 & (11) & 402 & 44 & (11) & 368 & 40 & (11) \\
\hline
\end{tabular}

Male/female ratio for all patients: $52.2 \%$ male and $47.8 \%$ female.

Male/female ratio for patients with seizures: $52.4 \%$ male and $47.6 \%$ female.

Table 3.3b: Age-distribution and male/female ratio of all patients, and of those who developed PSS, summarized for three age-groups (percentages between parentheses)

\begin{tabular}{lccccccccrr}
\hline Age & $\begin{array}{c}\text { Total number } \\
\text { of patients }\end{array}$ & $\begin{array}{c}\text { Number } \\
\text { with PSS }\end{array}$ & $\begin{array}{c}\text { Males } \\
\text { total N }\end{array}$ & $\begin{array}{c}\text { Number } \\
\text { with PSS }\end{array}$ & $\begin{array}{r}\text { Females } \\
\text { total N }\end{array}$ & $\begin{array}{r}\text { Number } \\
\text { with PSS }\end{array}$ \\
\hline $26-64$ & 190 & $(25)$ & 14 & $(7)$ & 128 & 9 & $(7)$ & 62 & 5 & $(8)$ \\
$65-74$ & 267 & $(35)$ & 22 & $(8)$ & 155 & 16 & $(10)$ & 112 & 6 & $(5)$ \\
$75-96$ & 313 & $(40)$ & 48 & $(15)$ & 119 & 19 & $(16)$ & 194 & 29 & $(15)$ \\
\hline Total & 770 & $(100)$ & 84 & $(11)$ & 402 & 44 & $(11)$ & 368 & 40 & $(11)$ \\
\hline
\end{tabular}


which was not different. In accord with our study aim, in analysing these eleven patients, the first symptomatic brain infarct was used as the index stroke.

Table 3.2 shows some general features of the patients with seizures and those without. There were no differences in male/female ratio and length of total follow-up between the patients who developed seizures and those who did not (Mann-Whitney test $p=0.973$ and $p=0.797$ respectively). However, the agedistribution was significantly different between both groups (Mann-Whitney test $\mathrm{p}=0.022$ ): patients with post-stroke seizures were significantly older than those without. Therefore in table $3.3^{a}$ the age-distribution and male/female ratio of all patients and of those who developed PSS are shown in more detail. As age, ranging from 26 - 96 years, had an uneven distribution (half of the patients were between the age of 65 and 79), age-groups of five years were considered. There was no predominance of one of the two sexes in developing PSS: in both groups it was $11 \%$ with a $95 \%$ CI of 8-14. Patients aged $40-54$ (group 1), and those aged 75 - 89 (group 3) had the highest risk for PSS (both 16\% with 95\% CI: 6-25 and 12-20 respectively), whereas of the patients younger than 40 or older than 89 no one developed PSS. Patients between 55 and 74 years of age (group 2) had a risk of $7 \%$ ( $95 \% \mathrm{CI}: 4-10)$. Using IRR's the difference between groups 1 and 2 was not statistically significant (IRR $=1.86 ; 95 \% \mathrm{CI}$ : $0.88-3.96$ ), whereas the dilferences between groups 3 and $I$ (IRR $=2.06 ; 95 \% \mathrm{CI}: 1.01-4.21 ; \mathrm{p}=0.046$ ), and between groups 3 and 2 (IRR $=3.85: 95 \% \mathrm{CI}: 2.40-6.17: \mathrm{p}=0.000$ ) were signiticant. (ising 75 years as a cut-off point, patients younger than 75 years had a risk of $8 \%(95 \% \mathrm{Cl}: 5-10)$, whereas patients aged 75 or older had a risk of $15 \%$ (95\% CI: 11-19) for developing seizures following a first-ever supratentorial brain infarct. The IRR for patients from 75 years and older versus the younger patients is $3.36(95 \% \mathrm{Cl}: 2.18-5.17 ; \mathrm{p}=0.000)$.

\section{Delay between stroke and first epileptic seizure}

Median delay between stroke and first epileptic seizure was 149 (range 0-1848) days. In 28 patients $(33 \%)$ the first seizure occurred early $(\leq 2$ weeks poststroke): in $56(67 \%)$ it occurred late (>2 weeks post-stroke). Table 3.2 shows some general features of the patients with early seizures and those with late scizures. There was no difference in male/female ratio between both groups (Mann-Whitney test $p=0.878$ ). Age-distribution, on the other hand, was significantly different: patients with early post-stroke seizures were significantly older than those with late seizures (Mann-Whitney test $p=0.000$ ). Total length of follow-up was significantly different too: patients with late seizures had a longer follow-up probably due to the fact that one quarter of the patients with early seizures died within two wecks following stroke (Mann-Whitney test $p=0.001$ ). Delay between stroke and the first seizure was significantly different by definition. 
Early seizures occurred after a median of one day after stroke (range by definition 0-14 days). In 25 patients (89\%) with early seizures the first seizure occurred within one week; 19 of them had the first seizure in the acute phase after stroke (the first 72 hours), eleven even within the first 24 hours. Three patients $(11 \%)$ with early onset seizures had their first seizure during the second week post-stroke.

Late onset seizures occurred after a median of 261 (range 18-1848) days. Thirtyseven patients $(66 \%)$ had their first seizure within the first year after stroke (median delay 0.5 year), eleven $(20 \%)$ during the second year (median delay 1.3 years), and eight patients ( $14 \%$ ) had their first seizure later than two years after stroke (median delay 2.9 years, range 2-5 years).

Table 3.4 shows seizure delay for the whole group. In table 3.5 the median seizure delay in days per age-group of five years is given, showing a decrease in median delay hetween stroke and first epileptic seizure with increasing age at stroke-onset. lrum table 3.5 and table 3.2 it is apparent that early seizures only occurred in patients 6.5 years or older. In patients below the age of 65 the shortest delay between stroke and first epileptic seizure was 34 days. So, with regard to seizure delay, patients 65 years or older differed significantly from the younger patients (Mann-Whitney test $p=0.002$ ).

In combination with the above mentioned finding that patients 75 years and older developed post-stroke seizures significantly more often than younger patients, we decided to use 65 years and 75 years as cut-off points, to divide the patients in three age-groups, for our analyses of risk factors. Tables $3.3^{b}, 3.6$, 3.7 and 3.8 show the male/female ratio, number with PSS and the seizure delay for those three age-groups. In figures 3.1 and 3.2 Kaplan Meier survival curves for the whole population and per age-group are given. These show that patients 75 years and older not only develop more seizures but also develop seizures with a shorter seizure delay.

\section{Early seizures and the risk of "lut" seizuri's}

Nine of the twenty-one patients with early seizures, who had survived at least two weeks after their stroke, also had late seizures $(43 \% ; 95 \% \mathrm{Cl}: 22-64)$; of the 695 patients without early seizures, who had survived at least two weeks, 56 had late seizures $(8 \% ; 95 \% \mathrm{CI}: 6-10)$; IRR $=9.07 ; 95 \% \mathrm{CI}: 4.49-18.33 ; \mathrm{p}=0.000$. However, in four of the nine patients with "early and late" seizures, late seizures started as early seizures but continued over the arbitrary limit of two weeks poststroke. In three other patients early seizures had stopped within two weeks without treatment, then they had a recurrent stroke and some scizures again. The remaining two patients had early seizures for a few days. Subsequently, they were seizure-free for more than seven months. and then again had seizures. As these seizures occurred without any obvious causc they were regarded as lateonset seizures. Thus, two patients remained with early-and late-onset seizures, 
being $10 \%$ of all patients with early seizures. This was not different from the $8 \%$ of the patients without early-onset seizures who had late-onset seizures: $\mathrm{IRR}=1.62 ; 95 \% \mathrm{CI}: 0.40-6.64$. In total 58 of the 716 fourteen-day-survivors ( $8 \% ; 95 \% \mathrm{CI}: 6-10)$ had "real" late-onset seizures.

Table 3.4: Delay between stroke and first epileptic seizure in all patients (percentages between parentheses)

\begin{tabular}{lccccccc}
\hline Delay & \multicolumn{2}{c}{$\begin{array}{c}\text { Total number } \\
\text { with PSS }\end{array}$} & & \multicolumn{2}{c}{$\begin{array}{c}\text { Patients with } \\
\text { one seizure }\end{array}$} & \multicolumn{2}{c}{$\begin{array}{c}\text { Patients with two } \\
\text { or more seizures }\end{array}$} \\
\hline $0-24$ hours & 11 & $(13)$ & 1 & $(9)$ & 10 & $(91)$ \\
1 day - 2 weeks & 17 & $(20)$ & 5 & $(29)$ & 12 & $(71)$ \\
$>2$ weeks - $\leq 1$ year & 37 & $(44)$ & 5 & $(13)$ & 32 & $(87)$ \\
$>1$ year - $\leq 2$ years & 11 & $(13)$ & 4 & $(36)$ & 7 & $(64)$ \\
$>2$ years & 8 & $(10)$ & 4 & $(50)$ & 4 & $(50)$ \\
\hline Total & 84 & $(100)$ & 19 & $(23)$ & 65 & $(77)$ \\
\hline Early & 28 & $(33)$ & 6 & $(21)$ & 22 & $(79)$ \\
Late & 56 & $(67)$ & 13 & $(23)$ & 43 & $(77)$ \\
\hline
\end{tabular}

Table 3.5: Delay in days between stroke and first epileptic seizure per age-group

\begin{tabular}{lccr}
\hline Age & $\begin{array}{c}\text { Number } \\
\text { with PSS }\end{array}$ & $\begin{array}{c}\text { Median } \\
\text { delay }\end{array}$ & \multicolumn{1}{c}{ Range } \\
\hline $26-39$ & 0 & & \\
$40-44$ & 2 & 435 & $181-689$ \\
$45-49$ & 3 & 374 & $286-575$ \\
$50-54$ & 4 & 293 & $133-1327$ \\
$55-59$ & 4 & 268 & $34-817$ \\
$60-64$ & 1 & 487 & $487-487$ \\
$65-69$ & 12 & 239 & $0-451$ \\
$70-74$ & 10 & 192 & $0-1848$ \\
$75-79$ & 21 & 177 & $0-1133$ \\
$80-84$ & 19 & 12 & $0-998$ \\
$85-89$ & 8 & 16 & $1-735$ \\
$90-96$ & 0 & & $0-1848$ \\
\hline Total & 84 & 149 & 0 \\
\hline
\end{tabular}


Table 3.6: Delay between stroke and first epileptic seizure in patients 26-64 years

\begin{tabular}{|c|c|c|c|c|c|c|}
\hline \multirow{2}{*}{$\begin{array}{l}\text { Delay } \\
0-24 \text { hours }\end{array}$} & \multicolumn{2}{|c|}{$\begin{array}{l}\text { Total number } \\
\text { with PSS (\%) }\end{array}$} & \multicolumn{2}{|c|}{$\begin{array}{l}\text { Patients with } \\
\text { one seizure }\end{array}$} & \multicolumn{2}{|c|}{$\begin{array}{l}\text { Patients with two } \\
\text { or more seizures }\end{array}$} \\
\hline & 0 & & 0 & & 0 & \\
\hline 1 day $-\leq 2$ weeks & 0 & & 0 & & 0 & \\
\hline$>2$ weeks - $\leq 1$ year & 7 & $(50)$ & 1 & & 6 & \\
\hline$>1$ year $-\leq 2$ years & 5 & $(36)$ & 1 & & 4 & \\
\hline$>2$ years & 2 & $(14)$ & 0 & & 2 & \\
\hline Total & 14 & $(100)$ & 2 & (14) & 12 & $(86)$ \\
\hline Early & 0 & & 0 & & 0 & \\
\hline Late & 14 & $(100)$ & 2 & (14) & 12 & (86) \\
\hline
\end{tabular}

Table 3.7: Delay between stroke and first epileptic seizure in patients 65-74 years

\begin{tabular}{|c|c|c|c|c|c|c|}
\hline \multirow{2}{*}{$\begin{array}{l}\text { Delay } \\
0-24 \text { hours }\end{array}$} & \multicolumn{2}{|c|}{$\begin{array}{l}\text { Total number } \\
\text { with PSS (\%) }\end{array}$} & \multicolumn{2}{|c|}{$\begin{array}{l}\text { Patients with } \\
\text { one seizure }\end{array}$} & \multicolumn{2}{|c|}{$\begin{array}{l}\text { Patients with two } \\
\text { or more seizures }\end{array}$} \\
\hline & 2 & (9) & 0 & & 2 & \\
\hline 1 day $-\leq 2$ weeks & 4 & (18) & 1 & & 3 & \\
\hline$>2$ weeks $-\leq 1$ year & 11 & $(50)$ & 1 & & 10 & \\
\hline$>1$ year $-\leq 2$ years & 4 & (18) & 2 & & 2 & \\
\hline$>2$ years & 1 & (5) & 0 & & 1 & \\
\hline Total & 22 & $(100)$ & 4 & (18) & 18 & $(82)$ \\
\hline Early & 6 & (27) & 1 & (17) & 5 & (83) \\
\hline Late & 16 & (73) & 3 & (19) & 13 & (81) \\
\hline
\end{tabular}

Table 3.8: Delay between stroke and first epileptic seizure in patients 75-96 years

\begin{tabular}{|c|c|c|c|c|c|c|}
\hline \multirow{2}{*}{$\begin{array}{l}\text { Delay } \\
0-24 \text { hours }\end{array}$} & \multicolumn{2}{|c|}{$\begin{array}{l}\text { Total number } \\
\text { with PSS }(\%)\end{array}$} & \multicolumn{2}{|c|}{$\begin{array}{l}\text { Patients with } \\
\text { one seizure }\end{array}$} & \multicolumn{2}{|c|}{$\begin{array}{l}\text { Patients with two } \\
\text { or more seizures }\end{array}$} \\
\hline & 9 & (19) & 1 & & 8 & \\
\hline 1 day $-\leq 2$ weeks & 13 & (27) & 4 & & 9 & \\
\hline$>2$ weeks $-\leq 1$ year & 19 & $(40)$ & 3 & & 16 & \\
\hline$>1$ year $-\leq 2$ years & 2 & (4) & 1 & & 1 & \\
\hline$>2$ years & 5 & $(10)$ & 4 & & 1 & \\
\hline Total & 48 & $(100)$ & 13 & (27) & 35 & (73) \\
\hline Early & 22 & (46) & 5 & (23) & 17 & (77) \\
\hline Late & 26 & (54) & 8 & (31) & 18 & (69) \\
\hline
\end{tabular}


Figure 3.7: Survival free of epileptic seizures for all patients

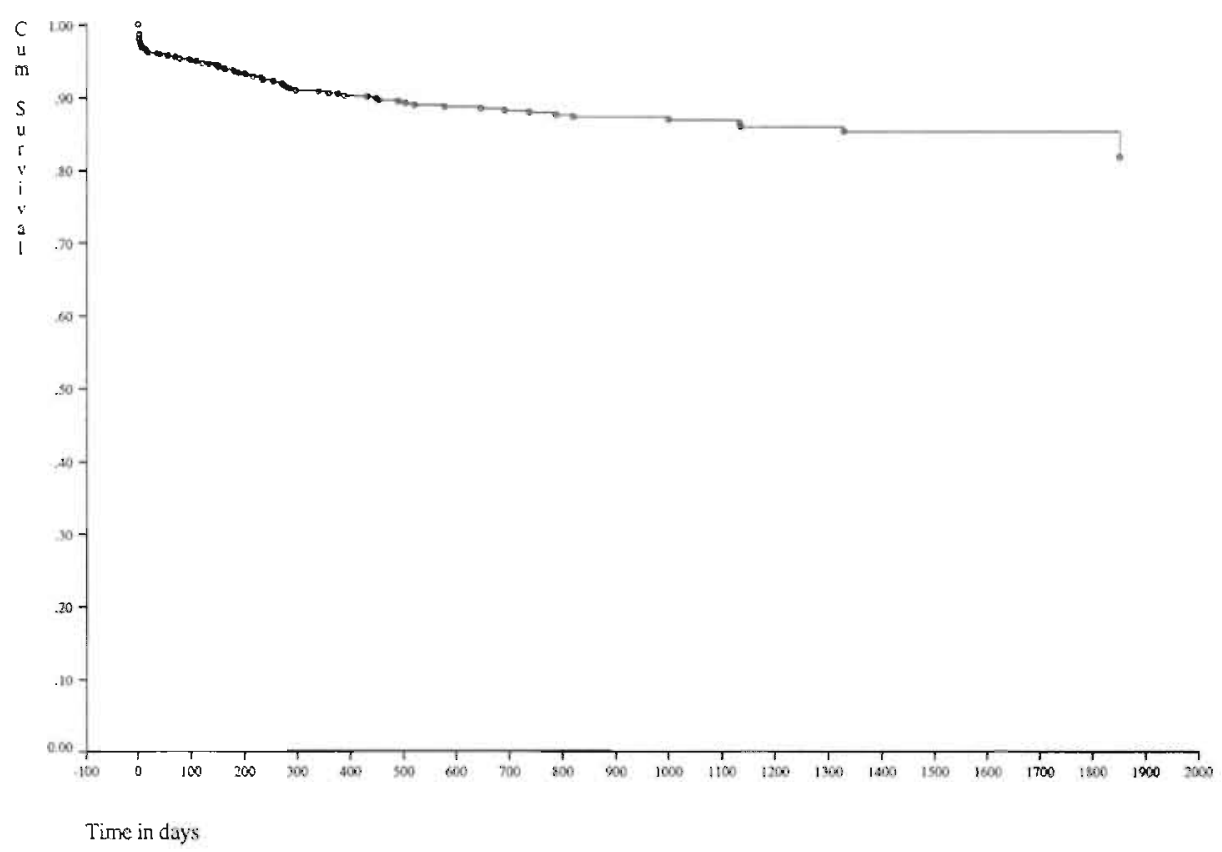

Figure 3.2: Survival free of epileptic seizures for three age-groups

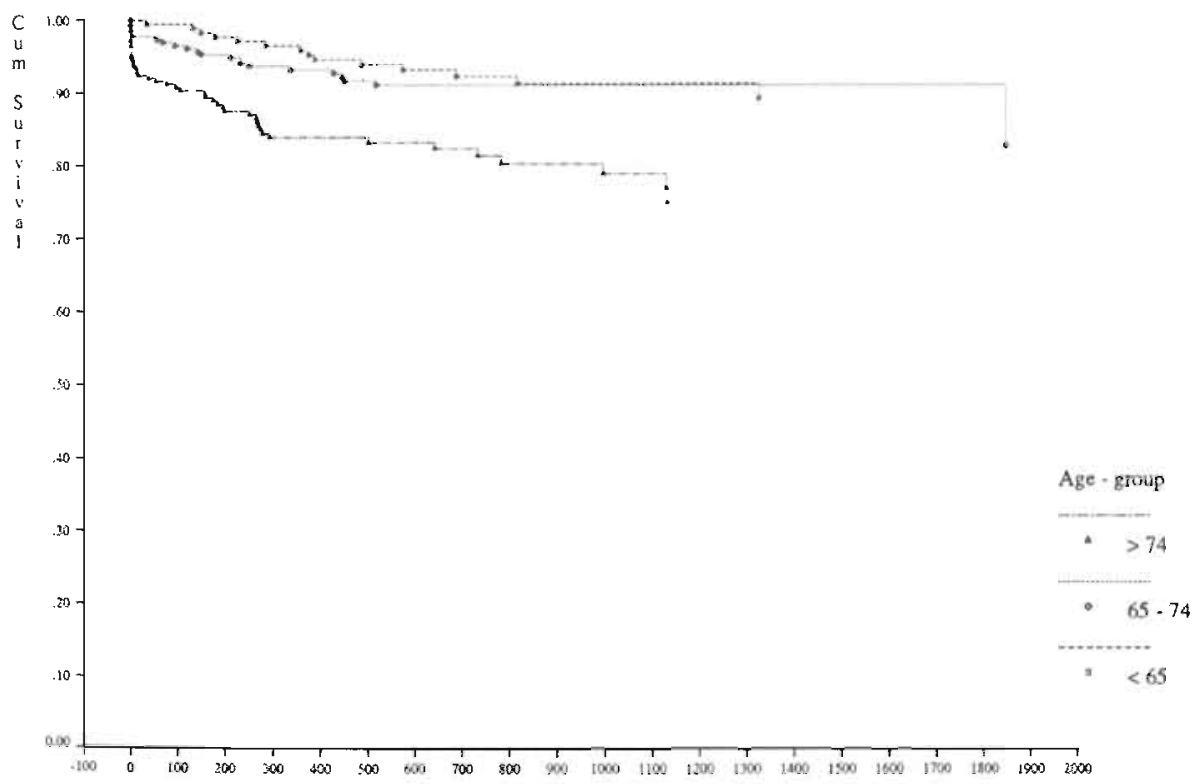

Time in days 
Table 3.9: Recurrent versus non-recurrent seizures

$A=$ all patients $T=$ patients treated with $A E D$ 's

\begin{tabular}{lccccccccc}
\hline All patients & $\begin{array}{c}\text { Number } \\
\text { with PSS }\end{array}$ & \multicolumn{2}{c}{$\begin{array}{c}\text { Died within } \\
\text { 2 weeks after } \\
\text { first seizure }\end{array}$} & $\begin{array}{c}\text { Non-recurrent } \\
\text { seizures }\end{array}$ & & \multicolumn{2}{c}{$\begin{array}{c}\text { Recurrent } \\
\text { seizures }\end{array}$} \\
& A & T & A & T & A & T & A & T \\
\hline Early & 28 & 22 & & 8 & 5 & 16 & 13 & 4 & 4 \\
Late & 56 & 37 & 6 & 2 & 26 & 12 & 24 & 23 \\
\hline Total & 84 & 59 & 14 & 7 & 42 & 25 & 28 & 27
\end{tabular}

\begin{tabular}{|c|c|c|c|c|c|c|c|c|}
\hline \multirow[t]{2}{*}{$\begin{array}{l}\text { Only patients } \\
<65 \text { years }\end{array}$} & \multicolumn{2}{|c|}{$\begin{array}{l}\text { Number } \\
\text { with PSS }\end{array}$} & \multicolumn{2}{|c|}{$\begin{array}{l}\text { Died within } \\
2 \text { weeks after } \\
\text { first seizure }\end{array}$} & \multicolumn{2}{|c|}{$\begin{array}{c}\text { Non-recurrent } \\
\text { seizures }\end{array}$} & \multicolumn{2}{|c|}{$\begin{array}{r}\text { Recurrent } \\
\text { seizures }\end{array}$} \\
\hline & A & $T$ & $A$ & $\mathrm{~T}$ & $A$ & $\mathrm{~T}$ & A & $\mathrm{T}$ \\
\hline Early & 0 & & 0 & & 0 & & 0 & \\
\hline Late & 14 & 12 & 1 & 1 & 4 & 2 & 9 & 9 \\
\hline Total & 14 & 12 & 1 & 1 & 4 & 2 & 9 & 9 \\
\hline
\end{tabular}

\begin{tabular}{|c|c|c|c|c|c|c|c|c|}
\hline \multirow[t]{2}{*}{$\begin{array}{l}\text { Patients } \\
65-74 \text { years }\end{array}$} & \multicolumn{2}{|c|}{$\begin{array}{l}\text { Number } \\
\text { with PSS }\end{array}$} & \multicolumn{2}{|c|}{$\begin{array}{l}\text { Died within } \\
2 \text { weeks after } \\
\text { first seizure }\end{array}$} & \multicolumn{2}{|c|}{$\begin{array}{c}\text { Non-recurrent } \\
\text { seizures }\end{array}$} & \multicolumn{2}{|c|}{$\begin{array}{c}\text { Recurrent } \\
\text { seizures }\end{array}$} \\
\hline & A & $T$ & A & $\mathrm{T}$ & A & $\mathrm{T}$ & A & $\mathrm{T}$ \\
\hline Early & 6 & 6 & 0 & & 5 & 5 & 1 & 1 \\
\hline Late & 16 & 12 & 0 & & 9 & 5 & 7 & 7 \\
\hline Total & 22 & 18 & 0 & & 14 & 10 & 8 & 8 \\
\hline
\end{tabular}

\begin{tabular}{lcccccccc}
$\begin{array}{l}\text { Patients } \\
\geq 75 \text { years }\end{array}$ & $\begin{array}{c}\text { Number } \\
\text { with PSS }\end{array}$ & \multicolumn{2}{c}{$\begin{array}{c}\text { Died within } \\
\text { 2 weeks after } \\
\text { first seizure }\end{array}$} & $\begin{array}{c}\text { Non-recurrent } \\
\text { seizures }\end{array}$ & $\begin{array}{c}\text { Recurrent } \\
\text { seizures }\end{array}$ \\
\hline Early & A & T & A & T & A & T & A & T \\
Late & 22 & 16 & 8 & 5 & 11 & 8 & 3 & 3 \\
\hline Total & 26 & 13 & 5 & 1 & 13 & 5 & 8 & 7 \\
\hline & 48 & 29 & 13 & 6 & 24 & 13 & 11 & 10
\end{tabular}


Table 3.4 shows that 19 patients $(23 \%)$ experienced a single seizure and 65 patients $(77 \%)$ had two or more epileptic seizures. Early-onset seizures were single epileptic events, approximately as often as late-onset seizures were. Tables 3.6, 3.7 and 3.8 show no statistically significant $(p>0.26$ ) differences between the three age-groups. The occurrence of a second seizure after the first seizure was probably affected by anti-epileptic drug treatment. However. patients were not uniformly treated: treatment in younger patients with lateonset seizures and in older patients with early-onset seizures tended to be started rather early, whereas in patients older than 75 years with a first late-onset seizure treatment was rather postponed until at least a second seizure (table 3.9). Besides AED treatment, survival time after the first seizure may also influence the occurrence of recurrent seizures, and therefore, we decided to differentiate between so-called recurrent and non-recurrent seizures, instead of single and multiple seizures. For this difference the first two weeks after the first epileptic seizure are relevant: only seizures that occur after this period are called recurrent seizures and are considered as "real epilepsy". 80 Table 3.9 shows the number of patients with recurrent and non-recurrent seizures for the total patient group and per age-group. In addition, the number of patients treated with AED's are given for each subgroup. Of the 25 patients not treated with AED's only one had recurrent seizures (4\%; $95 \%$ CI: $0-12)$, whereas $27(46 \%: 95 \% \mathrm{CI}: 33-58)$ of the 59 treated patients had recurrent seizures. Despite the fact that $27 \%$ of the patients older than 75 years died within the first two weeks after the first seizure, the table shows that late seizures are recurrent more often than early seizures, despite AED treatment in $96 \%$ of the patients. Especially patients younger than 65 suffered recurrent seizures despite AED treatment in all of them. In $40 \%$ of the patients with non-recurrent seizures the seizures had stopped without AED's being taken, whereas $96 \%$ of the patients with recurrent seizures continued to have seizures despite AED treatment. If we consider only the 70 patients who survived the first two weeks after their first seizure, then in patients older than 65 years early-onset seizures appeared to be non-recurrent in as many as $80 \%$, however, $81 \%$ was treated with AED's. Late-onset seizures were non-recurrent in $59 \%$ in this age-group, whereas only $45 \%$ was treated with AED's and the patients were followed for a median of 453 (range 17-1342) days after their first seizure. As in $93 \%$ of the patients with recurrent seizures the seizures recurred shortly after the fourteenth day. this follow-up was long enough to allow recurrent seizures to occur. Late-onset seizures in patients younger than 65 years were non-recurrent in $31 \%$ and half of them was treated with AED's.

\section{0-day case fatality rate}

Eighty-one of the 770 patients died within one month following stroke $(11 \%$; $95 \% \mathrm{CI}: 8-13$ ). More patients with than without seizures during the first month 
post-stroke died during this first month: 11 of the 29 with seizures $(38 \%$; 95\% CI: 20-56) versus 70 of the 741 without seizures (9\%: $95 \% \mathrm{Cl}: 7-12$ ). This difference was statistically significant: IRR is $4.72(95 \%$ CI: 2.50-8.91; $\mathrm{p}=0.000)$. However, after adjusting for interaction of different prognostic variables, known to affect survival, $34,153,184,187$ in a time-dependent Cox regression analysis, the contribution of seizures to mortality was no longer statistically significant. The higher mortality in patients with seizures appeared to depend on high age, the presence of a cortical syndrome, post-stroke hyperglycaemia, a potential cardiac source of embolism, and a history of ischaemic heart disease. These variables were all independently related to higher mortality. In addition, the effect of seizures appeared to be constant over time. Table 3.10 shows the results of the analysis.

Table 3.10: Prognostic factors affecting 30-day case fatality rate

Time-dependent Cox regression analysis

\begin{tabular}{llrl}
\hline & HR & $95 \% \mathrm{Cl}$ & p-value \\
\hline age $\geq 75$ & 2.21 & $1.31-3.71$ & 0.003 \\
cortical syndrome & 8.68 & $2.70-27.90$ & 0.000 \\
Rankin $\geq 3$ & 3.75 & $0.88-15.84$ & 0.073 \\
post-stroke hyperglycaemia & 3.01 & $1.86-4.88$ & 0.000 \\
cardiac source of embolism & 1.97 & $1.24-3.14$ & 0.004 \\
history of ischaemic heart disease & 1.84 & $1.17-2.88$ & 0.009 \\
post-stroke seizures $\leq 30$ days & 1.62 & $0.84-3.10$ & 0.148 \\
& & & \\
effect of post-stroke seizures not time-dependent $\mathrm{p}=0.968$ & \\
\hline
\end{tabular}

Table 3.11: Prognostic factors affecting 1-year mortality Time-dependent Cox regression analysis

\begin{tabular}{lccc}
\hline & $H R$ & $95 \% \mathrm{Cl}$ & p-value \\
\hline age $\geq 75$ & 2.79 & $2.02-3.84$ & 0.000 \\
cortical syndrome & 1.95 & $1.33-2.86$ & 0.001 \\
Rankin $\geq 3$ & 2.23 & $1.26-3.97$ & 0.007 \\
post-stroke hyperglycaemia & 1.82 & $1.34-2.48$ & 0.001 \\
cardiac source of embolism & 1.77 & $1.31-2.38$ & 0.000 \\
history of ischaemic heart disease & 1.43 & $1.05-1.94$ & 0.023 \\
post-stroke seizures $\leq 30$ days & 0.83 & $0.52-1.31$ & 0.423 \\
& & & \\
effect of post-stroke seizures not time-dependent $\mathrm{p}=0.142$ & & \\
\hline
\end{tabular}


Within the first year after stroke 191 patients died (25\%; 95\% CI: 22-28). Twenty-two of the 65 patients who had experienced their first seizure within one year following stroke died (34\%; 95\% CI: 22-45), whereas of the 705 patients without epileptic seizures 169 died (24\%; 95\% CI: 21-27). This difference was statistically significant: IRR is $1.58(95 \% \mathrm{CI}: 1.01-2.47 ; \mathrm{p}=0.043)$. However, after adjusting for interaction of different prognostic variables, $34,153,184,187$ the contribution of seizures to mortality again was no Jonger statistically significant, and the higher mortality in patients with seizures appeared to depend on the same prognostic variables as in the analysis on 30-day case fatality rate. Results of this analysis are shown in table 3.11 .

\section{Discussion}

In this prospective register of 770 patients with a first-ever symptomatic supratentorial brain infarct, epileptic seizures were observed in nearly eleven per cent, during a median follow-up of almost two ycars.

Although our register is hospital-based, we suspect no major bias in our patient sampling technique, as our hospital is the only hospital in the Maastricht referral areil, and we registered not only patients admitted, but also those visiting the outpatients' clinic. In The Netherlands patients with a stroke are usually admitted during the acute phase of their illness ( 85 per cent of all stroke-patients and even more in first-ever cases ${ }^{86}$ ), whereas the remaining patients are likely to visit the outpatients' clinic. In addition, patients not seen at a hospital are most likely those with rapid disappearance of symptoms and those who die early. representing transient ischaemic attack and cerebral haemorrhage, respectively, which were not included in our register.

During the five year intake period 816 patients with a first-ever symptomatic supratentorial brain infarct were registered: males forming a small majority, and the median patient age at the time of stroke being high, in agreement with the findings of other stroke registers. ${ }^{14.69 .86}$ The incidence rates for stroke. first-ever stroke and cerebral infarction in The Netherlands are known from the "Tilburg Epidemiological Study of Stroke 1978- 1981".86 The adherent population of our hospital was approximately 190.000 people. So the estimated number of patients with a first-ever symptomatic supratentorial brain infarct in five years in our adherent population is 903 patients, implying that $90(88-92)$ per cent of all patients was registered. However. taking into account the downward trend in stroke incidence over the years in The Netherlands, ${ }^{131}$ this estimated number could be lower. and the percentage of registered patients higher. In comparison with a more recent (1985 - 1992) population-based study in France, ${ }^{67-69}$ the estimated number for our study was 836 patients with a first-ever symptomatic supratentorial brain infarct, implying that $98(97-99)$ per cent of all patients was 
registered. Therefore, we concluded that our register was suited for our study on several aspects of post-stroke seizures following a first cerebral infarct.

\section{Frequency of post-stroke seizures and seizure delay}

Although the frequency of so-called post-stroke epilepsy varies between studies from zero to more than 50 per cent, $17.19,20,29,36,37,45+47,54,55,58,69.83,88.90 .100,102.104 .113$, $118,124,127,136,137,140-142.146,15+156,166,168,174,188,193$ our overall frequency for post-stroke seizures of 11 per cent concurs with the frequencies found in other studies on brain infarct patients: 8 per cent in 1000 patients with "non-embolic cerebral infarction", 13 | 4 per cent in 500 patients with "cerebral infarction",90 13 per cent in 77 patients with "brain intarcts", 137 and 7 per cent in 183 patients with "ischaemic stroke". I1" We unlikely underestimated the seizure occurrence hecause patients were asked for seizure occurrences at every follow-up visit.

As the aim of this thesis is to establish the risk of post-stroke epilepsy following a first symptomatic supratentorial brain infarct, patients with a possible additional cause for their first seizure, and patients who had experienced a recurrent stroke before the first seizure. were included as suffering from poststroke seizures. as did others. ${ }^{100.101}$ Little is mentioned in the literature on how such patients' data were analysed.

We found that in one third of the patients the first seizure occurred within two weeks following stroke-onset. This number is undoubtedly influenced by length of follow-up. Studies in brain infarct patients with a similar follow-up length reported frequencies varying from 30 per cent ${ }^{125}$ and 33 per cent of seizures occurring early, ${ }^{80.113}$ to 54 per cent ${ }^{114}$ and 62 per cent occurring early. ${ }^{90}$ The distinction between early and late seizures is not uniform in the literature, and varies from one to two weeks, or even one month post-stroke. As most others. we arbitrarily chose for the cut off point at two wecks post-stroke. $46.80,107.113$ Almost 90 per cent of the early seizures in our patients occurred in the first week post-stroke, and 98 per cent of the late seizures occurred later than one month post-stroke. Therefore, our choice for the cut off point between early and late seizures at two weeks post-stroke, instead of at one week or one month after stroke, unlikely influenced our final results significantly.

Seventy seven per cent of patients who developed post-stroke seizures did so within the first year post-stroke, and 90 per cent within the first two years. These findings concur with the general opinion in the literature that most PSS develop during the first year post-stroke. ${ }^{36,46,49,60,80,90,137,140,146,176}$ 
No predominance of one of the two sexes in developing PSS was found. This agrees with Lancman et al. ${ }^{104}$ and Kilpatrick et al., ${ }^{101}$ whereas Olsen et al., ${ }^{137}$ Davalos et al. ${ }^{45}$ and Giroud et al. ${ }^{69}$ found a male. and Kotila et al. ${ }^{102}$ a female predominance. However, Olsen studied only 77 brain infarct patients of whom seven developed seizures, whereas Davalos and Giroud studied early seizures in stroke and TIA patients. and Kotila studied the occurrence of epilepsy in stroke patients.

From studies on the incidence of epilepsy in the general population it is known that after a high incidence in childhood and a decline in adulthood, the incidence of new-onset seizure disorders increases significantly after the age of 60 , with the highest incidence rate noted in the age group $70-79$ years. ${ }^{82,111.114,181.182}$ This high incidence in the older age group may be strongly related to seizures in brain infarct patients, as our data suggest: patients who deviloped PSS were significantly older at the time of stroke-onset than the patients who remained seizure-free. Furthermore, patients 75 years or older developed post-stroke seizures significantly more often than patients younger than 75 years.

We also found a striking relation between age and seizure-delav: in patients 65 years and older the frequency of early-onset seizures increased with increasing age. whereas patients younger than 65 years developed only late-onset seizures.

\section{Early seizures and the risk of late scizures}

Patients with early seizures more often had seizures more than two weeks following stroke than the patients without seizures in the first two weeks. This difference was statistically significant, suggesting that early seizures predict the occurrence of late seizures. However, when the patients with both early and late seizures were studied more closely, and a distinction was made between earlyonset and late-onset seizures, there remained only two patients with both earlyand late-onset seizures, and the above mentioned difference was no longer statistically significant. Consequently, in our series, early-onset seizures were not related to the occurrence of late-onset seizures, whereas others, like Kilpatrick et al.. ${ }^{1+1}$ found a clearly increased risk of late seizures in patients with early scizures. This discrepancy may be explained by the fact that our study was prospective and we werc able to follow the patients with early-onset seizures for only 337 days (median: range 8-1614 days), whereas Kilpatrick et al. retrospectively studied patients who had had early seizures and had survived long enough to develop late scizures after 3 months to 2.5 years. In this way they excluded the patients who had died early alter the first early seizure and they studied a subpopulation with a significantly longer follow-up than our patients. probably increasing the risk of late seizures, and explaining the difference. 


\section{Seizure recurrence after a first post-stroke seizure}

Almost one quarter of the patients with post-stroke seizures experienced only one single epileptic seizure. Early-onset seizures tended to be single epileptic events as often as late-onset seizures, and there were no differences between age-groups in the occurrence of single and multiple seizures. However, treatment with AED's after the first seizure may influence the occurrence of a second seizure. In addition, the patient has to survive long enough to develop a second seizure. Therefore, we decided to look at the data at another way and to differentiate between so-called recurrent and non-recurrent seizures in patients who survived at least two weeks after their first seizure. ${ }^{81}$ In this way it appeared that early-onset seizures in patients older than 65 years had a good prognosis: they were non-recurrent in 80 per cent of the patients with early seizures who survived the first two weeks after their first seizure and rather easy to treat with AED's. Late-onset seizures on the other hand had a relatively bad prognosis: they were recurrent in almost half of the fourteen-day survivors. despite AED treatment. So, it appeared that if late seizures continued to occur later than two weeks after the first seizure, our patients, and especially the ones younger than 65 years, had developed a serious form of epilepsy, that was difficult to treat with AED's. In conclusion: age in combination with seizure delay appeared to be related to the seriousness of epilepsy that occurred after a first cerebral infarct: early-onset seizures in relatively old patients had a good prognosis, whereas lateonset seizures in relatively young patients were recurrent and difficult to treat with $A E D$ 's. Our finding that early-onset seizures have a low probability of recurrence in contrilst to late-onset seizures. concurs with that of others, and with the obstrvation that chronic epilepsy develops more often among patients who had had their first seizure with delayed onset. ${ }^{61.92 .102 .113 .115 .176}$

\section{Survival in patients with and without post-stroke seizures}

The 30-day case fatality rate and I-year mortality of our total population are in agreement with the rates for brain-infarct patients found in other prospective stroke-registers. ${ }^{14}$ However, when we differentiated between patients with and without seizures, both the 30-day case fatality rate and 1-year mortality, were significantly higher in the patients with seizures during this first month. respectively first year post-stroke. This finding is in contrast with most other investigators who found that (early) post-stroke scizures were not associated with higher mortality. ${ }^{19,45,100,10 !}$ Cox regression analysis of our data. revealed that our finding was biased by several other prognostic variables. especially high age and the presence of a (large) territorial infarct. After adjusting lor interaction of different prognostic variables. the contribution of post-stroke seizures to 30-day case fatality and I-year mortality was no longer statistically significant. Therefore, we conclude that post-stroke seizures are not related to a higher mortality through a causal relationship. but that mortality is higher in patients in 
a poor general condition, who are in addition also susceptible to develop (early) post-stroke seizures.

\section{Chapter conclusions}

- Nearly eleven per cent of patients with a first-ever symptomatic supratentorial brain infarct had epileptic seizures during a median follow-up of almost two years

- The first seizure occurred within two weeks following stroke-onset in one third of the patients, and in ninety per cent within the first two years

- No predominance of one of the two sexes in developing PSS was found

- Patients 75 years or older developed PSS significantly more often than younger patients

- Age and seizure delay ucre related: patients younger than 65 years developed only late-onsel seizures. whercas in patients from 65 years and older the frequency of early-onset seizures increased with increasing age

- Prognosis: early-onset seizures in relatively old patients were non-recurrent and easy to treat, their prognosis was good. Late-onset seizures in relatively young patients had a bad prognosis: they were recurrent in 31 per cent and difficult to treat in half of these patients

- Seizures were not related to a higher mortality rate

We conclude that early-and late-onset seizures represent two different types of epilepsy, probably with different pathogenesis and different risk factors.

Therefore in the next chapters, where risk factors are explored and wherein we try to identify high risk groups for the development of post-stroke seizures, separate analyses for early-onset and late-onset seizures will be performed. 



\section{CHAPTER 4}

Risk factors for developing epileptic seizures after a first-ever supratentorial brain infarct 
As described in the introduction of chapter 3, due to discrepancies in the literature, it still remains uncertain what particular factors influence the occurrence of seizures following a stroke. Stroke subtype, especially haemorrhagic infarction and (cardio) embolic infarction, large infarct size, and cortical location of the lesion have all been mentioned in the literature as possible risk factors for the development of epileptic seizures following a brain infaret.8.17.22,45,53-55,80,90,92,100.101.104,107.118,124,125.127.137.140,146,152.174,176 Age and sex could be important factors as well, although contradictory results have been reported, varying from a male $45,69.137$ to a female predominance 1.02 in developing post-stroke seizures (PSS), to similar frequencies in the two sexes (our findings in chapter 3).101.104 Data on the age-distribution of patients with and those without PSS have scarcely been reported, and when reported no differences were found.45,69,104.125 This contrasts with the findings described in the previous chapter that brain infarct patients 75 years or older developed post-stroke seizures significantly more often than patients below this age. In addition, we found that none of the patients younger than 65 years developed early-onset seizures. The question arises whether these patients differ in other risk factors besides age.

Some investigators suggested that systemic disease may affect not only the occurrence of strokes but also the occurrence of stroke-related seizures.47.107 Therefore cardiovascular or stroke risk factors and predisposing diseases like hypertension, diabetes or hyperglycaemia, angina pectoris, myocardial infarction, heart failure, atrial fibrillation, high cholesterol levels, previous stroke, intermittent claudication, and cigarette smoking, could all be possible risk factors for the development of post-stroke seizures. The role of some of these "risk factors" has been investigated. A history of hypertension was reported as an independent risk factor for new-onset unprovoked seizures in adults, especially, but not exclusively. in conjunction with a history of stroke. ${ }^{38.130}$ This finding has lead to the conclusion that hypertensive strokes are more "epileptogenic" than other strokes. and to the hypothesis that hypertension could lead to seizures through different kinds of vascular damage to the brain. only some of which manifest as clinical stroke. Hypertension is significantly associated with silent brain infarcts." and systolic hypertension is strongly correlated with carotid stenosis. ${ }^{177}$ Carotid stenosis is in turn a common cause of silent cerchral infarction according to some.: ": but others disagree. 26 "Therefore. carotid scnosis and silent brain infarction may be other ways through which hypertension could lead to seizures, the more so as both silent infarctions ${ }^{150.167 .176}$ and carotid stenosis ${ }^{36}$ have been recognized as increasing the risk of seizures. In experimental animal studies preischaemic hyperglycaemia markedly increased the number of early postischaemic seizures. ${ }^{170}$ Furthermore. in hyperglycaemic rats brain damage after ten minutes of forebrain ischaemia occurred earlier and was more severe than in normoglycaemic rats. In addition. the hyperglycaemic rats had lesions at unusual sites such as the cingulate cortex and subcortical nuclei, and especially the substantia nigra pars reticulata 
(SNPR). which is assumed to play a major role in preventing spread of seizure discharge by mechanisms related to GABA-ergic inhibition. ${ }^{170}$ Therefore, it was postulated that in hyperglycaemic rats subclinical seizure activity, that develops during recirculation, becomes amplified by the SNPR lesions and destruction of the GABA-ergic striatonigral pathway, finally leading to clinical (generalized) epileptic seizures. ${ }^{170}$ Hyperglycaemia may play a similar role in humans. However, this is difficult to investigate, as in most stroke patients it is unknown whether they were normo- or hyperglycaemic just before stroke-onset. Generally. only information on the blood glucose levels after stroke is available. Mean glucose level of the past four to six weeks before the stroke can be evaluated by measuring the haemoglobin $A_{1 C}$ level, however, this test still does not give information on the blood glucose level shortly before stroke-onset. Therefore, the first measured blood glucose level after stroke was used to determine if the patient was hyperglycaemic or not.

So far, few studies focused on comorbidity factors, such as diabetes and hypertension. in relation to post-stroke seizures. In a retrospective study on patients with post-stroke seizures (early and late seizures after an infarct or haemorrhage) no differences in age. sex, arterial hypertension, diabetes, atrial fibrillation. and heart failure were found between the patients with seizures and a control group of stroke patients without post-stroke seizures admitted during the same period. ${ }^{125}$ However. the proportion of patients with alcohol abuse was significantly greater in the patients with seizures. ${ }^{125}$ In a prospective study on epileptic seizures at the onset of stroke (within 48 hours after an infarct, haemorrhage or TIA) cardiovascular risk factors (hypertension, diabetes, myocardial infarct or angina, rheumatic heart disease, heart failure, atrial fibrillation, previous stroke, intermittent claudication), age, smoking ( $>10$ cigarettes per day) and alcohol use (>80 g/day) were similar in groups with and those without seizures. ${ }^{45}$ However, seizures were more frequent in males. These results are similar with those of a prospective study on early seizures following acute stroke (within 15 days after an infarct, haemorrhage. TIA or SAH), which showed no differences between patients with and those without seizures in arterial hypertension, diabetes, high cholesterol levels, ischaemic heart disease. heart failure, atrial fibrillation, tobacco abuse ( $>10$ cigarettes a day), alcohol abuse (> $60 \mathrm{~g} / \mathrm{day}$ ), and age. ${ }^{69}$ In this study seizures were also more frequent among males. ${ }^{69}$

In summary. studies so far do not suggest that cardiovascular risk factors increase the risk of post-stroke seizures. However, patients with all kinds of stroke subtypes. including TIA's, were studied as one group, whereas there may be differences between stroke subtypes. justifying separate analysis. Furthermore. early and late seizures were not examined separately, whereas these two may have different mechanisms ${ }^{43.45,46,53,61.80,92,107,113.152,176}$ and different risk factors. In the previous chapter we already found obvious differences between early-onset and late-onset post-stroke seizures. Therefore, we decided to explore possible risk factors for early-onset and late-onset seizures separately 
in our prospective register of adult patients with a first-ever-in-a-lifetime symptomatic supratentorial brain infarct.

\section{Patients and methods}

As described in chapter 3, patients were registered in an ongoing prospective register at the University Hospital Maastricht, that includes all adult patients admitted to the Neurological Department or seen at the outpatients' clinic during a five year intake-period, with a first-ever symptomatic supratentorial brain infarct with symptoms lasting longer than 24 hours. In- and exclusion criteria. data which were recorded, investigations that were performed, definitions of brain infarction, cortical and lacunar syndrome. symptomatic versus silent infarct, and of post-stroke epilepsy, method of assigning the patients to either one of four infarct groups (infarcts with a rare cause, lacunar infarcts LACI, cirdioembolic territorial infarcts $\mathrm{CE}$ or remaining territorial infarcts $\mathrm{RI}$ ), methods of follow-up, and data recorded during follow-up. are described in detail in chapter 3 .

The degree of handicap on admission was measured using the modified Rankin scale (see Appendix), 13.14.131.143.179 Patients with a Rankin grade 0, 1, or 2 (grade 0 naturally did not occur shortly after stroke-onset) were considered totally independent for their activities of daily life (ADL), whereas patients with a Rankin grade 3,4 , or 5 were considered functionally dependent, contorm the classification in other prospective stroke-registers. ${ }^{14.131 .199}$

Besides age and sex, the following possible risk factors were recorded: ischaemic heart disease (IHD), defined as a history of angina pectoris. myocardial infarction or coronary bypass operation. Hypertension, defined as known hypertension whether or not treated with anti-hypertensive medication. or blood pressure recordings of more than $160 / 90 \mathrm{~mm} \mathrm{Hg}$ on at least two different occasions before, or at least one week atter the stroke. Diabstes mellitus (DM), defined as known diabetes treated with diet or medication (oral or insulin), or either a fasting blood glucose higher than $7 \mathrm{mmol} / \mathrm{l}$ or a postprandial blood glucose higher than $11 \mathrm{mmol} / \mathrm{l}$ measured on at least two separate occasions before or after stroke, but not during the first 72 hours after the stroke. Chronic ohstructive pulmonary disease (COPD), defined as a history of chronic obstructive pulmonary disease treated with medication. The presence of a potential cardiac source of embolism (CE) in the medical history, on ECG. or echocardiography: chronic or intermittent ECG confirmed atrial fibrillation; left ventricular myocardial infarction within six weeks preceding stroke: left wentricular or atrial thrombus; left ventricular aneurysm: left ventricular akinetic segment: cardiomyopathy: mitral or atrtic valve abnormalities as endocarditis. mitral stenosis, prosthetic aortic or mitral values: and atrial or ventricle septal defect. Carotid stenosis: a lesion with a diameter reduction of more than 50 per cent on non-invasive carotid tests was defined as a significant carotid stenosis. 32 
Hyperglycaemia: the first measured blood glucose level after stroke-onset was recorded. In 659 patients ( $86 \%$ ) blood glucose was determined within one week after stroke-onset, in 565 patients (73\%) within 48 hours and in 524 patients $(68 \%)$ within 24 hours after stroke-onset. Hyperglycaemia was defined as a fasting blood glucose higher than $7 \mathrm{mmol} / \mathrm{l}$ or a postprandial blood glucose higher than $11 \mathrm{mmol} / \mathrm{J}$. The CT-scan features infarct size, cortical location of the infarct, haemorrhagic infarction, presence of silent infarcts, and leukoaraiosis were noted. As in a substantial number of patients no abnormalities were visible on CT, these CT-scan features could only be studied in a subgroup of patients (see chapter 5).

As survival time after stroke is an important factor in the occurrence of poststroke seizures (especially late-onset). and because early-onset and late-onset seizures may represent two different types of epilepsy with different underlying epileptic mechanisms and different risk factors, $43,45,46,53,61,80.92,107,113,152,176$ they were analysed separately. Risk factors for early-onset seizures were analysed in all 770 patients. As late seizures occur by definition two weeks or more after stroke-onset, only patients who survive at least two weeks after their stroke are at risk for experiencing late-onset seizures, and therefore risk factors for lateonset seizures were analysed in the 716 fourteen-day survivors. As some of these patients had experienced early-onset seizures, and some of them were treated with anti-epileptic drugs (AED's) after early seizures, these variables were included in the analysis on late-onset seizures as well.

According to our findings in the previous chapter, age was divided in three categories which were used in the Cox regression analyses as well: age $<65$ years, $65 \leq$ age $<75$, and age $\geq 75$ years. However, as none of the patients younger than 65 years experienced an early seizure, the age-limit at 65 years could not be used in the Cox regression analysis on risk factors for early-onset seizures. Therefore we decided to use only the age-limit at 75 years and to analyse the patients younger than 75 years as one group, instead of two, in order to analyse all patients. instead of excluding the patients younger than 65 years.

\section{Statistical methods}

Differences in age-distribution, male/female ratio, median follow-up times and survival were analysed using the distribution-free, nonparametric MannWhitney Test. ${ }^{133}$ After simply counting and comparing the number of patients with seizures in different risk factor subgroups, differences between groups were analysed accounting for differences in exposure time, using Incidence Rate Ratio's (IRR) with $95 \%$ confidence intervals (Cl), and two-tailed p-values. ${ }^{151}$ When this correction for diffirences in exposure time was not necessary, the odds ratio with Yates' continuity correction (OR) with $95 \%$ confidence interval and Chi-square test $\left(X^{2}\right)$ with two-tailed p-value was used to estimate the relative risk. +2.119 .159 When the number of patients in a specific risk group was less than 
five, or even equal to zero, Fisher's exact test was used to estimate the two-tailed p-value.42,119,133 In addition the estimated effect of each possible risk factor on the occurrence of post-stroke seizures, was statistically adjusted for differences in the distribution of the other risk factors (explanatory independent variables or covariates) by means of a Cox regression analysis (proportional hazards model), resulting in hazard ratio's (HR) with 95\% Cl's and two-tailed p-valucs.+2.119.13.+ The Cox regression analysis is a specific regression model for survival data. able to handle censored data (incomplete observations) and varying lengths of exposure times. With this model it is possible to study the association between a number of different explanatory factors (covariates) and an outcome variable that is time dependent e.g. survival time, or, as in our study, time between brain infarct and first epileptic seizure.

As early-onset seizures occurred by definition within two weeks following stroke-onset, in the analyses on early-onset seizures for every patient the maximal length of follow-up was set at 14 days. In the analyses on late-onset seizures the patients' complete available length of follow-up was used. Our results were not biased by the differences in length of these total follow-up times, as we corrected for this possible bias in our statistical analyses.

\section{Results}

As described in chapter 3 during the intake-period of five years. 816 patients with a first cerebral infarct were registered. Forty-six patients were excluded for different reasons (see chapter 3 ), leaving 770 patients at risk for developing poststroke seizures. Post-stroke seizures (PSS) were divided in early-onset seizures (occurring during the first two weeks following stroke-onset), and late-onset seizures (later than two weeks following stroke).

\section{Eurly-onset seizures}

Twenty-eight patients of the 770 patients at risk (4\%) experienced early-onset posi-stroke seizures after a median of 1 day (range by definition 0-14 days). Tables 4.1 and 4.2 show the general features of the patients with early seizures and those without. There were no differences in male/female ratio between the patients who developed early seizures and those who did not. However, there were significant differences in age-distribution and length of total follow-up between both groups: patients who developed early post-stroke scizures were significantly older than those who did not (none of the patients younger than 65 years developed early seizures), and their median follow-up was shorter. This difference in follow-up is explained by the fact that significantly more patients with early seizures died during follow-up. In addition. the patients with early seizures who died. died earlier after their stroke than the patients without early 
seizures who died. The follow-up time of the patients still alive at the end of our study did not differ between groups. Table 4.3 shows the frequencies of possible risk factors among patients with and those without early-onset seizures, with IRR's indicating differences between both groups. In figure 4.1 the IRR's and their $95 \%$ CI's are displayed graphically. As none of the patients with early-onset seizures experienced a recurrent stroke before the first seizure, recurrent stroke was not analysed as a possible risk factor. As early seizures occurred very shortly after stroke-onset, only blood glucose levels obtained during the first 24 hours post-stroke wer used to decermine hyper- or normoglycaemia. Otherwise, hyperglycaemia conld be the result rather than the cause of the epileptic seizure, and the intluence of hyperglycuemia on the occurrence of early seizures would be biased. The table and figure show that patients with early-onset seizures were

Table 4.1: Early-onset seizures following a first cerebral infarct General features of patients with and those without early seizures

\begin{tabular}{|c|c|c|c|}
\hline All patients $N=770$ & $\begin{array}{c}\text { With early-onset } \\
\text { seizures }\end{array}$ & $\begin{array}{c}\text { Without early-onset } \\
\text { seizures }\end{array}$ & $\begin{array}{c}\text { Mann-Whitney } \\
\text { test } p \text {-value }\end{array}$ \\
\hline
\end{tabular}

Number of patients (\% of total) 28

Males (\% in group)

Median age (range) in years

Md follow-up (range) in days

Deaths $(\%$ of group)

- Md death-delay (range) in days

Number still alive (\% of group)

- Md follow-up (range) in days

28

15

81

377

17

18

11

998 (330 - 1614)

$(65-88)$

(61)

(8- 1068)

(39)
(4) 742

(54) 387

72

629

276

188

466

858 (195-1998)
(96)

(52)

0.8831

(26 - 96)

0.0000

0.0080

0.0119

0.0225

0.0119

0.8882

Table 4.2: Age-distribution and male/female ratio of all patients, and of those who developed early-onset PSS, summarized for three age-groups (percentages between parentheses)

\begin{tabular}{|c|c|c|c|c|c|c|c|c|c|}
\hline \multirow{2}{*}{$\begin{array}{l}\text { Age } \\
26-64\end{array}$} & $\begin{array}{c}\text { Total number } \\
\text { of patients }\end{array}$ & \multicolumn{2}{|c|}{$\begin{array}{c}\text { With } \\
\text { early PSS }\end{array}$} & \multirow{2}{*}{$\begin{array}{c}\text { Males } \\
\text { total N } \\
128\end{array}$} & \multicolumn{2}{|c|}{$\begin{array}{c}\text { With } \\
\text { early PSS }\end{array}$} & \multirow{2}{*}{$\begin{array}{c}\text { Females } \\
\text { total N } \\
62\end{array}$} & \multicolumn{2}{|c|}{$\begin{array}{c}\text { With } \\
\text { early PSS }\end{array}$} \\
\hline & (25) & 0 & & & 0 & & & 0 & \\
\hline $65-74$ & $267 \quad(35)$ & 6 & (2) & 155 & 6 & (4) & 112 & 0 & \\
\hline $75-96$ & $313(40)$ & 22 & (7) & 119 & 9 & $(8)$ & 194 & 13 & (7) \\
\hline Total & $770(100)$ & 28 & (4) & 402 & 15 & (4) & 368 & 13 & (4) \\
\hline
\end{tabular}


Table 4.3: Early-onset seizures: Frequency of possible risk factors in patients with and those without early-onset seizures following a first cerebral infarct, and the relative risk (IRR) for developing these early-onset seizures when the risk factor is present (compared with factor absent)

\begin{tabular}{|c|c|c|c|c|c|c|c|}
\hline & \multicolumn{2}{|c|}{$\begin{array}{l}\text { With seiz } \\
\mathrm{N}=28\end{array}$} & \multicolumn{2}{|c|}{$\begin{array}{l}\text { Without seiz } \\
\qquad \mathrm{N}=742 \\
\end{array}$} & \multirow[b]{2}{*}{ IRR } & \multirow[b]{2}{*}{$95 \% \mathrm{Cl}$} & \multirow[b]{2}{*}{$\mathrm{p}$-value } \\
\hline & $N$ & $(\%)$ & $\mathrm{N}$ & $(\%)$ & & & \\
\hline Age $<65$; young & 0 & & 190 & $(26)$ & & & \\
\hline $65-75 ;$ middle & 6 & (21) & 261 & $(35)$ & & & \\
\hline$\geq 75 ;$ old & 22 & (79) & 291 & $(39)$ & & & \\
\hline - old versus middle & & & & & 3.40 & $1.38-$ & 0.008 \\
\hline- age $\geq 75$ vs age $<75$ & & & & & 5.84 & $2.37-14.40$ & 0.000 \\
\hline Male sex & 15 & (54) & 387 & $(52)$ & 1.03 & $0.49-\quad 2.17$ & \\
\hline Ischaemic heart disease & 9 & $(32)$ & 191 & $(26)$ & 1.41 & $0.64-3.11$ & \\
\hline Hypertension & 11 & (39) & 346 & $(47)$ & 0.75 & $0.35-$ & \\
\hline Diabetes mellitus & 8 & (29) & 144 & $(19)$ & 1.69 & $0.74-$ & \\
\hline Glucose $<24$ hours available & 23 & $(82)$ & 501 & $(68)$ & OR 2.21 & $0.74-6.61$ & \\
\hline - hyperglycaemia & 12 & $52 \%$ & 172 & $34 \%$ & 2.27 & $1.00-\quad 5.15$ & 0.049 \\
\hline COPD & 9 & $(32)$ & 76 & $(10)$ & 4.12 & $1.86-9.10$ & 0.000 \\
\hline - without theophylline & 2 & $22 \%$ & 49 & $64 \%$ & & & \\
\hline - with theophylline & 7 & $78 \%$ & 27 & $36 \%$ & & & \\
\hline \multicolumn{3}{|l|}{ - COPD without theo vs no COPD } & & & 1.42 & $0.33-6.08$ & \\
\hline - COPD with theo vs no COPD & & & & & 9.06 & $3.81-21.56$ & 0.000 \\
\hline \multicolumn{3}{|l|}{ - COPD with theo vs COPD without } & & & 6.40 & $1.33-30.82$ & 0.021 \\
\hline Presence of CE & 18 & (64) & 199 & $(27)$ & 5.14 & $2.37-11.13$ & 0.000 \\
\hline Cortical syndrome & 27 & (96) & 470 & $(63)$ & 16.51 & $2.24-121.51$ & 0.006 \\
\hline Rankin score $\geq 3$ & 28 & $(100)$ & 573 & $(77)$ & - & Fisher exact: & 0.009 \\
\hline Carotid test available & 9 & $(32)$ & 488 & $(66)$ & OR 0.25 & $0.11-\quad 0.55$ & 0.001 \\
\hline - ipsilateral stenosis & 0 & $0 \%$ & 106 & $22 \%$ & - & Fisher exact: & 0.215 \\
\hline \multicolumn{8}{|l|}{ Infarct sub-group } \\
\hline - territorial CE or RI & 25 & (89) & 480 & $(65)$ & & & \\
\hline - territorial CE & 16 & $64 \%$ & 159 & $33 \%$ & & & \\
\hline - territorial RI & 9 & $36 \%$ & 321 & $67 \%$ & & & \\
\hline - CE versus RI & & & & & 3.77 & $1.66-8.52$ & 0.001 \\
\hline - lacunar & 3 & (11) & 262 & $(35)$ & & & \\
\hline - Iacunar with CE & 2 & $67 \%$ & 40 & $15 \%$ & & & \\
\hline - other lacunar & 1 & $33 \%$ & 222 & $85 \%$ & & & \\
\hline - laci CE vs other laci & & & & & 11.08 & $1.00-122.16$ & 0.049 \\
\hline - territorial vs lacunar & & & & & 4.79 & $1.45-15.86$ & 0.010 \\
\hline CT-scan available & 25 & (89) & 712 & $(96)$ & OR 0.35 & $0.07-1.85$ & \\
\hline - no infarct visible & 9 & $36 \%$ & 197 & $28 \%$ & OR 1.47 & $0.49-4.43$ & \\
\hline - large cortical infarct & 6 & $24 \%$ & 110 & $15 \%$ & & & \\
\hline - smaller cortical infarct & 8 & $32 \%$ & 244 & $34 \%$ & & & \\
\hline - lacunar infarct & 2 & $8 \%$ & 161 & $23 \%$ & & & \\
\hline - cortical vs lacunar infarct & & & & & 3.33 & $0.76-14.64$ & \\
\hline - large cortical vs lacunar & & & & & 5.15 & $1.04-25.53$ & 0.045 \\
\hline - smaller cortical vs lacunar & & & & & 2.63 & $0.56-12.38$ & \\
\hline - large vs smaller cortical & & & & & 1.96 & $0.68-\quad 5.65$ & \\
\hline - silent lesions & 7 & $28 \%$ & 198 & $28 \%$ & 1.00 & $0.42-\quad 2.39$ & \\
\hline
\end{tabular}


significantly older, they presented more often with a cortical syndrome and a Rankin score $\geq 3$, they significantly more often had a potential cardiac source of embolism, a territorial infarct, a hyperglycaemia in the first 24 hours after stroke, and a history of COPD treated with theophylline. In patients with early-onset seizures non-invasive carotid test had significantly less frequently been performed. probably related to a worse general condition of these patients. When carotid test was available, in none of the patients with early seizures a significant ipsilateral carotid stenosis was detected. As the variables "cardiac source of embolism" and "clinical syndrome" were used to define the variable "stroketype" (see chapter 3: Classification of patients in infarct subgroups), there was an interaction between these variables and consequently they were not analysed in the same regression model. Therefore two different Cox regression models were used. The results are shown in table 4.4. In the first model, Cox regression analysis was performed with the following variables: age, sex, IHD, hypertension. DM. hyperglycaemia, COPD without or with theophylline use, cardiac source of embolism, and cortical syndrome. High age, the presence of a cardiac source of embolism, a cortical syndrome, and COPD treated with theophylline remained significantly associated with the occurrence of earlyonset seizures. In the second model the variables "cardiac source of embolism" and "clinical syndrome" were replaced by "stroketype". Then, as expected, high age, a cardioembolic territorial infarct, and COPD treated with theophylline were significantly associated with the occurrence of early-onset seizures. The variable "dependent Rankin" could not be analysed in the Cox regression models because all patients who developed early-onset seizures had a Rankin score $\geq 3$. However, from the Fisher exact test in table 4.3 it is obvious that a "dependent Rankin" (a Rankin score $\geq 3$ ) is highly significantly associated with the occurrence of early-onset seizures. The variable "ipsilateral carotid stenosis" could not be analysed as it did not occur among the patients with early seizures, however it seemed not related with the occurrence of early onset seizures (table 4.3).

Consequently, patients at risk for developing early-onset seizures were the patients of 65 years or older who had a cortical syndrome, a Rankin score $\geq 3$, and a potential cardiac source of embolism. These 144 high risk patients ( $19 \%$ of the total patient group at risk). of whom 17 experienced early-onset seizures (61\% of all early-onset seizures: five patients died early, 11 had non-recurrent seizures, one had recurrent seizures), had a risk of early-onset seizures of $12 \%$ ( $95 \% \mathrm{CI}: 10-14$ ). whereas the remaining 626 patients, of whom 11 experienced early-onset seizures, had a risk of early-onset seizures of $2 \%(95 \% \mathrm{CI}: 1-3)$ ). The IRR for this high risk group is $8.05(95 \% \mathrm{CI}: 3.77-17.18 ; \mathrm{p}=0.000)$. If the variable "history of COPD treated with theophylline" was added to this high risk group, only seven patients remained at risk, but the risk of early seizures rose to $29 \%$ (95\% CI: $0-63$ ), whereas the remaining 763 patients had a risk of early seizures of $3 \%$ (95\% CI: $2-4$ ). The IRR for this small high risk group is 12.45 (95\% CI: 2.96-52.47; $\mathrm{p}=0.001$ ). 
Tab!e 4.4: Cox regression analysis, risk of early-onset seizures

Cox regression model one:

Variables affecting the risk of early-onset seizures

The variables "cardiac source of embolism" and "clinical syndrome" are included in the model

\begin{tabular}{lccc}
\hline & HR & $95 \% \mathrm{Cl}$ & p-value \\
\hline Age $\geq 75$ vs age $<75$ & 3.95 & $1.53-10.17$ & 0.004 \\
Male & 1.62 & $0.70-3.79$ & \\
Ischaemic heart disease & 1.25 & $0.55-2.86$ & \\
Hypertension & 0.82 & $0.36-1.87$ & \\
Diabetes mellitus & 1.43 & $0.53-3.87$ & \\
Hyperglycaemia & 1.50 & $0.55-4.05$ & 0.000 \\
COPD without theo vs no COPD & 1.12 & $0.25-5.03$ & 0.007 \\
COPD with theo vs no COPD & 8.37 & $3.30-21.25$ & 0.025 \\
Presence of CE & 3.03 & $1.36-6.75$ & \\
Cortical syndrome & 10.05 & $1.33-75.81$ & \\
\hline
\end{tabular}

Second Cox regression model:

The variables "cardiac source of embolism" and "clinical syndrome" are replaced by the variable "stroketype"

\begin{tabular}{llll}
\hline & HR & $95 \% \mathrm{Cl}$ & p-value \\
\hline Age $\geq 75$ vs age < 75 & 4.26 & $1.66-10.94$ & 0.003 \\
Male & 1.55 & $0.67-3.56$ & \\
Ischaemic heart disease & 1.16 & $0.51-2.62$ & \\
Hypertension & 0.73 & $0.33-1.66$ & \\
Diabetes mellitus & 1.43 & $0.52-3.88$ & \\
Hyperglycaemia & 1.62 & $0.59-4.45$ & \\
COPD without theo vs no COPD & 1.10 & $0.25-4.94$ & 0.000 \\
COPD with theo vs no COPD & 7.31 & $2.93-18.23$ & 0.015 \\
CE versus RI & 2.85 & $1.22-6.61$ & 0.010 \\
CE versus laci & 5.30 & $1.50-18.70$ & \\
RI versus laci & 1.86 & $0.50-6.96$ & \\
\hline
\end{tabular}


Of the 716 fourteen-day survivors 58 patients (8\%) developed "real" late-onset post-stroke seizures, according to our definition in the previous chapter, after a median of 261 (range 18-1848) days. Tables 4.5 and 4.6 show the general features of the patients with late-onset seizures and those without. There were no significant differences in age-distribution, male/female ratio, length of total follow-up, and number of patients who died during follow-up, between the patients who developed late-onset seizures and those who did not. Table 4.7 shows the frequencies of possible risk factors among patients with and those without late-onset seizures, with IRR's indicating differences between both groups. In figure 4.1 the IRR's and their $95 \% \mathrm{CI}$ 's are displayed graphically. As there were eleven patients who experienced a recurrent stroke before the first epileptic seizure, the occurrence of a recurrent stroke was analysed as a possible risk factor. Some patients had experienced early-onset seizures, and a number of them was treated with anti-epileptic drugs (AED's). Therefore, these variables were included in the analysis as well. The table and figure show that patients with late-onset seizures were significantly older, had significantly more often a cortical syndrome, a Rankin score $\geq 3$, a territorial infarct, an ipsilateral carotid stenosis, and a history of COPD treated with theophylline.

Five patients without late-onset seizures (two males, threc females, aged 76-88 years, four with a cortical syndrome and all five with a Rankin score $\geq 3$ ) were excluded from the Cox regression analysis, as they were censored before the earliest event occurred, meaning they died (three on day 15 , one on day 16 and one on day 17 post-stroke) before the first late seizure among the patients with late seizures (day 18). As these five patients were at risk for developing late-onset seizures for just eight days, excluding these five patients unlikely affected the final results; consequently Cox regression analysis was performed on 711 patients.

As in the analyses on early-onset seizures, again two different Cox regression models were used. Table 4.8 shows the results. When all possible risk factors were entered in the model, only the cortical syndrome and Rankin score $\geq 3$ remained significantly associated with the occurrence of late-onset seizures. In the second model, when the variables "cardiac source of embolism" and "clinical syndrome" were replaced by "stroketype", only the Rankin score $\geq 3$ remained significantly associated with the occurrence of late-onset seizures. However, when stroketype was divided in lacunar versus territorial (CE and RI together), territorial infarcts and Rankin score $\geq 3$ were both significantly associated, irrespective of the stroke cause.

Consequently, patients at risk for developing late-onset seizures were those who had a cortical syndrome and a Rankin score $\geq 3$, irrespective of age and stroke cause. These 381 high risk patients ( $53 \%$ of all patients at risk), of whom 50 experienced late-onset seizures ( $86 \%$ of all late-onset seizures; six patients died early, 21 had non-recurrent seizures, 23 had recurrent seizures), had a risk of 
Table 4.5: Late-onset seizures in patients who survived the first two weeks after a first cerebral infarct

General features of patients with and those without late seizures

\begin{tabular}{lrrrrr}
\hline $\begin{array}{l}\text { Fourteen-day } \\
\text { survivors N=716 }\end{array}$ & \multicolumn{2}{c}{$\begin{array}{c}\text { With late-onset } \\
\text { seizures }\end{array}$} & $\begin{array}{c}\text { Without late-onset } \\
\text { seizures }\end{array}$ & $\begin{array}{c}\text { Mann-Whitney } \\
\text { test p-value }\end{array}$ \\
\hline Number of patients (\% of total) & 58 & $(8)$ & 658 & $(92)$ & \\
Males (\% in group) & 30 & $(52)$ & 349 & $(53)$ & 0.8475 \\
Median age (range) in years & 74 & $(40-87)$ & 71 & $(26-95)$ & 0.9649 \\
Md follow-up (range) in days & 972 & $(21-1897)$ & 681 & $(15-1998)$ & 0.1322 \\
Deaths (\% of group) & 23 & $(40)$ & 216 & $(33)$ & 0.2908 \\
- Md death-delay (range) in days & 484 & $(21-1897)$ & 261 & $(15-1781)$ & 0.0204 \\
Number still alive (\% of group) & 35 & $(60)$ & 442 & $(67)$ & 0.2908 \\
- Md follow-up (range) in days & 1033 & $(306-1755)$ & 841 & $(195-1998)$ & 0.4233 \\
\hline
\end{tabular}

Table 4.6: Age-distribution and male/female ratio of all patients, and of those who developed late-onset PSS, summarized for three age-groups (percentages between parentheses)

\begin{tabular}{lcccccccccc}
\hline Age & $\begin{array}{c}\text { Total number } \\
\text { of patients }\end{array}$ & $\begin{array}{c}\text { With } \\
\text { late PSS }\end{array}$ & $\begin{array}{c}\text { Males } \\
\text { total N }\end{array}$ & $\begin{array}{c}\text { With } \\
\text { late PSS }\end{array}$ & $\begin{array}{c}\text { Females } \\
\text { total N }\end{array}$ & $\begin{array}{c}\text { With } \\
\text { late PSS }\end{array}$ \\
\hline $26-64$ & 179 & $(25)$ & 14 & $(8)$ & 120 & 9 & $(8)$ & 59 & 5 & $(8)$ \\
$65-74$ & 259 & $(36)$ & 17 & $(7)$ & 152 & 11 & $(7)$ & 107 & 6 & $(6)$ \\
$75-96$ & 278 & $(39)$ & 27 & $(10)$ & 107 & 10 & $(10)$ & 171 & 17 & $(10)$ \\
\hline Total & 716 & $(100)$ & 58 & $(8)$ & 379 & 30 & $(8)$ & 337 & 28 & $(8)$ \\
\hline
\end{tabular}


Table 4.7: Late-onset seizures: Frequency of possible risk factors in fourteen-day survivors with and those without late-onset seizures following a first cerebral infarct, and the relative risk (IRR) for developing these late-onset seizures when the risk factor is present (compared with factor absent)

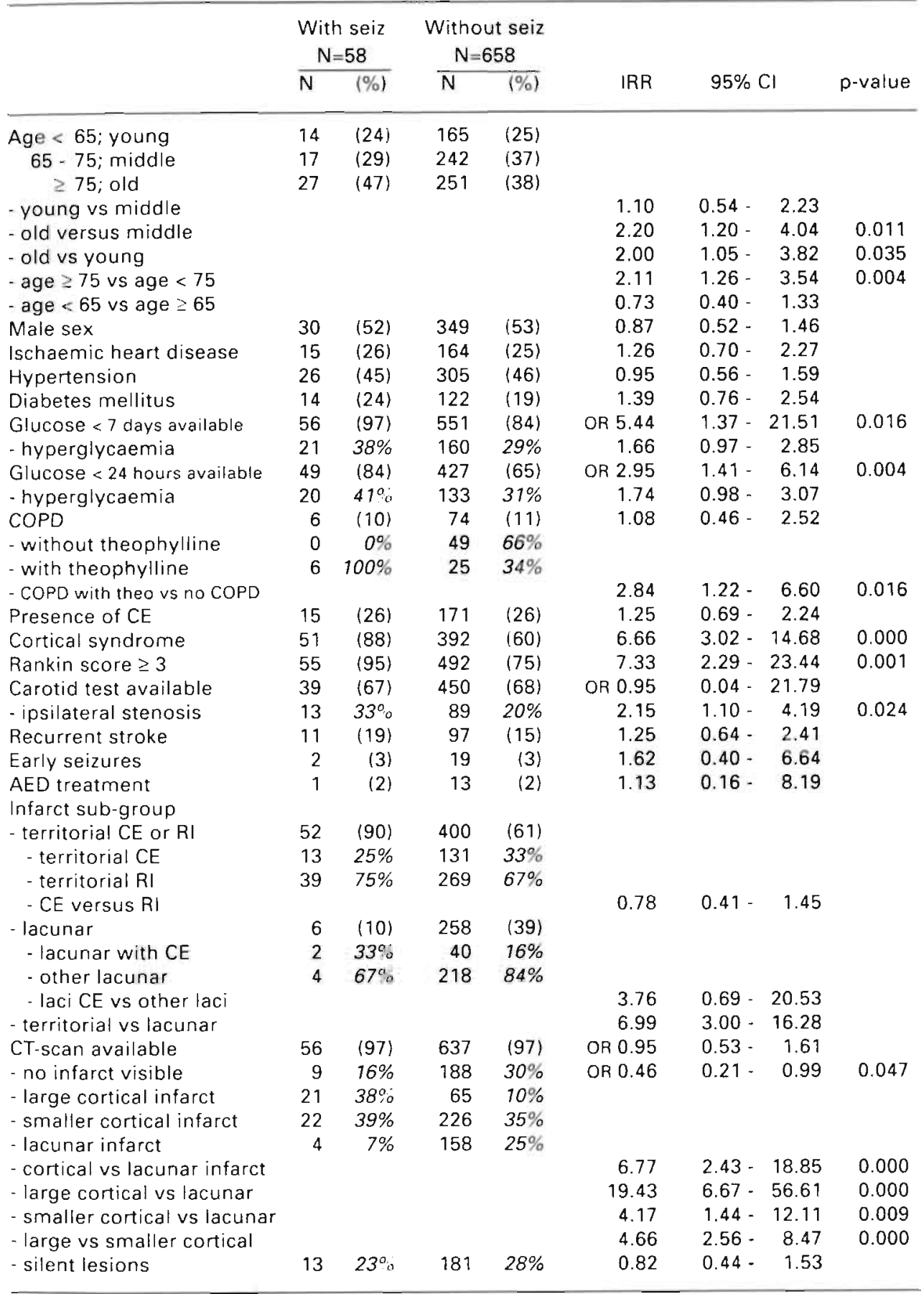


Figure 4.1: Possible risk factors for seizures following a first cerebral infarct

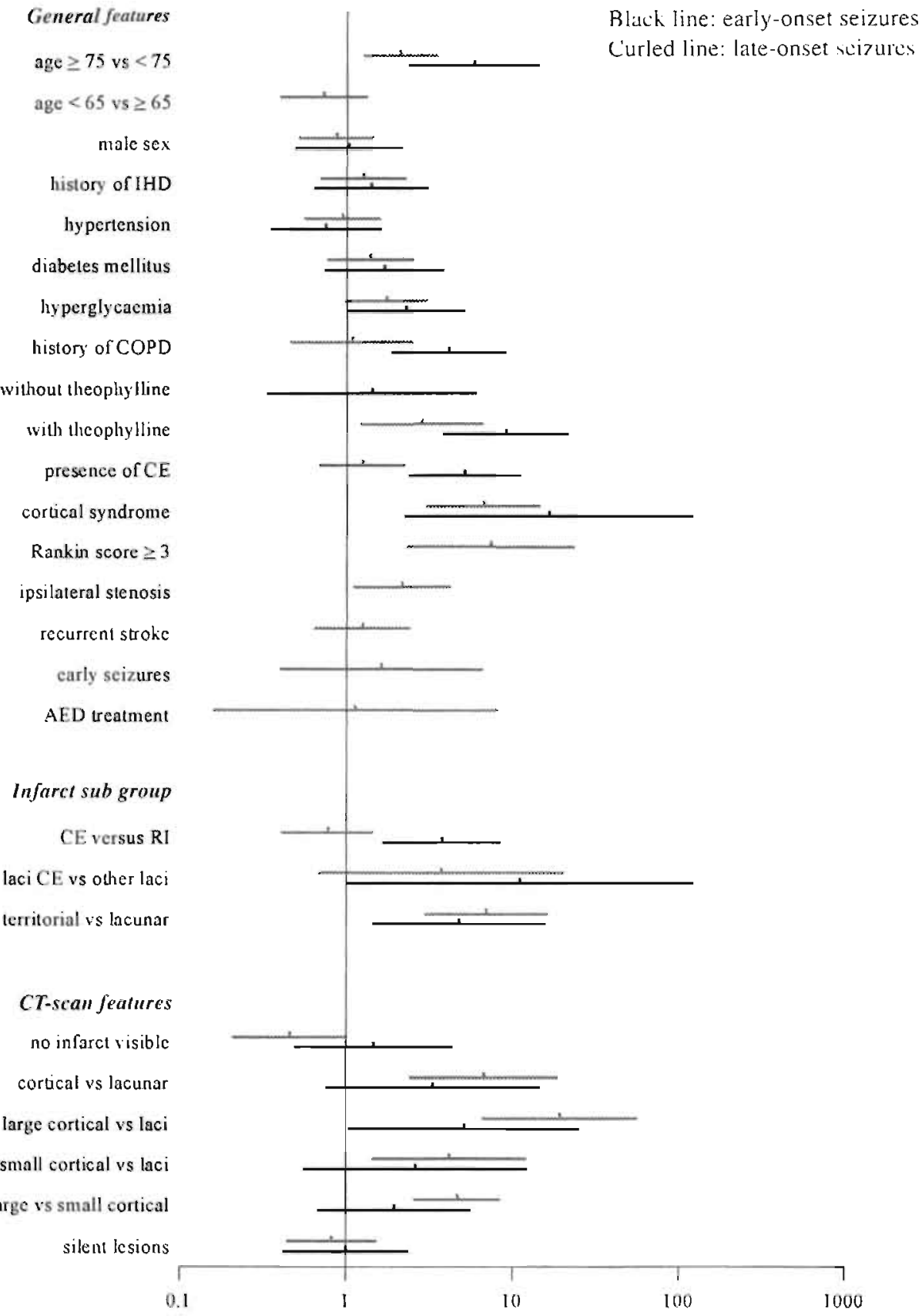

Diagram of IRR's with $95 \% \mathrm{Cl}$ 's on a logarithmic scale; IRR $>1$ means an increased risk of seizures when the possible risk factor is present (compared with factor absent); $95 \% \mathrm{Cl}$ not including the value 1 means that the difference in risk is statistically significant with $p<0.05$ 


\section{Table 4.8: Cox regression analysis, risk of late-onset seizures}

Cox regression model one: The variables "cardiac source of embolism"

and "clinical syndrome" are included in the model

\begin{tabular}{llll}
\hline & HR & $95 \% \mathrm{Cl}$ & p-value \\
\hline Young age vs middle age & 1.28 & $0.62-2.65$ & \\
Old age vs middle age & 1.59 & $0.83-3.04$ & \\
Old age vs young age & 1.24 & $0.59-2.59$ & \\
Male sex & 1.20 & $0.68-2.12$ & \\
Ischaemic heart disease & 1.24 & $0.68-2.28$ & \\
Hypertension & 0.98 & $0.57-1.69$ & 0.036 \\
Diabetes mellitus & 1.13 & $0.55-2.31$ & \\
Hyperglycaemia $<24$ hours & 1.31 & $0.68-2.50$ & \\
COPD with theo vs no COPD & 2.03 & $0.79-5.25$ & \\
Rankin score $\geq 3$ & 3.66 & $1.09-12.30$ & \\
Ipsilateral stenosis & 1.36 & $0.68-2.69$ & \\
Recurrent stroke & 1.22 & $0.60-2.49$ & 0.000 \\
Early seizures & 0.73 & $0.09-5.94$ & \\
AED treatment & 0.70 & $0.04-11.89$ & \\
Presence of CE & 0.83 & $0.45-1.56$ & \\
Cortical syndrome & 4.55 & $2.00-10.33$ & \\
\hline
\end{tabular}

Second Cox regression model: The variables "cardiac source of embolism" and "clinical syndrome" are replaced by the variable "stroketype"

\begin{tabular}{llll}
\hline & HR & $95 \% \mathrm{Cl}$ & p-value \\
\hline Young age vs middle age & 1.22 & $0.59-2.53$ & \\
Old age vs middle age & 1.67 & $0.87-3.20$ & \\
Old age vs young age & 1.37 & $0.65-2.87$ & \\
Male sex & 1.22 & $0.69-2.15$ & \\
Ischaemic heart disease & 1.11 & $0.61-2.03$ & 0.042 \\
Hypertension & 0.99 & $0.58-1.70$ & \\
Diabetes mellitus & 1.11 & $0.54-2.32$ & \\
Hyperglycaemia $<24$ hours & 1.37 & $0.71-2.65$ & \\
CoPD with theo vs no COPD & 2.12 & $0.83-5.38$ & \\
Rankin score $\geq 3$ & 3.51 & $1.05-11.74$ & \\
Ipsilateral stenosis & 1.40 & $0.71-2.78$ & 0.000 \\
Recurrent stroke & 1.07 & $0.53-2.15$ & \\
Early seizures & 1.11 & $0.15-8.46$ & \\
AED treatment & 0.46 & $0.03-7.64$ & \\
Territorial vs lacunar infarct & 4.84 & $2.04-11.45$ & \\
\hline
\end{tabular}


late-onset seizures of $13 \%$ (95\% CI: 10-16), whereas the remaining 335 patients, of whom eight experienced late seizures, had a risk of late-onset seizures of $2 \%$ (95\% CI: 1-3). The IRR for this high risk group is 8.52 (95\% CI: 4.04-17.97; $\mathrm{p}=0.000$ ).

\section{Discussion}

\section{Early-onset seizures}

Early-onset seizures were observed in nearly four per cent of our 770 patients with a first-ever symptomatic supratentorial brain infarct. This frequency concurs with that found in other studies on brain infarct patients: three prospective studies on patients with cerebral infarcts $(\mathrm{N}=508,546$ and 1213 patients respectively) found a frequency of five per cent: ${ }^{45.69 .100}$ three per cent was found in 1000 patients with "non-embolic cerebral infarction", 11.3 one per cent in 77 patients with "brain infarcts", 137 and four per cent in 183 patients with "ischaemic stroke". 10t

Age appeared to be an important factor for early-onset seizures, as none of the patients younger than 65 years developed early-onset seizures. Univariate analysis showed several other possible risk factors besides high age. However, Cox regression analysis showed that, adjusted for interactions between the different possible risk factors, only high age ( 75 years or older), the presence of a cardiac source of embolism. a cortical syndrome, and a history of COPD treated with theophylline remained significantly associated with the occurrence of early-onset seizures. As all patients with early-onset seizures had a Rankin score $\geq 3$, this variable could not be analysed in the Cox regression analysis. However, it is obvious that a high Rankin score (a severe early handicap) was highly significantly associated with the occurrence of early-onset seizures.

Therefore, the high risk group for developing early-onset seizures, with a more than twelve times increased risk, were patients of 65 years or older, who had a cortical syndrome, a Rankin score $\geq 3$, a potential cardiac source of embolism, and a history of COPD treated with theophylline. However, the number of patients with COPD and theophylline was small, restricting the number of patients in the high risk group to only seven. Therefore, we decided to confine the high risk group to the patients of 65 years or older, who had a curtical syndrome. a Rankin score $\geq 3$, and a potential cardiac source of embolism. These 144 patients had an eight times increased risk. Prophylactic treatment with AED's shortly after stroke-onset could be considered in such high risk patients. However. it is highly questionable whether this treatment can be started soon enough after stroke onset to prevent very early seizures, which occur within 48 hours after stroke-onset and comprise more than half of all the early-onset seizures. Besides, as described in the previous chapter, the prognosis of early- 
onset seizures in relatively old patients, who survived at least two weeks after their first seizure, was good. Seizures in such patients were non-recurrent, and, when treatment was indicated, rather easy to treat with AED's. Therefore, it is questionable whether prophylactic treatment is indicated in these patients.

\section{Late-onset seizures}

Eight per cent of the fourteen-day survivors developed one or more late-onset seizures. This frequency is somewhat higher than that found in other studies on brain infarct patients: three per cent in 1000 patients with "non-embolic cerebral infarction". 113 eight per cent in 77 patients with "brain infarcts", 137 and three per cent in 183 patients with "ischaemic stroke". 104 Differences in duration of follow-up probably account for these discrepancies.

Univariate analysis showed several possible risk factors related to the development of late-onset seizures. However. Cox regression analysis showed that, adjusted for interactions between the different possible risk factors, only the presence of a cortical syndrome, and a Rankin score $\geq 3$ remained significantly associated with the occurrence of late-onset seizures. These findings indicate that large, disabling territorial infarcts, are significantly related to late-onset seizures, irrespective of stroke cause and patient's age.

Therefore. the high risk group for developing late-onset seizures, with a more than eight times increased risk, were patients who had a cortical syndrome and a Rankin score $\geq 3$. As we found in chapter 3 that late-onset seizures in relatively young patients were recurrent and difficult to treat with the current AED's. prevention of these late-onset seizures following a brain infarct would be of significant clinical importance. However, it would remain difficult to determine when this prophylactic treatment with AED's should be started, as late seizures occurred somewhere between 18 and 1848 days after stroke-onset. Besides, more than half of the patients with a first-ever supratentorial brain infarct belong to the high risk group, and consequently are all candidates for prophylactic AED treatment. This means that 381 patients should be treated prophylactically with AED's and be exposed to possible side-effects, to prevent the occurrence of a first late-onset seizure in 50 of them $(13 \%)$. It scems unjustified to treat this rather large number of patients to prevent a first seizure in only ten per cent of them. Therefore, in the next chapters we will try to further specify the high risk group.

Our finding that a cortical syndrome and a Rankin score $\geq 3$ are related to the occurrence of post-stroke seizures (both early-and late-onset) concurs with the view of others that large infarct size and cortical location of the lesion are related to post-stroke seizures. $17.20,22,29,45,53,55,80,92,100,104,107,118,137,146,152,174$ Despite the hypotheses on hypertension and hyperglycaemia leading to epileptic seizures, ${ }^{38}$. 130.170 and the suggestion of some investigators that these factors could affect the 
occurrence of stroke-related seizures, 47,107 we did not find cardiovascular risk factors to be related to PSS in general. However, this may be due to the fact that we studied brain infarct patients, whereas others studied different stroke subtypes as a single category. $45,69,125$

In patients with early-onset seizures, besides cortical syndrome and a Rankin score $\geq 3$, we found that age of 65 years or older, the presence of a potential cardiac source of embolism, and a history of COPD treated with theophylline, were all significantly related to the occurrence of PSS. Age has not been mentioned in the literature as a risk factor so far. Theophylline is a methylxanthine known to be able to cause seizures when serum levels are above $35 \mathrm{mg} / \mathrm{l}$ (therapeutic range being 10-20 $\mathrm{mg} / \mathrm{l}$ ).65.169.178 As COPD without theophylline use was not related to the occurrence of PSS, we concluded that the drug theophylline triggered the seizures, not the COPD. In chapter 6 the influence of other drugs is studied. Cardioembolic stroke cause was considered as a possible risk factor by several authors already. ${ }^{90,107.118 .124,127,146}$ Cardiac emboli may resolve or disintegrate and so-called reperfusion damage may follow causing seizures. Such mechanism may only occur shortly after stroke onset, and does not necessarily initiate late seizures as well.

\section{Chapter conclusions}

- These results in combination with the findings from the previous chapter justify the distinction between early-and late-onset seizur's, and confirm that early- and late-onset seizures represent two different types of epilepsy, with different pathogenesis, different prognosis, and different risk lactors

- Early seizures may be merely secondary to a variety of disarrangements of non-cerebral factors in the early phase following stroke, such as electrolyte imbalance, acid-base disturbance, and decreased oxygenation by pneumonia. older patients being more sensitive for such disarrangements than young patients. The presence of a cardiac source of embolism increases the risk, as cardiac emboli may disintegrate, and reperfusion damage may cause seizures. Such mechanism probably occurs only shortly after stroke onset, and therefore does not play a role in the development of late-onset seizures. Early-onsel seizures tend to resolve spontaneously as the patient's condition improves

- Late-onset seizures may be regarded as "real" post-stroke epilepsy. caused by epileptic disturbances in cerchral "scar" tissue remaining from large territorial infarcts. leading to recurrent seizures that are difficult to treat. Scisures may be due to membrane instability of the injured brain cells. disturbancis in the GABA-elgic inhibitory system. or in the action of receptors involved in excitatory brain activity, all disturbing the delicate 
balance between excitatory and inhibitory neural mechanisms in favour of excitation in such "scarred" brain foci

- The risk of developing early-onset seizures is eight times higher in patients of 65 years or older. who have a cortical syndrome, a Rankin score $\geq 3$, and a potential cardiac source of embolism

- The risk of late-onset seizures is more than eight times higher in patients who have a cortical syndrome and a Rankin score $\geq 3$, irrespective of stroke cause and patient's age 



\section{CHAPTER 5}

Brain infarct lesion location and the risk of seizures
Can specific epileptogenic cortical gyri be identified?

Adapted from:

Heuts-van Raak EPM, Lodder J. Kessels F.

Late seizures following a first symptomatic brain infarct are related to large infarcts involving the posterior area around the lateral sulcus.

Seizure; accepted for publication. 
The frequency of so-called post-stroke epilepsy varies between studies from zero to more than $50 \% .17,19,20,29,36,37,45-47,54,55,58,69,83,88.90,100,102,104,113.118,124,127,136.137 .140-142$, 146,154-156,166, 168, 174, 188, 193 This large variation reflects differences in patient populations studied, study methods, and in the definition of what post-stroke epilepsy signifies. Many studies were retrospective, performed prior to the CTscan era, or based on small numbers. Also, a distinction between early and late seizures following a stroke was not uniformly made. Such distinction is relevant as early seizures may be related to non-cerebral disarrangements, such as electrolyte imbalance, acid-base disturbances, etc, whereas late seizures may be regarded as "real" post-stroke epilepsy. ${ }^{+5,107}$ Furthermore, it remains unclear what factors influence the occurrence of post-infarct seizures, although large infarct

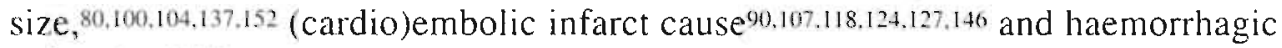
infarction ${ }^{45.107}$ may increase the risk. It is generally agreed that cortical involvement is an important risk factor, 17,20.22,29,45.53.55,80.92.100.104,107.118,137,146,152, 174.193 but as in posttraumatic epilepsy, some parts of the brain, like the hippocampus and the sensorimotor cortex, may be more susceptible to seizure development than others ${ }^{33.56,129.196 .197}$ Therefore, involvement of some specific cortical areas may also be an important factor in the development of epilepsy following a brain infarct. Studies on post-stroke seizures so far mentioned rather large possible epileptogenic brain areas: the frontal lobe: 80.125 the frontal or parietal lobe:53.176 the parietal lobe; 174 and the parietal or temporal lobe. ${ }^{54.55 .92}$ Taken together these studies reflect that the entire cerebral cortex, with the exception of the occipital lobe, could potentially cause seizures when damaged by a stroke, whereas studies on posttraumatic epilepsy showed that more discrete areas were involved, such as the area around the central sulcus. 3.56 .129 .196 .197 In a retrospective, autopsy study on patients with cerebral vascular damage, Richardson and Dodge ${ }^{1+6}$ already in 1954 concluded that in stroke-patients with seizures the diseased areas were in the region of the lateral (Sylvian) and central (Rolandic) fissures, thus in or near the sensorimotor cortex. In an earlier retrospective study on patients with epilepsy, registered in the Maastricht Epilepsy Case Register, who sustained prior stroke. we found the middle temporal. superior temporal, precentral, and supramarginal gyrus frequently involved, but no stroke patients without post-stroke epilepsy were available for comparison (chapter 2 of this thesis). ${ }^{87}$ Therefore, we could not exclude the possibility that these four middle cerebral artery (MCA) territory gyri merely reflected a more frequent involvement of this region in brain infarcts in general. Therefore, in the following prospective study, we compared cortical infarct areas on $C T$ between brain infarct patients who developed post-stroke seizures and those who did not, using a detailed topographical atlas. ${ }^{27}$

\section{Patients and methods}

Patients were registered between I July 1987 and I July 1992 in an ongoing 
prospective register at the University Hospital Maastricht, that includes all adult patients admitted to the Neurological Department or seen at the outpatients' clinic, with a first-ever symptomatic supratentorial brain infarct with symptoms lasting longer than 24 hours. In- and exclusion criteria, data which were recorded, investigations that were performed, definitions used (e.g. definition of brain infarction, symptomatic versus silent infarct, and of post-stroke epilepsy), method of assigning the patients to either one of four infarct groups (infarcts with a rare cause. lacunar infarcts, cardioembolic territorial infarcts or remaining territorial infarcts), methods of follow-up, and data recorded during follow-up, are described in detail in chapter 3.

Cerebral CT scans were indepundently reviewed by two neurologists without knowledge of the clinical data. except that the patient was in the register. CT delay, number and type of abnormalities, and affected hemisphere were noted. In those patients with a symptomatic infarct on CT, infarct type (lacunar, striatocapsular or territorial), size. location, and whether it was haemorrhagic were determined. The presince of leukoaraiosis was noted. In case of disagreement on the presence of an infarct or leukoaraiosis CT was regarded as negative for this particular item. Definitions of lacunar infaret, striatocapsular infarct and territorial infarct are described already in chapter 3 . With regard to infarct-size we distinguished beween large territorial infarcts that involved the entire area supplied by the anterior or posterior cerebral artery (ACA or PCA), or the complete or larger part of the middle cerebral artery (MCA), and territorial infarcts that were smaller, involving only a medium size branch or a small branch area. In addition the affected gyri of all cortical lesions (both the symptomatic and silent infarcts) were identified according to Bories' method ${ }^{27}$ allowing a detailed topographical description of cortically affected areas in different gyri. Three groups of gyri were distinguished that largely comply with the areas compatible with anterior, posterior and middle cerebral artery supply arcas. Although silent infarcts could be reliably differentiated from the syunptomalic one in most patients. either because of topographical incongruity with the clinical signs and symptoms, radiological characteristics, or both, the affected gyri of the silent infarcts were included, because excluding these silent stroke lesions would have left us unable to detect any bias towards an association between such lesions and the occurrence of seizures. Leukoaraiosis was defined as focal or diffuse hypodensities in the periventricular or deep white matter, not involving the cortex and not compatible with territorial infarction. ${ }^{95.171}$ Different sites of leukoaraiosis (around the frontal or occipital horn. the centrum semi-ovale, or combinations of these) were noted. but here only the presence of leukoaraiosis regardless its extension was used in the analyses.

\section{Patient selection}

During the five-year intake period 816 patients were registered. Thirteen patients suffered epileptic seizures before their first stroke, two were lost to follow-up 
very shortly after their stroke, and thirty-one had a variety of "rare" stroke causes, such as vasculitis, arterial dissection or haematologic disorders. These 46 patients were excluded, leaving 770 patients for our study on post-stroke seizures, 737 of whom had CT $(96 \%)$. Median delay between stroke and CT was 5 (range 0-882) days. In 206 patients (28\%), 110 of whom had a cortical syndrome, CT showed no infarct. In 163 patients (22\%) CT showed a symptomatic lacunar infarct, in 40 $(5 \%)$ a symptomatic striatocapsular infarct, and in $328(45 \%)$ a symptomatic territorial infarct involving the cortex. Those 328 patients were eligible for this part of the study, however, six of them (all without seizures) were subsequently excluded: three scans were missing, and three scans only showed spaceoccupying effect by infarct oedema as an indirect sign of infarction, leaving 322 patients who constituted our final study population. Patients with a symptomatic territorial infarct on ("I, and a presumed cardioembolic stroke cause were considered separately, versus the remaining infarcts group.

\section{Statistical methods}

After simply counting and comparing the number of patients with seizures in different risk factor subgroups, differences between groups were analysed accounting for differences in exposure time, using Incidence Rate Ratio's (IRR) with $95 \%$ confidence intervals $(\mathrm{CI})$ and two-tailed p-values. ${ }^{151}$ In addition the influence of exact cortical location on the occurrence of post-stroke scizures (dependent outcome variable), was statistically adjusted for differences in the distribution of the other possible risk factors (explanatory independent variables or covariates) by means of a Cox regression analysis (proportional hazards model), resulting in hazard ratio's (HR) with $95 \% \mathrm{Cl}^{\prime} \mathrm{s}$ and two-tailed p-values. ${ }^{42.119 .134}$ As large infarct size. (cardio)embolic infarction, haemorrhagic infarction, and cortical location of the lesion are all mentioned in the literature as possible risk factors for the development of epileptic seizures following a cerebral infarct, $8.17,45,53-55,80,9092,100,101.104 .107,118,124.125,127,137,140,146,152,174,176$ these characteristics were all included in the Cox regression models as covariates, along with the general variables age and sex.

As early-onset seizures and late-onset seizures may reflect two different underlying epileptic mechanisms with different risk factors (results chapter 4), $43,45,46,53,61,80,92,107.113,152,176$ early- and late-onset seizures were analysed separately. As early-onset seizures occurred by definition within two weeks following stroke-onset, in the analyses on early-onset seizures for every patient the maximal exposure time was set at 14 days.

\section{Results}

Fifty-four of the 322 patients (17\%) experienced one or more epileptic seizures during follow-up. after a median of 199 (range 0-1848) days between first 
symptomatic brain infarct and first epileptic seizure. Median follow-up was longer in patients with seizures, 702 (range 8-1897) days versus 492 (range 1-1998) days in those without seizures, biasing the occurrence of seizures towards longer follow-up, because patients with a shorter exposure time are less likely to develop seizures. The percentage of patients who died during follow-up was similar in both groups: $43 \%$ (95\% CI: 29-56) of patients with seizures and $44 \%$ (95\% CI: $38-50$ ) of those without seizures died. However, patients without seizures who died, died earlier after their stroke: median survival time was 81 (range 1-1781) days versus 368 (range 8-1897) days in those with seizures. explaining the difference in median follow-up. By using IRR's and Cox regression analyses this difference was accounted for. Median age at the time of the symptomatic brain infarct was 74 years (range 40-88) for the patients with seizures and 72 years (range 32-96) for the patients without seizures. Further possible risk factors and corresponding IRR's for the patients with, and those without seizures are shown in table 5.1 and figure 5.1. Patients with seizures were significantly older, had significantly more often a large infarct, and their infarcts were significantly more often haemorrhagic. Table 5.2 shows the affected cortical gyri for both groups. Almost all MCA gyri were significantly more often affected in patients with seizures, whereas no differences in affected PCA and ACA gyri were found.

Table 5.1: Any seizures. Frequency of possible risk factors in patients with and those without seizures following a first cerebral infarct, and the relative risk (IRR) for developing these seizures when the risk factor is present (compared with factor absent)

\begin{tabular}{|c|c|c|c|c|c|c|c|}
\hline & \multicolumn{2}{|c|}{$\begin{array}{l}\text { With seiz } \\
N=54\end{array}$} & \multicolumn{2}{|c|}{$\begin{array}{l}\text { Without seiz } \\
\qquad N=268\end{array}$} & \multirow[b]{2}{*}{ IRR } & \multirow[b]{2}{*}{$95 \% \mathrm{Cl}$} & \multirow[b]{2}{*}{ p-value } \\
\hline & $\bar{N}$ & $(\%)$ & $\overline{\mathrm{N}}$ & $(\%)$ & & & \\
\hline Age < 65; young & 12 & (22) & 72 & (27) & & & \\
\hline Age $65-75 ;$ middle & 16 & $(30)$ & 84 & (31) & & & \\
\hline Age $\geq 75 ;$ old & 26 & (48) & 112 & (42) & & & \\
\hline old versus young & & & & & 2.64 & $1.33-5.22$ & 0.005 \\
\hline old versus middle & & & & & 2.18 & $1.17-4.07$ & 0.014 \\
\hline middle versus young & & & & & 1.21 & $0.57-2.55$ & \\
\hline Male sex & 26 & $(48)$ & 140 & (52) & 0.67 & $0.39-1.15$ & \\
\hline Cardioembolic infarct & 21 & (39) & 88 & (33) & 1.60 & $0.92-2.76$ & \\
\hline Large cortical infarct & 27 & $(50)$ & 85 & (32) & 4.31 & $2.53-7.34$ & 0.000 \\
\hline Haemorrhagic infarct & 8 & (15) & 23 & (9) & 2.45 & $1.16-5.19$ & 0.019 \\
\hline Silent cortical lesion & 1 & (2) & 27 & $(10)$ & 0.18 & $0.02-1.27$ & \\
\hline Leukoaraiosis & 9 & (17) & 55 & $(21)$ & 0.98 & $0.48-2.00$ & \\
\hline Lesion in ACM territory & 47 & (87) & 231 & $(86)$ & 1.31 & $0.59-2.90$ & \\
\hline Lesion in ACP territory & 8 & (15) & 47 & $(18)$ & 0.86 & $0.41-1.82$ & \\
\hline Lesion in ACA territory & 2 & (4) & 28 & (10) & 0.35 & $0.08-1.43$ & \\
\hline
\end{tabular}

Some patients had infarcts in more than one vascular territory, therefore the total number of lesions in ACM, ACP, and ACA territory exceeds $100 \%$ 
Table 5.2: Any seizures

Affected cortical gyri in patients with and those without seizures following a first cerebral infarct, and the relative risk (IRR) for developing these seizures when the gyrus is affected (compared with gyrus not affected)

\begin{tabular}{|c|c|c|c|c|c|c|c|}
\hline \multirow[b]{2}{*}{ Affected gyrus } & \multicolumn{2}{|c|}{$\begin{array}{l}\text { With seiz } \\
N=54\end{array}$} & \multicolumn{2}{|c|}{$\begin{array}{l}\text { Without seiz } \\
\qquad \mathrm{N}=268\end{array}$} & \multirow[b]{2}{*}{ IRR } & \multirow[b]{2}{*}{$95 \% \mathrm{Cl}$} & \multirow[b]{2}{*}{$p$-value } \\
\hline & $N$ & $(\%)$ & $N$ & $(\%)$ & & & \\
\hline \multicolumn{8}{|l|}{ ACM territory } \\
\hline Orbital & 4 & (7) & 31 & $(12)$ & 2.97 & $1.07-8.21$ & 0.036 \\
\hline Superior temporal & 27 & $(50)$ & 85 & $(32)$ & 3.17 & $1.86-5.41$ & 0.000 \\
\hline Middle temporal & 29 & (54) & 89 & (33) & 3.01 & $1.76-5.13$ & 0.000 \\
\hline Inferior temporal & 9 & (17) & 40 & (15) & 2.83 & $1.38-5.79$ & 0.004 \\
\hline Middle frontal & 10 & (19) & 49 & (18) & 1.77 & $0.89-3.51$ & \\
\hline Inferior frontal & 17 & (31) & 70 & $(26)$ & 2.36 & $1.33-4.19$ & 0.003 \\
\hline Precentral & 28 & (52) & 117 & $(44)$ & 2.01 & $1.18-3.43$ & 0.010 \\
\hline Post-central & 31 & (57) & 116 & (43) & 2.42 & $1.41-4.16$ & 0.001 \\
\hline Supramarginal & 36 & (67) & 126 & (47) & 3.01 & $1.71-5.30$ & 0.000 \\
\hline Occipital lobe & 7 & (13) & 43 & $(36)$ & 2.46 & $1.11-5.44$ & 0.026 \\
\hline Angular & 18 & (33) & 74 & (28) & 2.30 & $1.31-4.06$ & 0.004 \\
\hline Superior parietal lobule & 4 & (7) & 35 & (13) & 1.78 & $0.64-4.92$ & \\
\hline Insular cortex & 6 & (11) & 46 & (17) & 1.51 & $0.65-3.53$ & \\
\hline \multicolumn{8}{|l|}{ ACP territory } \\
\hline Parahippocampal & 3 & (6) & 14 & (5) & 1.65 & $0.51-5.28$ & \\
\hline Fusiform & 4 & (7) & 17 & (6) & 1.86 & $0.67-5.14$ & \\
\hline Uncus & 0 & & 9 & (3) & & & \\
\hline Occipital lobe & 5 & (9) & 25 & (9) & 1.07 & $0.43-2.68$ & \\
\hline Cingulate & 2 & (4) & 9 & (3) & 1.11 & $0.27-4.53$ & \\
\hline Lingual & 3 & (6) & 22 & (8) & 0.81 & $0.25-2.60$ & \\
\hline Cuneus & 3 & (6) & 12 & (4) & 1.69 & $0.53-5.40$ & \\
\hline Precuneus & 0 & & 8 & (3) & & & \\
\hline \multicolumn{8}{|l|}{ ACA territory } \\
\hline Superior frontal & 0 & & 14 & (5) & & & \\
\hline Rectal & 0 & & 6 & (2) & & & \\
\hline Cingulate & 0 & & 10 & (4) & & & \\
\hline Precuneus & 0 & & 13 & (5) & & & \\
\hline Paracentral lobule & 2 & (4) & 9 & (3) & 1.27 & $0.31-5.20$ & \\
\hline
\end{tabular}


Figure 5.1: Possible risk factors for seizures following a first cerebral infarct

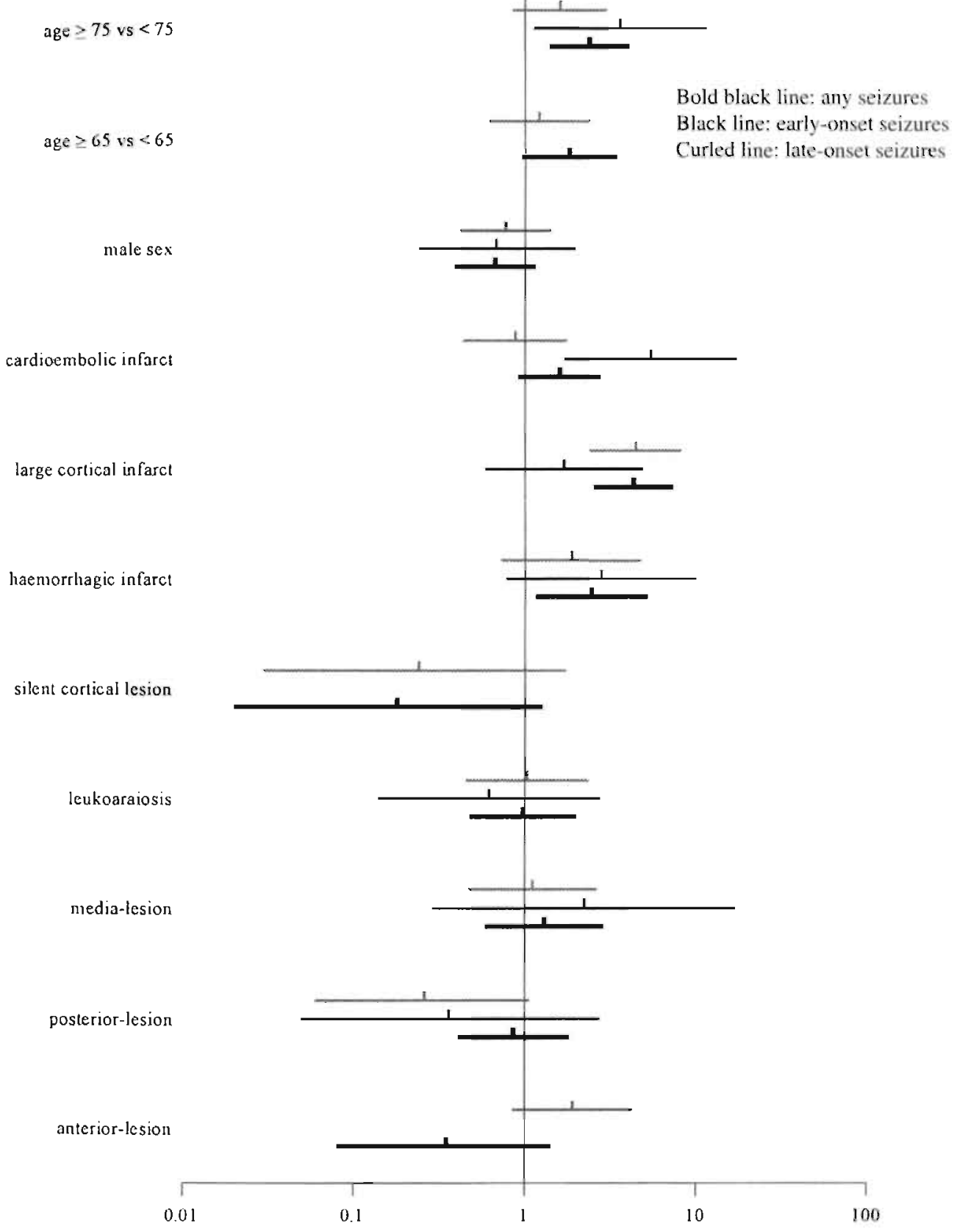

Diagram of Incidence Risk Ratio's (IRR's) with 95\% confidence intervals (Cl's) on a logarithmic scale; IRR > 1 means an increased risk of seizures when the risk factor is present (compared with factor absent); $95 \% \mathrm{Cl}$ not including the value 1 means that the difference in risk is statistically significant with $p<0.05$ 


\section{Table 5.3: Early-onset seizures}

Frequency of possible risk factors and affected cortical gyri in patients with and those without early-onset seizures following a first cerebral infarct, and the relative risk (IRR) for developing these early-onset seizures when the risk factor is present or the gyrus is affected (compared with factor not present or gyrus not affected)

\begin{tabular}{|c|c|c|c|c|c|c|c|}
\hline & \multicolumn{2}{|c|}{$\begin{array}{l}\text { With seiz } \\
\mathrm{N}=14 \\
\end{array}$} & \multicolumn{2}{|c|}{$\begin{array}{l}\text { Without seiz } \\
\qquad \mathrm{N}=308 \\
\end{array}$} & \multirow[b]{2}{*}{ IRR } & \multirow[b]{2}{*}{$95 \% \mathrm{Cl}$} & \multirow[b]{2}{*}{$p$-value } \\
\hline & $\mathrm{N}$ & $(\%)$ & $\mathrm{N}$ & $(\%)$ & & & \\
\hline Age $<65$ & 0 & & 84 & (27) & & & \\
\hline Age $65-75$ & 4 & (29) & 96 & $(31)$ & & & \\
\hline Age $\geq 75$ & 10 & (71) & 128 & (42) & & & \\
\hline Age $\geq 75$ vs age $65-75$ & & & & & 1.97 & $0.62-6.27$ & \\
\hline Age $\geq 75$ vs age $<75$ & & & & & 3.59 & $1.13-11.44$ & 0.031 \\
\hline Male sex & 6 & (43) & 160 & (52) & 0.68 & $0.24-1.96$ & \\
\hline Cardioembolic infarct & 10 & (71) & 99 & (32) & 5.45 & $1.71-17.39$ & 0.004 \\
\hline Large cortical infarct & 6 & (43) & 106 & (34) & 1.69 & $0.59-4.88$ & \\
\hline Haemorrhagic infarct & 3 & (21) & 28 & (9) & 2.79 & $0.78-10.00$ & \\
\hline Silent cortical lesion & 0 & & 28 & (9) & & & \\
\hline Leukoaraiosis & 2 & (14) & 62 & $(20)$ & 0.62 & $0.14-2.77$ & \\
\hline Lesion in ACM territory & 13 & (93) & 265 & (86) & 2.23 & $0.29-17.07$ & \\
\hline Lesion in ACP territory & 1 & (7) & 54 & (18) & 0.36 & $0.05-2.75$ & \\
\hline Lesion in ACA territory & 0 & & 30 & $(10)$ & & & \\
\hline \multicolumn{8}{|l|}{ ACM territory } \\
\hline Orbital & 1 & (7) & 34 & $(11)$ & 0.99 & $0.13-7.63$ & \\
\hline Superior temporal & 7 & $(50)$ & 105 & (34) & 2.21 & $0.78-6.31$ & \\
\hline Middle temporal & 10 & $(71)$ & 108 & (35) & 5.22 & $1.64-16.64$ & 0.005 \\
\hline Inferior temporal & 5 & $(36)$ & 44 & $(14)$ & 4.65 & $1.56-13.86$ & 0.006 \\
\hline Middle frontal & 2 & $(14)$ & 57 & (19) & 0.99 & $0.22-4.45$ & \\
\hline Inferior frontal & 5 & (36) & 82 & (27) & 1.88 & $0.63-5.61$ & \\
\hline Precentral & 8 & (57) & 137 & $(44)$ & 1.85 & $0.64-5.32$ & \\
\hline Post-central & 10 & (71) & 137 & $(44)$ & 3.45 & $1.08-11.00$ & 0.036 \\
\hline Supramarginal & 10 & (71) & 152 & (49) & 2.87 & $0.90-9.16$ & \\
\hline Occipital lobe & 4 & (29) & 46 & (15) & 2.34 & $0.73-7.45$ & \\
\hline Angular & 7 & $(50)$ & 85 & (28) & 3.05 & $1.07-8.69$ & 0.037 \\
\hline Superior parietal lobule & 1 & (7) & 38 & (12) & 0.83 & $0.11-6.31$ & \\
\hline Insular cortex & 3 & (21) & 49 & $(76)$ & 1.94 & $0.54-6.94$ & \\
\hline \multicolumn{8}{|c|}{ ACP territory (only the affected gyri) } \\
\hline Occipital lobe & 1 & (7) & 29 & (9) & 0.77 & $0.10-5.88$ & \\
\hline Cingulate & 1 & (7) & 10 & (3) & 2.84 & $0.37-21.72$ & \\
\hline Cuneus & 1 & (7) & 14 & (5) & 1.85 & $0.24-14.11$ & \\
\hline
\end{tabular}




\section{Early-onset seizures}

Fourteen of the 322 patients at risk (4\%) experienced their first seizure within two weeks following stroke-onset, after a median of 1.5 (range 0-14) days. Median follow-up was 224 (range 8-1614) days for the patients with early seizures, and 514 (range 1-1998) days for those without early seizures. More patients with than without early seizures died during follow-up: $71 \%$ (95\% CI: $47-95 \%$ ) of the patients with early seizures died after a median of 35 days, and $43 \%$ (95\% CI: $37-49 \%)$ of those without early seizures died after a median of 95 days. Median age at the time of the symptomatic brain infarct was 78 years (range 65-88) for the patients with early seizures and 72 years (range 32-96) for the patients without early seizures, probably the explanation for the difference in death-rate. Table 5.3 shows the frequency of possible risk factors and affected cortical gyri in patients with and those without early-onset seizures. In figures 5.1 and 5.2 corresponding IRR's with $95 \%$ CI's are displayed graphically. Patients with early seizures were significantly older, and had significantly more often a cardioembolic stroke cause. whereas the middle temporal, inferior temporal, post-central and angular gyrus were significantly more often affected. As none of the patients younger than 65 years experienced an early seizure, the age-limit at 65 years could not be used in the Cox regression analysis. In order not to exclude patients below 65 years, only the age-limit at 75 years was used, and patients younger than 75 years were analysed as one group.

Complete results of the different Cox regression analyses are shown in table 5.4. Cox regression analysis showed that adjusted for age. sex. haemorrhagic infarction, and infarct size (asymptomatic lesions did not occur among the patients with early seizures), only cardioembolic stroke cause was significantly associated with the occurrence of early seizures $(\mathrm{HR}=4.07)$. When. instead of stroke cause. infarct location was added to the model, only the middle temporal gyrus was significintly associated with the occurrence of early seizures $(\mathrm{HR}=4.06$ ). When both stroke cause and infarct location were included in the regression model, beside cardioembolic stroke cause, two gyri were significantly associated with the occurrence of early seizures: the middle temporal gyrus $(\mathrm{HR}=3.38)$ and the post-central gyrus $(H R=3.95)$. When both gyri were included at the same time in one model, they both remained significantly associated (table 5.4).

Consequently, patients at risk for developing early-onset seizures were the patients of 65 years or older with a cardioembolic brain infarct, involving at least the middle temporal ór post-central gyrus. These 69 high risk patients $(21 \%$ of all patients at risk), of whom nine experienced early-onset seizures ( $64 \%$ of all early-onset seizures; three patients died early, six had non-recurrent seizures), had a risk of early-onset seizures of $13 \%$ (95\% CI: 5-21), whereas the remaining 253 patients, of whom five experienced early-onset seizures, had a risk of earlyonset seizures of $2 \%$ (95\% CI: $0-4)$. The IRR for this high risk group is 7.7 I $(95 \% \mathrm{Cl}: 2.58-23.00 ; \mathrm{p}=0.000)$. 
Figure 5.2: Affected cortical gyri and the risk of seizures following a first cerebral infarct

orbital

superior tempora]

middle temporal

inferior temporal

middle frontal

inferior frontal

precentral

post-centra!

supramargingl

occipital lobe

angular

sup.parictal lobulc

insular cortex

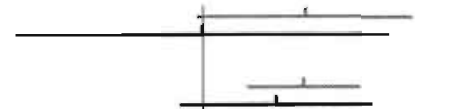

Black line: early-onset seizures

Curled line: late-onset seizures

parahippocampal

fusiforni

occipital lobe

cingulate

lingual

cuncus

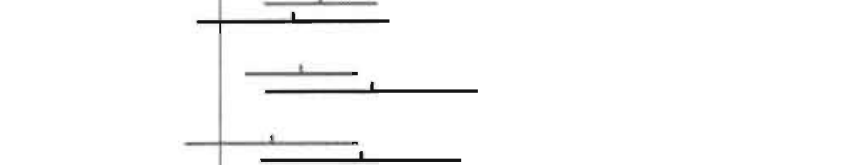

paracentral lobule

$0.0 \mathrm{I}$

0.1
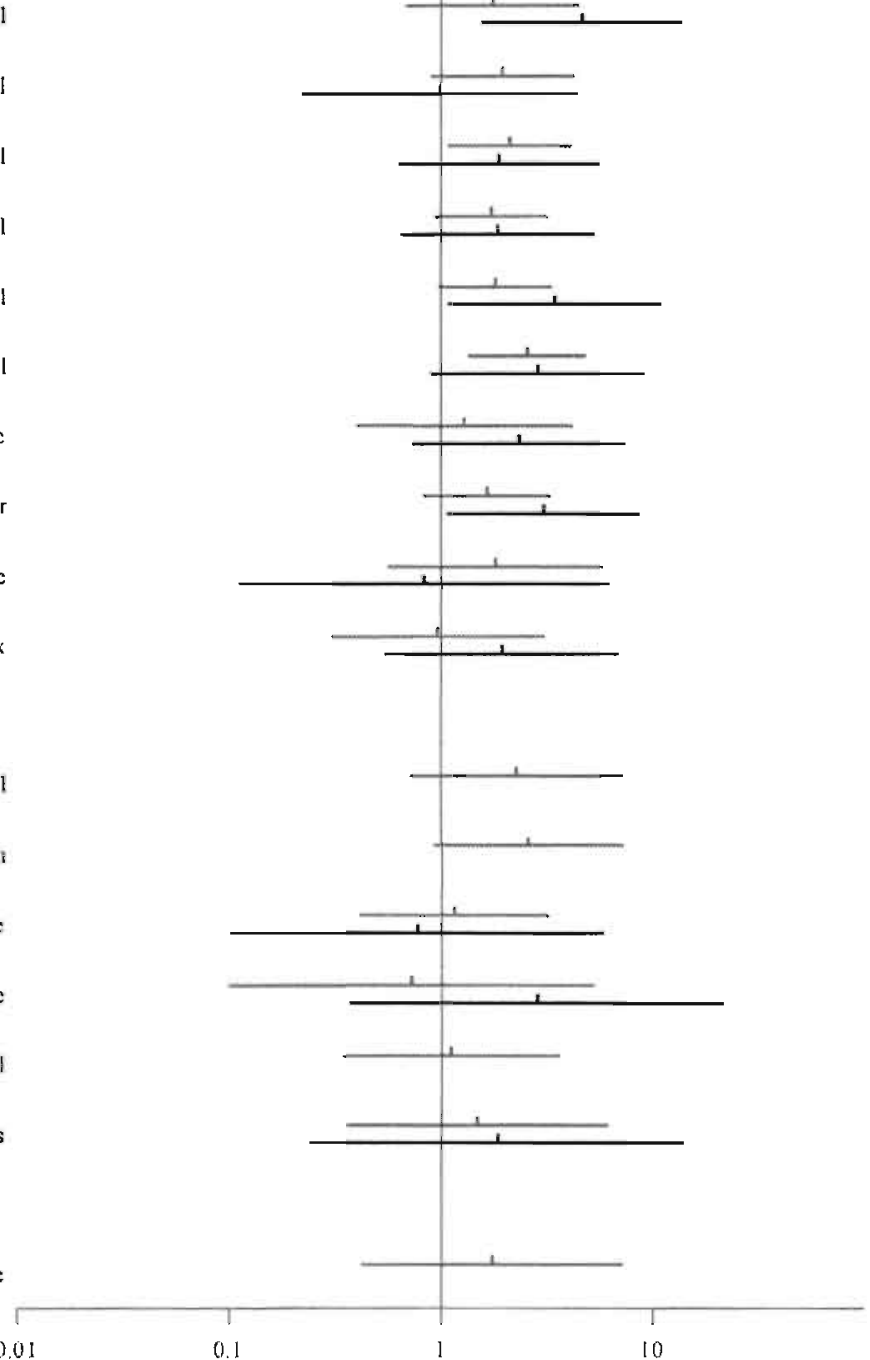

Diagram of incidence Risk Ratio's (IRR's) with $95 \%$ confidence intervals (Cl's) on a logarithmic scale: IRR > 1 means an increased risk of seizures when the gyrus is affected (compared with gyrus not affected); $95 \% \mathrm{Cl}$ not including the value 1 means that the difference in risk is statistically significant with $p<0.05$ 
Table 5.4: Cox regression analysis, risk of early-onset seizures

Various models as described in this chapter, with different variables affecting the risk of early-onset seizures, including affected cortical gyrus

\begin{tabular}{|c|c|c|c|c|c|c|c|c|c|}
\hline & HR & $95 \% \mathrm{Cl}$ & $p$-value & $H R$ & $95 \% \mathrm{Cl}$ & p-value & $H R$ & $95 \% \mathrm{Cl}$ & $p$-value \\
\hline Age $\geq 75$ vs age $<75$ & 2.54 & $0.75-8.62$ & & 3.37 & $1.02-11.13$ & 0.047 & 2.99 & $0.89 \cdot 10.05$ & \\
\hline Male sex & 1.08 & $0.36-3.25$ & & 0.91 & $0.30 \cdot 2.74$ & & 1.01 & $0.33-3.07$ & \\
\hline Haemorrhagic infarct & 2.48 & $0.64-9.63$ & & 2.49 & $0.61-10.17$ & & 2.16 & $0.54-8.60$ & \\
\hline Large infarct & 0.98 & $0.32-3.06$ & & 1.15 & $0.36-3.69$ & & 0.85 & $0.26-2.75$ & \\
\hline Cardioembolic cause & 4.07 & $1.22 \cdot 13.52$ & 0.022 & & & & & & \\
\hline Middle temporal gyrus & & & & & & & 4.06 & $1.22-13.53$ & 0.023 \\
\hline \multicolumn{10}{|l|}{ Inferior temporal gyrus } \\
\hline \multicolumn{10}{|l|}{ Post-central gyrus } \\
\hline Angular gyrus & & & & & & & & & \\
\hline
\end{tabular}

\begin{tabular}{|c|c|c|c|c|c|c|c|c|c|}
\hline & HR & $95 \% \mathrm{Cl}$ & $p \cdot v a l u e$ & $H R$ & $95 \% \mathrm{Cl}$ & p-value & $H R$ & $95 \% \mathrm{Cl}$ & p-value \\
\hline Age $\geq 75$ vs age $<75$ & 3.36 & $0.99-11.42$ & & 3.71 & $1.12 \cdot 12.30$ & 0.032 & 3.08 & $0.92 \cdot 10.28$ & \\
\hline Male sex & 0.96 & $0.31-2.93$ & & 1.01 & $0.34-3.03$ & & 0.92 & $0.31-2.76$ & \\
\hline Haemorrhagic infarct & 1.93 & $0.46 \cdot 8.01$ & & 2.39 & $0.56-10.27$ & & 2.30 & $0.58-9.17$ & \\
\hline Large infarct & 0.64 & $0.16-2.58$ & & 0.58 & $0.15-2.21$ & & 0.94 & $0.29-3.08$ & \\
\hline \multicolumn{10}{|l|}{ Cardioembolic cause } \\
\hline \multicolumn{10}{|l|}{ Middle temporal gyrus } \\
\hline Inferior temporal gyrus & 4.02 & $0.96 \cdot 16.87$ & & & & & & & \\
\hline Post-central gyrus & & & & 3.70 & $0.99 \cdot 13.78$ & & & & \\
\hline Angular gyrus & & & & & & & 2.19 & $0.72 \cdot 6.67$ & \\
\hline
\end{tabular}

\begin{tabular}{|c|c|c|c|c|c|c|c|c|c|}
\hline & $H R$ & $95 \% \mathrm{Cl}$ & p-value & $\mathrm{HR}$ & $95 \% \mathrm{Cl}$ & $p$-value & HR & $95 \% \mathrm{Cl}$ & p-value \\
\hline Age $\geq 75$ vs age $<75$ & 2.37 & $0.69-8.09$ & & 2.62 & $0.76-8.99$ & & 2.86 & $0.84 ;-9.68$ & \\
\hline Male sex & 1.13 & $0.37 \cdot 3.42$ & & 1.07 & $0.35-3.26$ & & 1.23 & $0.40-3.71$ & \\
\hline Haemorrhagic infarct & 2.20 & $0.56-8.59$ & & 1.91 & $0.47-7.79$ & & 2.53 & $0.61-10.50$ & \\
\hline Large infarct & 0.78 & $0.25-2.47$ & & 0.54 & $0.13 \cdot 2.25$ & & 0.45 & $0.12-1.74$ & \\
\hline Cardioembolic cause & 3.40 & $1.01-11.39$ & 0.048 & 3.83 & $1.15-12.81$ & 0.029 & 4.21 & $1.26-14.12$ & 0.020 \\
\hline Middle temporal gyrus & 3.38 & $1.07-11.34$ & 0.049 & & & & & & \\
\hline Inferior temporal gyrus & & & & 3.73 & $0.85-16.30$ & & & & \\
\hline Post-central gyrus & & & & & & & 3.95 & $1.04 \cdot 15.07$ & 0.044 \\
\hline Angular gyrus & & & & & & & & & \\
\hline
\end{tabular}




\section{HR $\quad 95 \% \mathrm{Cl} \quad$ p-value $\mathrm{HR} \quad 95 \% \mathrm{Cl} \quad \mathrm{p}$-value $\mathrm{HR} \quad 95 \% \mathrm{Cl} \quad$ p-value}

\begin{tabular}{|c|c|c|c|c|c|c|c|c|c|}
\hline Age $\geq 75$ vs age $<75$ & 2.41 & $0.71-8.16$ & & 2.53 & $0.74-8.68$ & & 3.22 & $0.96-10.83$ & \\
\hline Male sex & 1.07 & $0.36-3.24$ & & 1.39 & $0.45-4.29$ & & 1.18 & $0.39-3.62$ & \\
\hline Haemorrhagic infarct & 2.20 & $0.57-8.57$ & & 2.29 & $0.55 \cdot 9.56$ & & 2.20 & $0.52-9.25$ & \\
\hline Large infarct & 0.79 & $0.24 \cdot 2.58$ & & 0.24 & $0.05-1.08$ & & 0.34 & $0.08-1.40$ & \\
\hline Cardioembolic cause & 3.92 & $1.17-13.10$ & 0.027 & 3.90 & $1.15 \cdot 13.25$ & 0.029 & & & \\
\hline Middle temporal gyrus & & & & 4.37 & $1.21-15.75$ & 0.024 & 4.61 & $1.33 \cdot 16.01$ & 0.016 \\
\hline \multicolumn{10}{|l|}{ Inferior temporal gyrus } \\
\hline Post-central gyrus & & & & 5.61 & $1.32-23.72$ & 0.019 & 4.48 & $1.13-17.75$ & 0.033 \\
\hline Angular gyrus & 2.06 & $0.66-6.48$ & & & & & & & \\
\hline
\end{tabular}

\section{Late-onset seizures}

As late-onset seizures occur by definition after two weeks following strokeonset, thirty-two patients (10\%) who died within these two weeks were not at risk for late-onset seizures and were consequently excluded from the analysis. Of the remaining 290 fourteen-day survivors. 45 patients experienced one or more epileptic seizures later than two weeks following stroke. However. in four of them these were early-onset seizures continuing over the arbitrary limit of two weeks post-stroke. Therefore, we decided to include eventually 41 patients $(14 \%)$ with "real" late-onset seizures. Although in four patients the first seizure occurred after a recurrent stroke. in accord with our study aim the first symptomatic brain infarct was used as the index stroke, and these four patients were analysed not taking into account the occurrence of recurrent stroke.

First late seizure occurred after 274 (median: range 18-1848) days. Median follow-up was longer in patients with seizures. 1005 (range 21-1897) days versus 549 (range 15-1998) days in those without late-onset seizures, biasing the occurrence of seizures towards longer follow-up. The percentage of patients who died during follow-up was similar in both groups: $32 \%(95 \% \mathrm{Cl}: 17-46)$ of patients with late seizures and 39\% (95\% CI: 33-45) of those without late scizures died. However, patients without seizures who died. died much sooner after their stroke than the patients with late-onset seizures (median delay 134 (range 15-1781) days and 484 (range 21-1897) days respectively). largely decreasing the median follow-up of the patients without seizures, and explaining the difference in median follow-up. Median age at the time of the symptomatic brain infarct was 72 years (range 40-86) for the patients with late-onset seizures. and also 72 years (range 32-92) for patients without late-onset seizures. Table 5.5 shows the frequency of possible risk factors and affected cortical gyri in patients with and those without late-onset seizures. Corresponding IRR's with 95\% CI's ale displilyed graphically in ligures 5.1 and 5.2. Pationts with late-onset scizures signilicantly more often had a large infarct, whereas the superior temporal. 
Table 5.5: Late-onset seizures

Frequency of possible risk factors and affected cortical gyri in 290 fourteen-day survivors at risk for developing late-onset seizures following a first cerebral infarct, and the relative risk (IRR) for developing these late-onset seizures when the risk factor is present or the gyrus is affected (compared with factor not present or gyrus not affected)

\begin{tabular}{|c|c|c|c|c|c|c|c|}
\hline & \multicolumn{2}{|c|}{$\begin{array}{l}\text { With seiz } \\
\qquad N=41\end{array}$} & \multicolumn{2}{|c|}{$\begin{array}{l}\text { Without seiz } \\
\qquad N=249\end{array}$} & \multirow[b]{2}{*}{ IRR } & \multirow[b]{2}{*}{$95 \% \mathrm{Cl}$} & \multirow[b]{2}{*}{$p$-value } \\
\hline & $N$ & $(\%)$ & $N$ & $(\%)$ & & & \\
\hline Age $<65$; young & 12 & (29) & 62 & (25) & & & \\
\hline Age $65-75 ;$ middle & 13 & (32) & 84 & (34) & & & \\
\hline Age $\geq 75$; old & 16 & (39) & 103 & (41) & & & \\
\hline young vs middle & & & & & 1.05 & $0.48-2.30$ & \\
\hline young versus old & & & & & 0.64 & $0.30-1.36$ & \\
\hline middle vs old & & & & & 0.61 & $0.29-1.27$ & \\
\hline Male sex & 21 & (51) & 131 & (53) & 0.77 & $0.42-1.41$ & \\
\hline Cardioembolic infarct & 11 & (27) & 79 & $(32)$ & 0.88 & $0.44-1.76$ & \\
\hline Large cortical infarct & 21 & (51) & 62 & (25) & 4.44 & $2.41-8.19$ & 0.000 \\
\hline Haemorrhagic infarct & 5 & (12) & 21 & (8) & 1.87 & $0.73-4.76$ & \\
\hline Silent cortical lesion & 1 & (2) & 24 & $(10)$ & 0.24 & $0.03-1.74$ & \\
\hline Leukoaraiosis & 7 & (17) & 56 & (22) & 1.03 & $0.46-2.33$ & \\
\hline Lesion in ACM territory & 35 & (85) & 211 & (85) & 1.11 & $0.47-2.65$ & \\
\hline Lesion in ACP territory & 2 & (5) & 49 & (20) & 0.26 & $0.06 \quad 1.07$ & \\
\hline Lesion in ACA territory & 7 & $(17)$ & 16 & (6) & 1.91 & $0.85-4.31$ & \\
\hline \multicolumn{8}{|c|}{ Affected gyrus ACM territory } \\
\hline Orbital & 3 & (7) & 12 & (5) & 3.04 & $0.94-9.85$ & \\
\hline Superior temporal & 20 & (49) & 65 & (26) & 2.99 & $1.62 \cdot 5.51$ & 0.000 \\
\hline Middle temporal & 20 & (49) & 72 & (29) & 2.41 & $1.31-4.45$ & 0.005 \\
\hline Inferior temporal & 5 & $(12)$ & 24 & (10) & 1.76 & $0.69-4.49$ & \\
\hline Middle frontal & 8 & $(20)$ & 27 & (11) & 1.94 & $0.90-4.21$ & \\
\hline Inferior frontal & 12 & (29) & 51 & $(20)$ & 2.11 & $1.08-4.14$ & 0.030 \\
\hline Precentral & 20 & (49) & 98 & (39) & 1.74 & $0.94-3.21$ & \\
\hline Post-central & 21 & (51) & 97 & (39) & 1.81 & $0.98 \cdot 3.35$ & \\
\hline Supramarginal & 26 & (63) & 104 & $(42)$ & 2.55 & $1.35-4.82$ & 0.004 \\
\hline Occipital lobe & 3 & (7) & 25 & (10) & 1.29 & $0.40-4.18$ & \\
\hline Angular & 11 & $(27)$ & 58 & (23) & 1.65 & $0.83-3.30$ & \\
\hline Superior parietal lobule & 3 & (7) & 16 & (6) & 1.81 & $0.56-5.87$ & \\
\hline Insular cortex & 3 & (7) & 28 & (11) & 0.96 & $0.30-3.10$ & \\
\hline \multicolumn{8}{|c|}{ Affected gyrus ACP territory } \\
\hline Parahippocampal & 3 & (7) & 11 & (4) & 2.27 & $0.70-7.34$ & \\
\hline Fusiform & 4 & $(10)$ & 14 & (6) & 2.57 & $0.92-7.21$ & \\
\hline Occipital lobe & 4 & (10) & 22 & (9) & 1.15 & $0.41-3.23$ & \\
\hline Cingulate & 1 & (2) & 7 & (3) & 0.72 & $0.10 \cdot 5.25$ & \\
\hline Lingual & 3 & (7) & 19 & (8) & 1.11 & $0.34-3.61$ & \\
\hline Cuneus & 2 & (5) & 10 & (4) & 1.48 & $0.36-6.11$ & \\
\hline \multicolumn{8}{|c|}{ Affected gyrus ACA territory } \\
\hline Paracentral lobule & 2 & $(5)$ & 7 & (3) & 1.73 & $0.42-7.16$ & \\
\hline
\end{tabular}


middle temporal, supramarginal and inferior frontal gyrus were significantly more often affected. Two patients without late-onset seizures (an 85-year old male with a large cardioembolic infarct. a 76-year old female with a small cardioembolic infarct) were excluded from the Cox regression analysis, as they were censored before the earliest event occurred, meaning they died (on day 16 and day 15 post-stroke respectively) before the first late seizure among the patients with late-onset seizures. As these two patients were at risk for developing late-onset seizures for as little as three days, excluding these two patients unlikely affected the final results; consequently Cox regression analysis was performed on 288 patients. The results of the different Cox regression analyses are shown in table 5.6.

Cox regression analysis showed that adjusted for age, sex, haemorrhagic infarction, asymptomatic lesions, and stroke cause, only large infarct size was significantly associated with the occurrence of late-onset seizures $(H R=4.70)$. When infarct location was added to the model instead of infarct size, the superior temporal (ST), middle temporal (MT), supramarginal (SM), middle frontal (MF) and inferior frontal (IF) gyrus were significantly associated with the occurrence of late-onset seizures $(\mathrm{HR}=2.89: \mathrm{HR}=2.30 ; \mathrm{HR}=2.27 ; \mathrm{HR}=2.30$ and $\mathrm{HR}=2.04$. respectively). When both infarct size and location were included in the regression model, none of the gyri remained significantly associated with the occurrence of late-onset seizures; only large infarct size remained significant. Therefore, as the MF and IF gyrus are adjacent areas. the influence of the combination MF and IF both aflected was studied, which showed an IRR of 2.99 (95\% Cl: 1.33-6.75: $\mathrm{p}=0.008)$. Because SM, ST and MT are adjacent areas the combinations SM and ST both affected, ST and MT both affected, and SM. ST and MT all three affected, were studied also, with resultant IRR's of 4.08 (95\% CI: $2.21-7.53 ; p=0.000): 3.23(95 \% \mathrm{CI}: 1.69-6.16 ; \mathrm{p}=0.000)$ and 4.35 (95\% CI: 2.28-8.29; $\mathrm{p}=0.000$ ). respectively. Cox regression analysis with the model witheut infarct size showed that all these combinations of adjacent gyri were significantly associated with the occurrence of late-onset seizures (MF and IF: $\mathrm{HR}=3.37 ; \mathrm{SM}$ and ST: HR $=3.94 ; \mathrm{ST}$ and MT: HR $=2.95 ; \mathrm{SM} . \mathrm{ST}$ and MT: $\mathrm{HR}=3.90$ ). However, when infarct size was also included in the model, only the combination SM and ST both affected remained significantly associated with the occurrence of late-onset seizures, together with large infarct size (HR $=2.26$ and $\mathrm{HR}=2.95$ respectively: table 5.6 ).

Consequently. patients with a first cerebral infarct at risk for developing lateonset seizures were those in whom both the supramarginal and the superior temporal gyrus were affected, irrespective of stroke cause and infarct size. These 71 high risk patients ( $24 \%$ of all patients at risk), of whom 20 experienced lateonset seizures ( $49 \%$ of all late-onset seizures; one patient died early, eight had non-recurrent seizures, eleven had recurrent seizures), had a risk of late-onset seizures of $28 \%$ (95\% CI: 18-38), whereas the remaining 219 patients, of whom 21 experienced late-onset seizures, had a risk of late-onset seizures of $10 \%$ 
Table 5.6: Cox regression analysis, risk of late-onset seizures

Various models as described in this chapter, with different variables affecting the risk of late-onset seizures, including affected cortical gyrus

\begin{tabular}{|c|c|c|c|c|c|c|c|c|c|}
\hline & $H R$ & $95 \% \mathrm{Cl}$ & $p$-value & $H R$ & $95 \% \mathrm{Cl}$ & $p$-value & $H R$ & $95 \% \mathrm{Cl}$ & $p$-value \\
\hline Age young vs middle & 1.36 & $0.60-3.06$ & & 1.09 & $0.49 \cdot 2.43$ & & 1.16 & $0.52-2.60$ & \\
\hline Age old vs middle & 2.02 & $0.94 \cdot 4.35$ & & 1.59 & $0.75-3.37$ & & 1.86 & $0.86-4.00$ & \\
\hline Male sex & 1.14 & $0.58-2.23$ & & 0.90 & $0.47 \cdot 1.70$ & & 0.96 & $0.50-1.83$ & \\
\hline Cardioembolic, cause & 0.87 & $0.42-1.79$ & & 0.88 & $0.43-1.79$ & & 0.73 & $0.35-1.52$ & \\
\hline Silent lesion & 0.27 & $0.04-2.02$ & & 0.22 & $0.03-1.66$ & & 0.27 & $0.04 \cdot 2.00$ & \\
\hline Haemorrhagic infarct & 0.88 & $0.32-2.44$ & & 2.35 & $0.90 \cdot 6.12$ & & 1.45 & $0.53 \cdot 3.95$ & \\
\hline Large infarct & 4.70 & $2.34-9.42$ & 0.000 & & & & & & \\
\hline Superior temporal gyrus & & & & & & & 2.89 & $1.50 \cdot 5.59$ & 0.002 \\
\hline \multicolumn{10}{|l|}{ Middle temporal gyrus } \\
\hline \multicolumn{10}{|l|}{ Supramarginal gyrus } \\
\hline \multicolumn{10}{|l|}{ Middle frontal gyrus } \\
\hline Inferior frontal gyrus & & & & & & & & & \\
\hline
\end{tabular}

\begin{tabular}{|c|c|c|c|c|c|c|c|c|c|}
\hline & $\mathrm{HR}$ & $95 \% \mathrm{Cl}$ & $p$-value & $\mathrm{HR}$ & $95 \% \mathrm{Cl}$ & p-value & $H R$ & $95 \% \mathrm{Cl}$ & p-value. \\
\hline Age young vs middle & 1.13 & $0.51-2.53$ & & 1.10 & $0.49 \cdot 2.45$ & & 1.17 & $0.52 \cdot 2.64$ & \\
\hline Age old vs middle & 1.53 & $0.72 \cdot 3.26$ & & 9.55 & $0.72 \cdot 3.32$ & & 1.56 & $0.73 \cdot 3.32$ & \\
\hline Male sex & 0.90 & $0.47 \cdot 1.72$ & & 0.98 & $0.52 \cdot 1.87$ & & 0.92 & $0.48 \cdot 1.75$ & \\
\hline Cardioembolic cause & 0.71 & $0.34 \cdot 1.48$ & & 0.88 & $0.43-1.79$ & & 0.92 & $0.45 \cdot 1.88$ & \\
\hline Silent lesion & 0.28 & $0.04-2.06$ & & 0.23 & $0.03-1.70$ & & 0.18 & $0.02-1.38$ & \\
\hline Haemorrhagic infarct & 1.92 & $0.73 \cdot 5.06$ & & 1.68 & $0.62-4.51$ & & 1.91 & $0.71 \cdot 5.11$ & \\
\hline \multicolumn{10}{|l|}{ Large infarct } \\
\hline \multicolumn{10}{|l|}{ Superior temporal gyrus } \\
\hline Middle temporal gyrus & 2.30 & $1.21-4.40$ & 0.011 & & & & & & \\
\hline Supramarginal gyrus & & & & 2.27 & $1.17-4.40$ & 0.016 & & & \\
\hline Middle frontal gyrus & & & & & & & 2.30 & $1.01-5.24$ & 0.047 \\
\hline Inferior frontal gyrus & & & & & & & & & \\
\hline
\end{tabular}




\begin{tabular}{|c|c|c|c|c|c|c|c|c|c|}
\hline & HR & $95 \% \mathrm{Cl}$ & $p$-value & $\mathrm{HR}$ & $95 \% \mathrm{Cl}$ & p-value & $\mathrm{HR}$ & $95 \% \mathrm{Cl}$ & p-value \\
\hline Age young vs middle & 1.16 & $0.52-2.60$ & & 1.38 & $0.61-3.12$ & & 1.35 & $0.60-3.05$ & \\
\hline Age old vs middle & 1.65 & $0.78-3.52$ & & 2.10 & $0.97-4.56$ & & 2.00 & $0.93-4.30$ & \\
\hline Male sex & 0.88 & $0.46-1.67$ & & 1.13 & $0.57-2.20$ & & 1.15 & $0.59-2.26$ & \\
\hline Cardioembolic cause & 0.90 & $0.44-1.83$ & & 0.78 & $0.37-1.65$ & & 0.72 & $0.34-1.53$ & \\
\hline Silent lesion & 0.23 & $0.03 \cdot 1.72$ & & 0.27 & $0.04 \cdot 2.05$ & & 0.32 & $0.04-2.39$ & \\
\hline Haemorrhagic infarct & 1.90 & $0.71-5.06$ & & 0.85 & $0.31-2.38$ & & 0.83 & $0.30-2.32$ & \\
\hline Large infarct & & & & 3.65 & $1.61-8.28$ & 0.002 & 4.14 & $2.02-8.47$ & 0.000 \\
\hline Superior temporal gyrus & & & & 1.59 & $0.73-3.45$ & & & & \\
\hline Middle temporal gyrus & & & & & & & 1.78 & $0.92-3.48$ & \\
\hline \multicolumn{10}{|l|}{ Supramarginal gyrus } \\
\hline \multicolumn{10}{|l|}{ Middle frontal gyrus } \\
\hline Inferior frontal gyrus & 2.04 & $1.01-4.14$ & 0.048 & & & & & & \\
\hline
\end{tabular}

\begin{tabular}{|c|c|c|c|c|c|c|c|c|c|}
\hline & $\mathrm{HR}$ & $95 \% \mathrm{Cl}$ & $p$-value & $H R$ & $95 \% \mathrm{Cl}$ & $p$-value & $\mathrm{HR}$ & $95 \% \mathrm{Cl}$ & $\rho$-value \\
\hline Age young vs middle & 1.35 & $0.60-3.03$ & & 1.35 & $0.60-3.05$ & & 1.37 & $0.61-3.08$ & \\
\hline Age old vs middle & 1.97 & $0.91-4.28$ & & 1.89 & $0.87-4.08$ & & 1.98 & $0.92-4.25$ & \\
\hline Male sex & 1.14 & $0.59-2.23$ & & 1.16 & $0.58-2.29$ & & 1.11 & $0.56-2.18$ & \\
\hline Cardioembolic cause & 0.84 & $0.41 \cdot 1.73$ & & 0.87 & $0.42-1.80$ & & 0.86 & $0.42-1.78$ & \\
\hline Silent lesion & 0.27 & $0.04-2.05$ & & 0.21 & $0.03-1.63$ & & 0.27 & $0.04-2.03$ & \\
\hline Haemorrhagic infarct & 0.79 & $0.28-2.22$ & & 0.75 & $0.26 \cdot 2.13$ & & 0.85 & $0.31-2.35$ & \\
\hline Large infarct & 4.02 & $1.94-8.34$ & 0.000 & 4.49 & $2.24 \cdot 9.00$ & 0.000 & 4.32 & $2.10-8.87$ & 0.000 \\
\hline \multicolumn{10}{|l|}{ Superior temporal gyrus } \\
\hline \multicolumn{10}{|l|}{ Middle temporal gyrus } \\
\hline Supramarginal gyrus & 1.61 & $0.80-3.23$ & & & & & & & \\
\hline Middle frontal gyrus & & & & 2.01 & $0.88-4.61$ & & & & \\
\hline Inferior frontal gyrus & & & & & & & 1.42 & $0.69-2.92$ & \\
\hline
\end{tabular}




\section{$\mathrm{HR} \quad 95 \% \mathrm{Cl} \quad \mathrm{p}$-value $\mathrm{HR} \quad 95 \% \mathrm{Cl}$ p-value $\mathrm{HR} \quad 95 \% \mathrm{Cl} \quad \mathrm{p}$-value}

\begin{tabular}{|c|c|c|c|c|c|c|c|c|c|}
\hline Age young vs middle & 1.14 & $0.51-2.56$ & & 1.26 & $0.57-2.83$ & & 1.16 & $0.52 \cdot 2.60$ & \\
\hline Age old vs middle & 1.43 & $0.67-3.07$ & & 1.79 & $0.83-3.87$ & & 1.65 & $0.77-3.52$ & \\
\hline Male sex & 0.91 & $0.47-1.73$ & & 0.96 & $0.50-1.84$ & & 0.94 & $0.49-1.79$ & \\
\hline Cardioembolic cause & 0.90 & $0.44-1.83$ & & 0.68 & $0.33-1.43$ & & 0.71 & $0.34-1.48$ & \\
\hline Silent lesion & 0.19 & $0.03-1.42$ & & 0.28 & $0.04 \cdot 2.13$ & & 0.32 & $0.04-2.37$ & \\
\hline Haemorrhagic infarct & 1.61 & $0.58 \cdot 4.46$ & & 1.27 & $0.46-3.49$ & & 1.48 & $0.54-4.05$ & \\
\hline \multicolumn{10}{|l|}{ Large infarct } \\
\hline MF and IF gyrus & 3.37 & $1.37-8.28$ & 0.008 & & & & & & \\
\hline SM and ST gyrus & & & & 3.94 & $2.02 \cdot 7.70$ & 0.000 & & & \\
\hline ST and MT gyrus & & & & & & & 2.95 & $1.45-6.00$ & 0.003 \\
\hline SM, ST and MT gyrus & & & & & & & & & \\
\hline
\end{tabular}

$\mathrm{HR} \quad 95 \% \mathrm{Cl} \quad \mathrm{p}$-value $\mathrm{HR} \quad 95 \% \mathrm{Cl} \quad \mathrm{p}$-value $\mathrm{HR} \quad 95 \% \mathrm{Cl} \quad \mathrm{p}$-value

\begin{tabular}{|c|c|c|c|c|c|c|c|c|c|}
\hline Age young vs middle & 1.13 & $0.50-2.51$ & & 1.32 & $0.59 \cdot 2.98$ & & 1.39 & $0.62-3.13$ & \\
\hline Age old vs middle & 1.47 & $0.68-3.18$ & & 1.80 & $0.82-3.93$ & & 2.01 & $0.92-4.37$ & \\
\hline Male sex & 0.93 & $0.49-1.77$ & & 1.15 & $0.58 \cdot 2.27$ & & 1.08 & $0.55-2.11$ & \\
\hline Cardioembolic cause & 0.68 & $0.32-1.43$ & & 0.85 & $0.41-1.76$ & & 0.74 & $0.35-1.56$ & \\
\hline Silent lesion & 0.35 & $0.05-2.58$ & & 0.24 & $0.03 \cdot 1.77$ & & 0.29 & $0.04 \cdot 2.18$ & \\
\hline Haemorrhagic infarct & 1.34 & $0.49-3.67$ & & 0.74 & $0.26-2.10$ & & 0.84 & $0.30-2.36$ & \\
\hline Large infarct & & & & 4.23 & $2.08-8.60$ & 0.000 & 2.95 & $1.28-6.84$ & 0.011 \\
\hline MF and IF gyrus & & & & 2.29 & $0.93-5.64$ & & & & \\
\hline SM and ST gyrus & & & & & & & 2.26 & $1.02 \cdot 5.02$ & 0.045 \\
\hline \multicolumn{10}{|l|}{ ST and MT gyrus } \\
\hline SM, ST and MT gyrus & 3.90 & $1.90-8.02$ & 0.000 & & & & & & \\
\hline
\end{tabular}

$\mathrm{HR} \quad 95 \% \mathrm{Cl}$ p-value $\mathrm{HR} \quad 95 \% \mathrm{Cl} \quad \mathrm{p}$-value

\begin{tabular}{|c|c|c|c|c|c|c|}
\hline Age young vs middle & 1.33 & $0.59-3.00$ & & 1.26 & $0.56-2.83$ & \\
\hline Age old vs middle & 1.99 & $0.92-4.30$ & & 1.81 & $0.83 \cdot 3.95$ & \\
\hline Male sex & 1.14 & $0.58-2.24$ & & 1.10 & $0.56-2.15$ & \\
\hline Cardioembolic cause & 0.75 & $0.35 \cdot 1.61$ & & 0.72 & $0.34-1.52$ & \\
\hline Silent lesion & 0.32 & $0.04-2.39$ & & 0.34 & $0.05 \cdot 2.57$ & \\
\hline Haemorrhagic infarct & 0.82 & $0.29 \cdot 2.29$ & & 0.80 & $0.28 \cdot 2.23$ & \\
\hline Large infarct & 3.87 & $1.79-8.35$ & 0.001 & 3.44 & $1.57-7.51$ & 0.002 \\
\hline \multicolumn{7}{|l|}{ MF and IF gyrus } \\
\hline \multicolumn{7}{|l|}{ SM and ST gyrus } \\
\hline ST and MT gyrus & 1.65 & $0.76-3.61$ & & & & \\
\hline SM, ST and MT gyrus & & & & 2.18 & $0.99-4.83$ & \\
\hline
\end{tabular}


(95\% CI: 6-14). The IRR for this high risk group is 4.08 (95\% CI: $2.21-7.53$; $\mathrm{p}=0.000$ ). When infaret size was taken into account, the high risk group could be described as: patients with a large brain infarct, that affected at least either the supramarginal or the superior temporal gyrus. These 69 high risk patients ( $24 \%$ of all patients at risk), of whom 20 experienced late-onset seizures ( $49 \%$ of all late-onset seizures; two patients died early, nine had non-recurrent seizures, nine had recurrent seizures), had a risk of late-onset seizures of $29 \%(95 \% \mathrm{CI}$ : 18-40), whercals the remaining 221 patients, of whom 21 experienced late-onset seiıures. had a risk of late-onset seizures of $10 \%$ (95\% CI: 6-14). The IRR for this high risk group is 5.07 (95\% CI: 2.75-9.36; $\mathrm{p}=0.000)$.

\section{Discussion}

So far it remained uncertain what factors predict the occurrence of epileptic seizures following a brain infarct. In this prospective study on 322 patients with a first CT-confirmed symptomatic brain infarct involving the cerebral cortex, we found that old age at the time of the brain infarct. large infarct size, hatemorrhagic infarction, and involvement of certain cortical MCA territory gyri all increased the risk of seizures. Reason for including only stroke patients with CT-confirmed infarcts relates to our study aim to investigate infarct characteristics on CT as risk factors for post-stroke seizures. Because patients with a shorter survival are less likely to have seizures, follow-up in patients with wizures was consequently longer. Nevertheless, follow-up in the seizure free group was long enough to develop seizures: a median of 492 days, whereas the median seizure-delily was only 199 days. In the analyses we accounted for these differences in exposure times and excluded this bias. As early-onset and lateonset seizures may represent two different types of epilepsy, they were analysed separately.

\section{Early-onset sei-ures}

The high risk group for developing early-onset seizures, with an almost eight times increased risk, were patients of 65 years or older with a cardioembolic brain infarct involving at least the middle temporal ór post-central gyrus. In comparison with the high risk group from the previous chapter, CT-scan features. especially infarct location, added no extra value to the prediction of the risk of early-onset seizures. In both chapters twenty per cent of all patients belonged to the high risk group with an eight times increased risk. It seems that early-onset seizures can be predicted from clinical features alone.

Prophylactic treatment with anti-epileptic drugs shortly after stroke-onset could be considered in the high risk patients. but, it still remains questionable whether such treatment can be started soon enough to prevent the occurrence of the very 
early seizures, which occur within 48 hours after stroke-onset and comprise half of all the early seizures.

\section{Late-onset seizures}

We found that among the 290 fourteen-day survivors the high risk group, with a four times increased risk for developing late-onset seizures, were patients with a brain infarct involving both the supramarginal and the superior temporal gyrus, or the patients with a large brain infarct involving at least either the supramarginal or the superior temporal gyrus. in whom such risk is five times increased.

In comparison with the high risk group from the previous chapter. CT-scan features, especially infarct location, were very helpful in reducing the high risk group from more than half of all patients, to only one quarter of all patients. Unfortunately, the percentage of patients with seizures that could be predicted were also almost halved: from $86 \%$ to $49 \%$, and the relative risk decreased from eight times to five times. It seems that CT-scan features are useful in predicting the risk of late-onset seizures, however, prophylactic treatment with antiepileptic drugs for this high risk groups still seems not feasible, as a rather large number of patients has to be treated to prevent seizures in a relatively small number of them, and as fifty per cent of the seizures will occur in the low risk group. Treatment after a first late seizure would therefore be a more preferable policy. but even then advantages and possible drawbacks of anti-epileptic drug use in elderly stroke patients should be carefully counterbalanced.

In this chapter a selective patient-group was used. In our opinion, this patientgroup is a fairly good sample of the total patient population. Forty-two percent of all patients are included without differences in sex distribution: $44 \%$ of the young patients, $37 \%$ of the middle aged patients, and $44 \%$ of the older patients. The percentage of patients with post-stroke seizures, however, was somewhat higher, probably related to the higher risk of post-stroke seizures in territorial infarcts, especially those aged $<75$ years: $64 \%$ of all epilepsy patients are included, $50 \%$ of those with early-onset seizures, and $71 \%$ of those with lateonset seizures. However, we do not expect our results to be biased by this difference. especially as, although a selective patient-group was used, the results of this chapter again justify the distinction between early- and late-onset seizures. and they confirm the hypothesis that early-and late-onset seizures may differ in terms of seizure mechanism, as we described in chapter 4. From this chapter it appeared that there are also differences in epileptogenic cortical gyri between early-onset and late-onset seizures.

Our finding that large infarct size is a risk factor for post-siroke seizures (especially for late-onset seizures) concurs with that of others, ${ }^{80,100,104,137.152}$ 
whereas cardioembolic stroke cause only increased the risk of early seizures. ${ }^{107}$ However, in contrast with the view of others, 45.107 we did not find haemorrhagic infarction on CT to occur more often in the seizure group (neither early- nor lateonset), or to be an independent predictor of seizures, but this could be related to the low frequency of haemorrhagic infarction in our study. Asymptomatic cortical lesions did not increase nor lower the risk of early nor late-onset seizures following a brain infarct in the regression analyses, supporting our decision to use the first symptomatic brain infarct as the index stroke in all patients whether or not they had sustained recurrent stroke. We found that the frequency of silent cortical lesions was lower in the seizure group, which may even point at a protective effect.

Exact cortical location of the lesion was related to the occurrence of seizures, and suggested the existence of specific epileptogenic cortical gyri. We found four middle cerebral artery (MCA) territory gyri significantly more often affected in patients with post-stroke seizures: the middle temporal and postcentral gyrus in those with early-onset seizures, and the supramarginal and superior temporal gyrus in those with late-onset seizures. This finding concurs with the results, described in chapter 2, of our earlier retrospective study in epilepsy patients with prior stroke. in whom we found the middle temporal, superior temporal, precentral and supramarginal gyrus more frequently affected. ${ }^{87}$ With the results from this prospective study we can now exclude the possibility that these four MCA territory gyri merely reflected a more frequent involvement of this region in brain infarcts in general, and conclude that they really do form epileptogenic areas. Figure 5.3 shows the location of these gyri.

In the traumatic injured brain the lesions with the highest risk of postraumatic seizures involved the central-parietal region, 33.56 .129 .196 .197 according with the general rule "the closer the (traumatic) lesion to the central sulcus, the greater the possibility of seizure development". 16 Our data show that this rule does not simply hold true for ischaemic stroke. It is partly true for early seizures. although the temporal area below the superior temporal sulcus showed to be rather vulnerable too. For late-onset seizures, however, the most vulnerable area lies in the temporal region below the lateral sulcus, and in the parietal region above the lateral sulcus: the superior temporal and supramarginal gyrus appear to lorm an epileptogenic area for late post brain infarct seizures. This difference in riskregions may indicate that different parts of the brain can be affected by different mechanisms causing hyperexcitation leading to epileptic activity.

We realize that our results apply only to stroke patients with CT-confirmed brain infarcts. Infarct visualisation may not only depend on infarct size. but also on the timing of CT: one quarter of clinically diagnosed patients with a cortical syndrome had no infarct on CT. Future MRT studics may further validate the role of certain brain areas in the development of post-stroke seizures. 
Figure 5.3: Location of epileptogenic cortical gyri

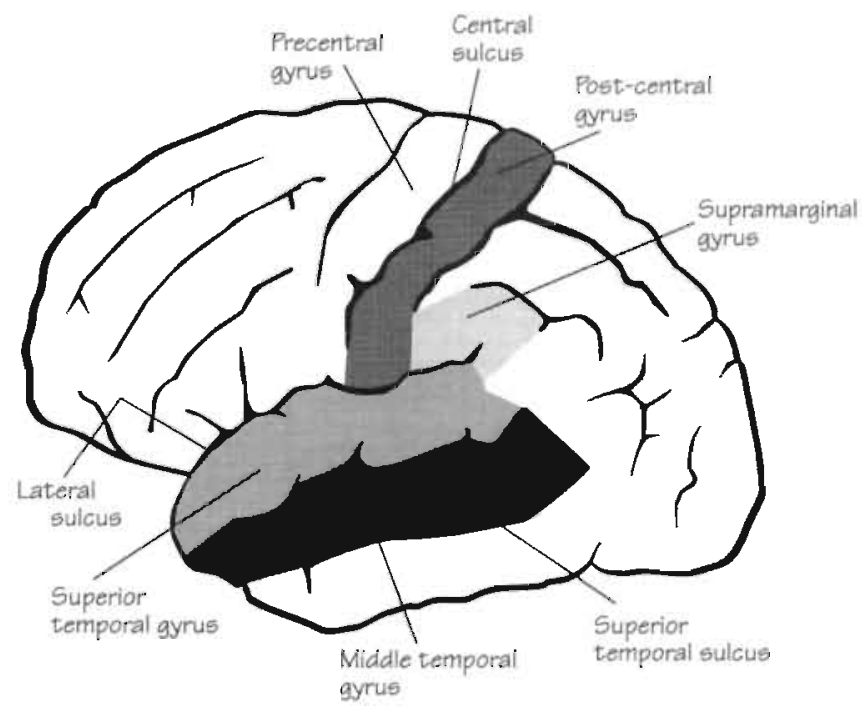

Infarction of dark area correlates with early-onset seizures

Infarction of light grey area correlates with late-onset seizures

\section{Chapter conclusions}

- Results of this chapter suggest that specific epileptogenic cortical areas exist, however they differ between patients with early-and those with late-onset seizures

- The risk of developing early-onset seizures is eight times higher in patients 65 years or older with a cardioembolic brain infarct involving at least the middle temporal or post-central gyrus. In the previous chapter the same risk was found. Infarct location seemed to add no extra value to the prediction of the risk of early unsct seizures: early-onset seizures can be predicted from clinical features alone

- The risk of late-onset seizura is five times higher in patients with a laige infarct involving the supramarginal or superior temporal gyrus. In comparison with the high risk group from the previous chapter, infarct location reduced the high risk group from more than half of all patients, to only one quarter of all patients, and is therefore useful in predicting the risk of late-onset seizures

- These data may influence treatment decisions in stroke patients with regard to "prophylactic" anti-epileptic drug treatment 



\section{CHAPTER 6}

Seizure risk and peri-stroke

medication use 
During the past decade there has been growing interest in the acute pharmacological treatment of brain infarct patients. Studies in laboratory animals have suggested that the functional recovery after experimental brain injury is influenced by a variety of drugs administered shortly before, during, or shortly after brain injury. For example, amphetamines, certain benzodiazepines, insulin and ACE inhibitors have been reported to improve neurological outcome, $57,94,106.157 .158 .189-191,194$ whereas certain antihypertensives, neuroleptics, benzodiazepines, and certain anticonvulsants may be detrimental and impair recovery after focal brain injury. ${ }^{28,57.72 .161 .192}$ It is not yet certain that these findings in brain-injured animals are also applicable to humans, however, some studie's suggest that similar effects may occur in humans. $+1.70 .71 .73-75$ Although the results of studies so far should be interpreted very carefully, it may be recommended to use the possible detrimental drugs with caution and, whenever possible, to avoid their use in the peri-infarct period. 70.75

Relating to this presumption that drugs administered during the acute phase after a brain infarct can influence functional recovery, we hypothesised that drugs administered during the acute phase after stroke might also influence the occurrence of post-stroke seizures. Not only could certain drugs have a direct toxic effect on the brain resulting in seizures, but they may also facilitate the formation of an epileptic focus that may cause seizures liater on.

In chapter 4 we found that theophylline treatment before a brain infarct increased the risk of early-onset seizures. As COPD without theophylline use was not related to the occurrence of such seizures, we concluded that theophylline triggered the seizures, not the concomitant COPD. Theophylline is a methylxanthine known to be able to cause seizures and other serious sideeffects. such as cardiac arrhythmias, brain damage and even death, when serum levels are above $35 \mathrm{mg} / \mathrm{l}$ (therapeutic range being $10-20 \mathrm{mg} / \mathrm{l}$ ). ${ }^{65.169 .178}$ The mechanism of theophylline induced seizures remains unclear. although inhibition of phosphodiesterase resulting in antagonism of the inhibitory effects of adenosine may play a role. $65.123 .1: 0$ However. advanced age, a low serum albumin, haemodynamic and hepatic dysfunction, pre-existing neurologic disease or brain injury, and the concomitant use of certain antibiotics or cimetidine. may all increase the likelihood of theophylline induced seizures, ${ }^{10.40 .98 .138 .139,169}$ even when theophylline is used with therapeutic or low serum levels. ${ }^{10,40,138,169}$ In addition, in patients receiving long term theophylline therapy. significant toxic reactions, such as seizures, can occur at any serum concentration. 18.138

Besides theophylline. a wide variety of other drugs may cause seizures. ${ }^{65.123}$ Certain drugs are frequently associated with seizures. even in the absence of predisposing factors, such as reduced drug elimination capacity, or neurologic abnormalities such as epilepsy and conditions with blood-brain barrier breakdown. ${ }^{65}$ Examples of these drugs. that may cause seizures at therapeutic doses in "normal" neurologically unimpaired patients. are phenothiazines, 
especially chlorpromazine, and butyrophenones such as haloperidol.65 The mechanism by which these drugs cause seizures is unknown. ${ }^{65}$

Some drugs cause seizures only when used in supratherapeutic doses (toxic effect, overdose) or in patients with predisposing conditions. $7,50,65,66,79,96,123,195$ A large number of drugs belong to this group, such as tricyclic antidepressants, lidocaine and structurally related antiarrhythmic agents, beta-adrenergic blocking agents, cardiac glycosides (digoxin), antihistamines, hypoglycaemic agents (insulin), beta-lactam antibiotics (especially penicillin), quinolone antibiotics. the antituberculosis agent isoniazid, antiviral agents, antineoplastic agents, and immunosuppressive agents.7.50,65,66,79,96,123,195 The anticonvulsants phenytoin and carbamazepine can paradoxically exacerbate seizures in drug overdosalge ${ }^{65}$ For most drugs the mechanism by which they cause seizures is unknown, however for some drugs a speculative mechanism has been described. Lidocaine and structurally related antiarrhythmic agents may interfere with membrane stibility. ${ }^{65.123}$ Digoxin may cause membrane instability and increased irritability by disregulating sodium and potassium transport. ${ }^{50,65.195}$ Beta-lactam antibiotics, especially penicillin, cause seizures by antagonizing gammaaminobutyric acid inhibition, both via the GABA receptor and the benzodiazepine receptor. ${ }^{7.65,79.123 .195}$ Quinolone antibiotics produce seizures, probably by inhibiting GABA-binding to membrane receptors.65.96 The antituberculosis agent isoniazid probably causes seizures by antagonizing pyridoxal phosphate, the active form of pyridoxine (Vitamin $B_{6}$ ), resulting in reduced brain levels of GABA. ${ }^{65,66.123}$ The immunosuppressive agent cyclosporin probably produces structural injury to the CNS leading to seizures. ${ }^{65}$

Finally, seizures can be related to drug withdrawal following prolonged administration. ${ }^{65}$ Alcohol and sedative drugs are examples of such drug types. ${ }^{65}$

Obviously, a wide variety of drugs can cause seizures, usually, but not exclusively when used in overdose, and also when administered in therapeutic doses to neurologically unimpaired patients. However. infarction may render the brain more susceptible to such drugs because of blood-brain barrier (BBB) impairments and increased permeability. ${ }^{91}$ Consequently, increased CNS penetration to drugs. that normally do not pass the $\mathrm{BBB}$. may more readily lead to central side-effects in patients with normal serum drug levels.

As we found obvious differences between early-onset and late-onset seizures (chapters 3-5), in this chapter. the influence of drugs on early-onset seizures and on late-onset seizures was studied separately. This distinction was also important because of the difference in seizure delay. Early-onset seizures occurred shortly after stroke onset, and therefore enabled us to study the possible direct toxic effect of certain drugs. administered shortly before stroke onset, on the brain resulting in early seizures. Late-onset seizures occurred with variable delay and could therefore be influenced by drugs that were administered in the first weeks after stroke-onset. As a result of this longer delay a direct toxic effect on the brain was less likely, however, certain drugs might be able to facilitate the 
formation of an epileptic focus that may cause seizures later on. This possibility could be studied in the patients with late-onset seizures.

\section{Patients and methods}

Patients were registered in an ongoing prospective register at the University Hospital Maastricht, that includes all adult patients admitted to the Neurological Department or seen at the outpatients' clinic, with a first-ever symptomatic supratentorial brain infarct with symptoms lasting longer than 24 hours. In- and exclusion criteria, data recorded, investigations performed, definitions used, CTscan features, and methods of follow-up are described in detail in the previous chapters. As described in chapter 3 during the intake-period of five years, 816 patients with a first-ever supratentorial brain infarct were registered. Forty-six patients were excluded for different reasons (see chapter 3), leaving 770 patients for our study on post-stroke seizures.

For every patient, medication used at the time of stroke and drugs administered during the first 28 days after the stroke were recorded. Patient medications on admission were determined by reviewing neurologists' and nurses' notes, and, whenever available. general practitioners' referral notes. Drugs prescribed during hospitalization were noted directly from physicians' order sheets and the nursing card-index system of drug administration. Discharge medication was determined by reviewing nurses' and physicians' discharge notes. For patients only seen at the outpatients' clinic. or discharged before the 28th day after stroke-onset, medication use was determined by reviewing their medical records at the outpatients' clinic.

As a large number of different drugs was used, it was not possible to analyse the effect of each single individual drug on the occurrence of seizures. Therefore, drugs were grouped by class, according to their chemical structure or pharmacological action. ${ }^{103,105}$

The following classes were distinguished and analysed:

- hypnotics and anxiolytics, subdivided in benzodiazepines, and barbiturates

- psychotropic drugs, subdivided in neuroleptics / antipsychotics, and antidepressants

- psychoactive drugs (only the xanthine theophylline was used)

- antihypertensive drugs acting on the CNS:

clonidine, methyldopa, and reserpine

- B-adrenoceptor blockers (betablockers), used as an antihypertensive as well as those used as antidysrhythmia or other indications

- diuretics

- vasudilators. subdivided in three classes:

- calcium channel blockers

- angiotensin converting enzyme (ACE) inhibitors

- remaining group including, organic nitrates, hydralazine, and prazosin 
- cardiac antidysrhythmic drugs (betablockers and calcium channel blockers used for this indication are considered separately above) including:

- cardiac glycosides: digoxin

- membrane stabilising drugs that act through sodium channel blockade: quinidine, disopyramide, mexiletine. flecainide, and propafenone

- lengtheners of refractoriness without sodium channel blockade: amiodarone

- histamine antagonists, subdivided in histamine $\mathrm{H}_{1}$ - and $\mathrm{H}_{2}$-receptor antagonists

- antidiabetic agents, subdivided in insulin, and oral antidiabetes drugs

- corticosteroids

- vitamin B and multivitamins containing vitamin B (remaining vitamins were used infrequently and therefore not analysed)

- antimicrobial drugs, of which only the antibacterial drugs (antibiotics) were analysed, subdivided in the following classes:

beta-lactams; penicillins and cephalosporins separately

aminoglycosides; - sulphonamides; - tetracyclines; azoles; - quinolones; - macrolides;

others including chloramphenicol and vancomycin

Remaining drug-classes were not analysed, either because nearly all patients were treated with such a drug (e.g. aspirin, heparin), or because only a very few patients were treated with drugs from one of these classes (e.g. morphine in terminal patients, or hormones and anti-hormones), or because we did not expect any influence on seizures of one of these drugs (such as laxatives, and medicines for outward application, external or topical use).

Because of the findings in the previous chapters, early-and late-onset seizures were analysed separately. As early-onset seizures occurred after a median delay of only one day following stroke-onset (chapter 3), the drugs administered after hospitalization could hardly have influenced the occurrence of these very early seizures, for most of these seizures already occurred before drug-administration was started. Therefore, only the medications used before stroke-onset were analysed in all 770 patients to study the drugs' influence on the occurrence of early-onset seizures. Late-onset seizures, however, occurred by definition two weeks or more after stroke-onset. Therefore. only the 716 patients who survived at least two weeks after their stroke were at risk for experiencing late-onset seizures, and all medications administered during this first two weeks following stroke-onset could have influenced the occurrence of late-onset seizures, and were therefore analysed. As it is unknown when the formation of an epileptic focus takes place after a brain infarct. separate analyses were performed for drugs administered during the first 48 hours following stroke-onset, drugs administered during the first week. and drugs administered during the first two weeks after stroke-onset. 


\section{Statistical methods}

After simply counting and comparing the number of patients with seizures in each different class of medication, differences in the occurrence of seizures between patients taking and those not taking the specific drug were analysed accounting for differences in exposure time, using Incidence Rate Ratio's (IRR) with $95 \%$ confidence intervals (CI) and two-tailed p-values..$^{151}$ When the number of patients in a specific risk group was less than five. or even equal to zero, Fisher's exact test was used to estimate the two-tailed p-value. ${ }^{42.119 .133}$ In addition the estimated effect of each class of medication on the occurrence of post-stroke seizures, was statistically adjusted for differences in the distribution of the risk factors already discovered in the previous chapters. being age, cardiac source of embolism, and clinical syndrome, for early-onset seizures, and clinical syndrome, and Rankin score $\geq 3$ for late-onset seizures, by means of a Cox regression analysis (proportional hazards model) resulting in hazard ratio's (HR) with $95 \% \mathrm{Cl}$ 's and two-tailed p-values. $42.119,134$

As early-onset seizures occurred by definition within two weeks following stroke-onset, in the analyses on early-onset seizures for every patient the maximal exposure time was set at 14 days. In the analyses on late-onset seizures the patients' complete available length of follow-up was used. Age was divided in three categories as described in the previous chapters: age $<65$ years, $65 \leq$ age $<75$, and age $\geq 75$ years. As none of the patients younger than 65 years had early-onset seizures, the age-limit at 65 years could not be used in the Cox regression analysis on early-onset seizures, and again only the age-limit at 75 years was used.

\section{Results}

\section{Early-onset seizures}

Twenty-eight patients of the 770 patients at risk (4\%) experienced early-onset seizures after a median delay of $I$ day (range by definition 0-14 days) following stroke-onset. Table 6.1 shows the number of patients with and those without early-onset seizures that had taken certain medications before stroke-onset. with IRR's indicating the differences between patients with and those without certain medications, and the risk of carly-onset seizures when drugs from a certain drugclass were taken. IRR's and their 95\% Cl's are graphically displayed in tigure 6.1. Siweral drugs were related to the occurrence of early-onset seizures. However, as we found in chapter 4 that patients at risk for developing early-onset seizures were those of 6.5 years or older who had a cortical syndrome. a Rankin score $\geq 3$. and a potential cardiac source of embolism. the estimated effect of each class of medication on the occurrence of early-onset seizures had to be adjusted for 
Table 6.1: Early-onset seizures: Medications taken before stroke-onset in patients with and those without early-onset seizures following a first cerebral infarct, and the relative risk (IRR) for developing these early-onset seizures when drugs from a certain drug-class had been used

\begin{tabular}{|c|c|c|c|c|c|c|c|}
\hline \multirow[b]{2}{*}{ Drug-class } & \multicolumn{2}{|c|}{$\begin{array}{l}\text { With seiz } \\
\mathrm{N}=28\end{array}$} & \multicolumn{2}{|c|}{$\begin{array}{l}\text { Without seiz } \\
\qquad \mathrm{N}=742\end{array}$} & \multirow[b]{2}{*}{ IRR } & \multirow[b]{2}{*}{$95 \% \mathrm{Cl}$} & \multirow[b]{2}{*}{ p-value } \\
\hline & $N$ & $(\%)$ & $N$ & $(\%)$ & & & \\
\hline Benzodiazepines & 8 & (29) & 94 & (13) & 2.80 & $1.23-6.35$ & 0.014 \\
\hline - BDZ withdrawal & 8 & (29) & 30 & (4) & 9.86 & $4.34-22.40$ & 0.000 \\
\hline Barbiturates & 0 & $(0)$ & 2 & $(<1)^{*}$ & & & \\
\hline Neuroleptics & 1 & (4) & 5 & $(1)$ & 4.54 & $0.62-33.41$ & \\
\hline Antidepressants & 0 & (0) & 14 & $(2)^{*}$ & & & \\
\hline Xanthines & 6 & (21) & 29 & (4) & 6.79 & $2.75-16.75$ & 0.000 \\
\hline Central antihypertensives & 1 & (4) & 19 & (3) & 1.35 & $0.18-9.94$ & \\
\hline Diuretics & 12 & (43) & 225 & $(30)$ & 1.81 & $0.85-3.82$ & \\
\hline B-adrenoceptor blockers & 4 & (14) & 133 & $(18)$ & 0.79 & $0.27-2.28$ & \\
\hline Calcium channel blockers & 2 & (7) & 79 & (11) & 0.64 & $0.15-2.71$ & \\
\hline ACE inhibitors & 1 & (4) & 95 & (13) & 0.26 & $0.04-1.92$ & \\
\hline Other vasodilators & 10 & $(36)$ & 137 & (18) & 2.57 & $1.19-5.56$ & 0.017 \\
\hline Other antidysrhythmics ${ }^{1}$ & 10 & (36) & 98 & (13) & 3.71 & $1.71-8.03$ & 0.001 \\
\hline - digoxin & 9 & $(32)$ & 89 & (12) & 3.55 & $1.61-7.84$ & 0.002 \\
\hline - membrane stabilisers & 1 & (4) & 6 & (1) & 4.98 & $0.68-36.67$ & \\
\hline - amiodarone & 0 & $(0)$ & 13 & $(2)^{*}$ & & & \\
\hline Histamine antagonists & 3 & $(11)$ & 40 & (5) & 2.11 & $0.64-7.00$ & \\
\hline - $H_{7}$-receptor antagonists & 0 & $(0)$ & 17 & $(2)^{*}$ & & & \\
\hline - $\mathrm{H}_{2}$-receptor antagonists & 3 & $(11)$ & 23 & (3) & 3.87 & $1.17-12.83$ & 0.027 \\
\hline Antidiabetic agents ${ }^{2}$ & 4 & $(14)$ & 86 & $(12)$ & 1.30 & $0.45-3.75$ & \\
\hline - insulin & 0 & (0) & 21 & $(3)^{*}$ & & & \\
\hline - oral antidiabetes drugs & 4 & (14) & 67 & (9) & 1.73 & $0.60-5.00$ & \\
\hline Corticosteroids & 3 & (11) & 29 & (4) & 2.94 & $0.89-9.73$ & \\
\hline Vitamin B complex & 3 & $(11)$ & 23 & (3) & 3.62 & $1.09-11.99$ & 0.035 \\
\hline Antibacterial drugs ${ }^{3}$ & 1 & (4) & 15 & (2) & 2.27 & $0.31-16.70$ & \\
\hline - Beta-lactams & 0 & (0) & 14 & $(2)^{*}$ & & & \\
\hline - Penicillins & 0 & $(0)$ & 12 & $(2)^{*}$ & & & \\
\hline - Cephalosporins & 0 & (0) & 2 & $(<1)^{*}$ & & & \\
\hline - Aminoglycosides & 0 & (0) & 1 & $(<1)^{*}$ & & & \\
\hline - Sulphonamides & 0 & (0) & 1 & $(<1)^{*}$ & & & \\
\hline - Tetracyclines & 1 & (4) & 1 & $(<1)$ & 26.51 & $3.60-195.10$ & 0.001 \\
\hline - Azoles or Quinolones & 0 & $(0)$ & 0 & (0) & & & \\
\hline - Macrolides & 0 & (0) & 0 & (0) & & & \\
\hline - Others & 0 & (0) & 1 & $(<1)^{*}$ & & & \\
\hline
\end{tabular}

$1=$ ten patients had a combination of drugs from different subgroups

$2=$ two patients had both insulin and oral antidiabetics

$3=$ three patients had a combination of antibacterial drugs from different subgroups

* $=$ Two tailed Fisher Exact test $p$-value $=1.000$ 
Table 6.2: Cox regression analysis, risk of early-onset seizures

Various models as described in this chapter: Drugs used before stroke-onset and the already discovered risk factors from chapter 4

\begin{tabular}{|c|c|c|c|c|c|c|c|c|c|}
\hline & HR & $95 \% \mathrm{Cl}$ & $\mathrm{p}$-value & HR & $95 \% \mathrm{Cl}$ & p-value & HR & $95 \% \mathrm{Cl}$ & p-value. \\
\hline Age $\geq 75$ vs age $<75$ & 4.12 & $1.62-10.51$ & 0.003 & 3.97 & $1.55-10.12$ & 0.004 & 3.97 & $1.56-10.08$ & 0.004 \\
\hline Male sex & 1.84 & $0.86-3.96$ & & 2.01 & $0.93 \cdot 4.35$ & & 1.51 & $0.69-3.30$ & \\
\hline Cardioembolic cause & 3.04 & $1.38-6.70$ & 0.006 & 3.17 & $1.44-7.01$ & 0.004 & 3.03 & $1.38 \cdot 6.66$ & 0.006 \\
\hline Cortical syndrome & 9.62 & $1.29 \cdot 71.64$ & 0.027 & 9.09 & $1.22 \cdot 67.71$ & 0.031 & 9.86 & $1.33-73.35$ & 0.025 \\
\hline Benzodiazepines & & & & 2.50 & $1.09 \cdot 5.73$ & 0.031 & & & \\
\hline Theophylline & & & & & & & 6.02 & $2.37 \cdot 15.24$ & 0.000 \\
\hline \multicolumn{10}{|l|}{$\mathrm{H}_{2}$-receptor antagonists } \\
\hline Vitamin B & & & & & & & & & \\
\hline
\end{tabular}

\begin{tabular}{|c|c|c|c|c|c|c|c|c|c|}
\hline & $H R$ & $95 \% \mathrm{Cl}$ & p-value & $\mathrm{HR}$ & $95 \% \mathrm{Cl}$ & p-value & $H R$ & $95 \% \mathrm{Cl}$ & $p$-value \\
\hline Age $\geq 75$ vs age $<75$ & 4.33 & $1.69 \cdot 11.08$ & 0.002 & 3.86 & $1.50-9.93$ & 0.005 & 4.37 & $1.68 \cdot 11.35$ & 0.002 \\
\hline Male sex & 1.90 & $0.88-4.13$ & & 1.88 & $0.87-4.06$ & & 1.76 & $0.80-3.90$ & \\
\hline Cardioembolic cause & 3.06 & $1.39-6.74$ & 0.006 & 3.07 & $1.39-6.80$ & 0.006 & 3.02 & $1.36 \cdot 6.67$ & 0.006 \\
\hline Cortical syndrome & 9.56 & $1.28-71.25$ & 0.028 & 9.62 & $1.29-71.68$ & 0.027 & 9.37 & $1.26-69.78$ & 0.029 \\
\hline Benzodiazepines & & & & & & & 2.44 & $1.06-5.61$ & 0.035 \\
\hline Theophylline & & & & & & & 5.22 & $1.95 \cdot 13.97$ & 0.001 \\
\hline $\mathrm{H}_{2}$-receptor antagonists & 3.79 & $1.14-12.62$ & 0.030 & & & & 2.05 & $0.54 \cdot 7.73$ & \\
\hline Vitamin B & & & & 2.63 & $0.78-8.85$ & & & & \\
\hline
\end{tabular}

Table 6.3: Cox regression analysis, risk of early-onset seizures Drugs used before stroke-onset:

Early $B D Z$ withdrawal instead of $B D Z$ use

HR $95 \% \mathrm{Cl}$ p-value $\mathrm{HR} \quad 95 \% \mathrm{Cl} \quad \mathrm{p}$-value

\begin{tabular}{|c|c|c|c|c|c|c|}
\hline Age $\geq 75$ vs age $<75$ & 4.33 & $1.70-11.01$ & 0.002 & 4.55 & $1.77 \cdot 11.65$ & 0.002 \\
\hline Male sex & 2.34 & $1.07-5.11$ & 0.033 & 2.19 & $0.98 \cdot 4.90$ & \\
\hline Cardioembolic cause & 2.94 & $1.34-6.46$ & 0.007 & 3.10 & $1.41-6.80$ & 0.005 \\
\hline Cortical synutrome & 8.90 & $1.20-66.34$ & 0.033 & 9.56 & $1.28-71.31$ & 0.028 \\
\hline Early BDZ withdrawa! & 7.83 & $3.35-18.31$ & 0.000 & 8.26 & $3.43-19.87$ & 0.000 \\
\hline Theophylline & & & & 4.23 & $1.61-11.06$ & 0.003 \\
\hline $\mathrm{H}_{2}$-receptor antagonists & & & & 3.63 & $0.97-13.60$ & \\
\hline
\end{tabular}


differences in the distribution of these already discovered risk factors. Therefore, Cox regression analysis was performed with the variables age, sex, cardiac source of embolism, clinical syndrome, and drug-class in the model (table 6.2). The Rankin score could not be included in the model as all patients with earlyonset seizures had a Rankin score $\geq 3$. Every single drug-class was included in the model one by one. High age, the presence of a cardiac source of embolism (CE), and a cortical syndrome, remained significantly associated with the occurrence of early-onset seizures in all analyses, with HR's closely varying around the HR's as found for these variables in chapter 4, which were four, three and ten, respectively. Results of the Cox regression analyses are shown in table 6.2. Three drug-classes appeared significantly associated with the occurrence of early-onset seizures: benzodiazepines $(\mathrm{HR}=2.50)$; theophylline $(\mathrm{HR}=6.02)$; and histamine $\mathrm{H}_{2}$-receptor antagonists $(\mathrm{HR}=3.79$ ). When these three drugclasses were analysed together in one model, only benzodiazepines and theophylline remained significantly associated with the occurrence of earlyonset seizures (table 6.2).

Consequently, the high risk group for developing early-onset seizures after a first-ever symptomatic supratentorial brain infarct were patients of 65 years or older who had a cortical syndrome, a Rankin score $\geq 3$, and a potential cardiac source of embolism, ánd who had used benzodiazepines or theophylline shortly before stroke-onset. There were 29 of such patients ( $4 \%$ of all patients at risk) of whom seven experienced early-onset seizures (25\% of all early-onset seizures; two patients died early. five had non-recurrent seizures), and consequently had a risk of early-onset seizures of $24 \%$ (95\% CI: $8-40$ ), whereas the remaining 741 patients, of whom 21 experienced early-onset seizures, had a risk of early-onset seizures of $3 \%(95 \% \mathrm{Cl}: 2-4)$. The IRR for this high risk group is 11.71 (95\% Cl: 4.98-27.54: $\mathrm{p}=0.000)$.

Subsequently, the 102 patients using benzodiazepines (BDZ) were further analysed regarding two characteristics: duration of BDZ action and (dis)continuation of treatment. Firstly, the duration of BDZ action: 59 patients used a short-acting agent and 6 of them developed seizures (10\%): 22 patients used a longer-acting agent and 2 developed seizures $(9 \%) ; 21$ used a long-acting agent and none developed seizures. Secondly. the patients using BDZ were analysed with regard to whether or not they continued to use BDZ's after strokeonset: 64 patients continued to use BDZ's after stroke-onset for at least one day, and none of them experienced early-onset seizures. However, in the remaining 38 patients the administration of BDZ's was abruptly discontinued early after stroke-onset: eight of these patients $\left(21 c_{i}\right)$ developed early-onset seizures.

The risk of early-onset seizures for patients who did not use BDZ at all was similar to the risk of those who used BD7. and continued to use them early after stroke-onset (Fisher Exact two tailed $p=0.245$ ). Therefore, in the Cox regression analyses, these two patient groups were analysed as one group and compared with the patients in whom the $\mathrm{BDZ}$ administration was abruptly 
discontinued early after stroke-onset. Adjusted for the other risk factors, high age, cortical syndrome, and cardiac source of embolism, abruptly discontinuing BDZ's was significantly associated with the occurrence of early-onset seizures $(\mathrm{HR}=7.83$; see table 6.3). When $\mathrm{BDZ}$ withdrawal, and the other two significantly associated drug-classes, theophylline and histamine $\mathrm{H}_{2}$-receptor antagonists, were analysed together in one model, the results were as shown in table 6.3, confirming the association of BDZ withdrawal and theophylline use with the occurrence of early-onset seizures. Patients using theophylline at stroke-onset all continued to use this drug for at least two weeks after stroke. Consequently, the high risk group for developing early-onset seizures after a first-ever symptomatic supratentorial brain infarct, can be defined more precisely as: patients of 65 years or older who had a cortical syndrome. a Rankin score $\geq 3$, and a potential cardiac source of embolism, ánd who had been using theophylline or henzodiazepines shortly before stroke-onset, and in whom the administration of henzodiazepines has been abruptly discontinued early after stroke-onset. Therc were 19 of such high risk patients ( $2 \%$ of all patients at risk) of whom seven experienced early-onset seizures (25\% of all early-onset seizures; two patients died early, five had non-recurrent seizures), who consequently had a risk of early-onset seizures of $37 \%$ (95\% CI: $0-18$ ), whereas the remaining 751 patients of whom 21 experienced early-onset seizures, had a risk of early-onset seizures of $3 \%(95 \% \mathrm{CI}: 2-4)$. The IRR for this high risk group is $23.82(95 \% \mathrm{CI}: 10.13-56.04 ; \mathrm{p}=0.000)$.

\section{Late-onset seizures}

Fifty-eight patients ( $8 \%$ ) of the 716 fourteen-day survivors developed late-onset seizures after a median delay of 261 (range 18-1848) days following strokeonset. Tables $6.4,6.5$. and 6.6 show the number of patients with and those without late-onset seizures who were treated with certain medications during the first 48 hours, the first week and the first two weeks after stroke-onset. respectively. IRR's are used to indicate the differences between groups in the risk of late-onset seizures. IRR's and their 95\% Cl's for medication-groups used during the first $t w o$ weeks following stroke-onset are graphically displayed in figure 6.1, together with the medication-groups used prior to stroke-onset. The tables show that drugs used during the first 48 hours after stroke-onset hardly had any effect on the occurrence of late-onset seizures, however, several drugs administered during the first week or the first two weeks post-stroke were related to the occurrence of late-onset seizures, whereas the results of the first week and the first two weeks were very similar. In chapter 4 we found that patients at risk for developing late-onset seizures were those who had a cortical syndrome and a Rankin score $\geq 3$, irrespective of age and stroke cause. Therefore, the estimated effect of each class of medication on the occurrence of late-onset seizures had to be adjusted (Cox regression analysis) for differences in 
Table 6.4: Late-onset seizures: Medications administered during the first 48 hours after stroke-onset in patients with and those without late-onset seizures following a first cerebral infarct, and the relative risk (IRR) for developing these late-onset seizures when drugs from a certain drugclass were used

\begin{tabular}{|c|c|c|c|c|c|c|c|}
\hline \multirow[b]{2}{*}{ Drug-class } & \multicolumn{2}{|c|}{$\begin{array}{l}\text { With seiz } \\
\qquad N=58\end{array}$} & \multicolumn{2}{|c|}{$\begin{array}{l}\text { Without seiz } \\
\qquad N=658\end{array}$} & \multirow[b]{2}{*}{ IRR } & \multirow[b]{2}{*}{$95 \% \mathrm{Cl}$} & \multirow[b]{2}{*}{ p-value } \\
\hline & $N$ & $(\%)$ & $N$ & $(\%)$ & & & \\
\hline Benzodiazepines & 6 & $(10)$ & 81 & $(12)$ & 0.99 & $0.43-2.31$ & \\
\hline - early $B D Z$ withdrawal & 6 & $(10)$ & 26 & (4) & 2.26 & $0.97-5.26$ & \\
\hline Barbiturates & 0 & (0) & 1 & $(<1)^{*}$ & & & \\
\hline Neuroleptics & 0 & (0) & 5 & $(<1)^{*}$ & & & \\
\hline Antidepressants & 0 & (0) & 12 & $(2)^{* *}$ & & & \\
\hline Xanthines & 4 & (7) & 31 & (5) & 1.60 & $0.58-4.43$ & \\
\hline Central antihypertensives & 1 & (2) & 19 & (3) & 0.47 & $0.06-3.36$ & \\
\hline Diuretics & 12 & (21) & 175 & (27) & 0.81 & $0.43-1.54$ & \\
\hline B-adrenoceptor blockers & 7 & (12) & 112 & (17) & 0.65 & $0.30-1.44$ & \\
\hline Calcium channel blockers & 5 & (9) & 73 & (11) & 0.85 & $0.34-2.13$ & \\
\hline ACE inhibitors & 7 & (12) & 77 & (12) & 1.21 & $0.55-2.67$ & \\
\hline Other vasodilators & 9 & $(16)$ & 114 & (17) & 1.11 & $0.55-2.27$ & \\
\hline Other antidysrhythmics ${ }^{1}$ & 7 & (12) & 100 & (15) & 0.97 & $0.44-2.13$ & \\
\hline - digoxin & 7 & (12) & 90 & (74) & 1.08 & $0.49 \cdot 2.38$ & \\
\hline - membrane stabilisers & 0 & (0) & 5 & $(<1)^{*}$ & & & \\
\hline - amiodarone & 0 & (0) & 13 & $(2)^{* *}$ & & & \\
\hline Histamine antagonists & 4 & (7) & 35 & (5) & 1.37 & $0.50-3.79$ & \\
\hline - $\mathrm{H}_{7}$-receptor antagonists & 0 & (0) & 13 & $(2)^{* *}$ & & & \\
\hline - $\mathrm{H}_{2}$-receptor antagonists & 4 & (7) & 22 & (3) & 2.38 & $0.86-6.58$ & \\
\hline Antidiabetic agents ${ }^{2}$ & 9 & $(16)$ & 77 & $(12)$ & 1.50 & $0.74-3.05$ & \\
\hline - insulin & 5 & (9) & 32 & (5) & 2.25 & $0.90-5.62$ & \\
\hline - oral antidiabetes drugs & 6 & (10) & 54 & $(8)$ & 1.23 & $0.53-2.86$ & \\
\hline Corticosteroids & 5 & (9) & 26 & (4) & 2.77 & $1.11-6.93$ & 0.030 \\
\hline Vitamin B complex & 3 & (5) & 28 & (4) & 1.43 & $0.45 \cdot 4.56$ & \\
\hline Antibacterial drugs ${ }^{3}$ & 3 & (5) & 29 & (4) & 1.91 & $0.60-6.10$ & \\
\hline - Beta-lactams & 2 & (3) & 19 & (3) & 2.41 & $0.59-9.89$ & \\
\hline - Penicillins & 7 & (2) & 17 & (2) & 7.95 & $0.27-14.08$ & \\
\hline - Cephalosporins & 1 & (2) & 8 & (1) & 3.08 & $0.43-22.27$ & \\
\hline - Aminoglycosides & 0 & (0) & 6 & $(1)^{*}$ & & & \\
\hline - Sulphonamides & 7 & (2) & 8 & (1) & 1.72 & $0.24-12.41$ & \\
\hline - Tetracyclines & 0 & (0) & 2 & $(<1)^{*}$ & & & \\
\hline - Azoles or Quinolones & 0 & (0) & 0 & (0) & & & \\
\hline - Macrolides & 0 & (0) & 0 & (0) & & & \\
\hline - Others & 0 & (0) & 1 & $(<7)^{*}$ & & & \\
\hline
\end{tabular}

= eight patients had a combination of drugs from different subgroups

= eleven patients had both insulin and oral antidiabetics

= seven patients had a combination of antibacterial drugs from different subgroups

$=$ Two tailed Fisher Exact test $p$-value $=1.000$

$=$ Two tailed Fisher Exact test $p$-value $=0.61$ 
Table 6.5: Late-onset seizures: Medications administered during the first week after stroke-onset in patients with and those without late-onset seizures following a first cerebral infarct, and the relative risk (IRR) for developing these late-onset seizures when drugs from a certain drugclass were used

\begin{tabular}{|c|c|c|c|c|c|c|c|}
\hline \multirow[b]{2}{*}{ Drug-class } & \multicolumn{2}{|c|}{$\begin{array}{l}\text { With seiz } \\
\quad \mathrm{N}=58 \\
\end{array}$} & \multicolumn{2}{|c|}{$\begin{array}{l}\text { Without seiz } \\
\qquad N=658 \\
\end{array}$} & \multirow[b]{2}{*}{ IRR } & \multirow[b]{2}{*}{$95 \% \mathrm{Cl}$} & \multirow[b]{2}{*}{$p$-value } \\
\hline & $\mathrm{N}$ & $(\%)$ & $N$ & $(\%)$ & & & \\
\hline Benzodiazepines & 7 & $(12)$ & 140 & (21) & 0.57 & $0.26-1.25$ & \\
\hline - early $B D Z$ withdrawal & 6 & (10) & 26 & (4) & 2.26 & $0.97-5.26$ & \\
\hline Barbiturates & 0 & (0) & 2 & $(<1)^{*}$ & & & \\
\hline Neuroleptics & 5 & (9) & 28 & (4) & 2.02 & $0.81-5.05$ & \\
\hline Antidepressants & 0 & (0) & 10 & $(2)^{*}$ & & & \\
\hline Xanthines & 7 & (12) & 37 & (6) & 2.52 & $1.14-5.55$ & 0.022 \\
\hline Central antihypertensives & 1 & (2) & 18 & (3) & 0.47 & $0.07-3.43$ & \\
\hline Diuretics & 11 & (19) & 180 & $(27)$ & 0.70 & $0.36-1.35$ & \\
\hline B-adrenoceptor blockers & 7 & (12) & 107 & $(16)$ & 0.65 & $0.29-1.43$ & \\
\hline Calcium channel blockers & 9 & (16) & 80 & $(12)$ & 1.37 & $0.67-2.78$ & \\
\hline ACE inhibitors & 8 & (14) & 84 & (13) & 1.24 & $0.59-2.62$ & \\
\hline Other vasodilators & 10 & $(17)$ & 117 & (18) & 1.17 & $0.59-2.32$ & \\
\hline Other antidysrhythmics ${ }^{1}$ & 6 & $(10)$ & 109 & $(17)$ & 0.72 & $0.31-1.67$ & \\
\hline - digoxin & 6 & $(10)$ & 99 & (15) & 0.79 & $0.34-1.85$ & \\
\hline - membrane stabilisers & 0 & (0) & 5 & $(<1)^{*}$ & & & \\
\hline - amiodarone & 0 & (0) & 14 & $(2)^{* *}$ & & & \\
\hline Histamine antagonists & 10 & (17) & 45 & (7) & 2.81 & $1.42-5.56$ & 0.003 \\
\hline - $H_{1}$-receptor antagonists & 1 & (2) & 12 & (2) & 0.97 & $0.13-7.00$ & \\
\hline - $\mathrm{H}_{2}$-receptor antagonists & 9 & $(16)$ & 33 & (5) & 3.40 & $7.67-6.93$ & 0.001 \\
\hline Antidiabetic agents ${ }^{2}$ & 11 & (19) & 85 & (13) & 1.65 & $0.86-3.18$ & \\
\hline - insulin & 5 & (9) & 33 & (5) & 2.10 & $0.84-5.25$ & \\
\hline - oral antidiabetes drugs & 8 & (14) & 62 & (9) & 1.44 & $0.68-3.03$ & \\
\hline Corticosteroids & 5 & (9) & 29 & (4) & 2.56 & $1.02-6.41$ & 0.044 \\
\hline Vitamin B complex & 9 & $(16)$ & 49 & (7) & 3.67 & $1.80-7.47$ & 0.000 \\
\hline Antibacterial drugs 3 & 11 & (19) & 77 & (12) & 2.71 & $1.40-5.22$ & 0.003 \\
\hline - Beta-lactams & 8 & (14) & 51 & (8) & 3.55 & $1.68-7.48$ & 0.007 \\
\hline - Penicillins & 6 & (10) & 24 & (4) & 4.93 & $2.12-11.48$ & 0.000 \\
\hline - Cephalosporins & 2 & (3) & 27 & (4) & 1.72 & $0.42-7.05$ & \\
\hline - Aminoglycosides & 2 & (3) & 14 & (2) & 3.36 & $0.82-13.78$ & \\
\hline - Sulphonamides & 2 & (3) & 30 & (5) & 0.91 & $0.22-3.74$ & \\
\hline - Tetracyclines & 1 & (2) & 3 & $(<1)$ & 5.36 & $0.74-38.71$ & \\
\hline - Azoles or Quinolones & 0 & (0) & 0 & (0) & & & \\
\hline - Macrolides & 0 & (0) & 1 & $(<1)^{*}$ & & & \\
\hline - Others & 0 & (0) & 1 & $(<1)^{*}$ & & & \\
\hline
\end{tabular}

$1=$ nine patients had a combination of drugs from different subgroups

$2=$ twelve patients had both insulin and oral antidiabetics

3 = twenty-four patients had a combination of antibacterial drugs from different subgroups

* $\quad=$ Two tailed Fisher Exact test $p$-value $=1.000$

** = Two tailed Fisher Exact test $p$-value $=0.62$ 
Table 6.6: Late-onset seizures: Medications administered during the first two weeks after stroke-onset in patients with and those without late-onset seizures following a first cerebral infarct, and the relative risk (IRR) for developing these late-onset seizures when drugs from a certain drugclass were used

\begin{tabular}{|c|c|c|c|c|c|c|c|}
\hline \multirow[b]{2}{*}{ Drug-class } & \multicolumn{2}{|c|}{$\begin{array}{l}\text { With seiz } \\
\mathrm{N}=58\end{array}$} & \multicolumn{2}{|c|}{$\begin{array}{l}\text { Without seiz } \\
\qquad N=658 \\
\end{array}$} & \multirow[b]{2}{*}{ IRR } & \multirow[b]{2}{*}{$95 \% \mathrm{Cl}$} & \multirow[b]{2}{*}{ p-value } \\
\hline & $N$ & $(\%)$ & $\mathrm{N}$ & $(\%)$ & & & \\
\hline Benzodiazepines & 14 & $(24)$ & 166 & (25) & 1.00 & $0.55-9.83$ & \\
\hline - early $B D Z$ withdrawal & 6 & (10) & 26 & (4) & 2.26 & $0.97-5.26$ & \\
\hline Barbiturates & 0 & (0) & 3 & $(<1)^{*}$ & & & \\
\hline Neuroleptics & 6 & $(10)$ & 37 & (6) & 1.99 & $0.86-4.64$ & \\
\hline Antidepressants & 1 & (2) & 10 & (2) & 7.66 & $0.23-11.98$ & \\
\hline Xanthines & 7 & $(12)$ & 39 & (6) & 2.52 & $1.14-5.54$ & 0.022 \\
\hline Central antihypertensives & 1 & $(2)$ & 18 & (3) & 0.47 & $0.07-3.43$ & \\
\hline Diuretics & 11 & (19) & 185 & (28) & 0.69 & $0.36-1.32$ & \\
\hline B-adrenoceptor blockers & 7 & $(12)$ & 110 & $(17)$ & 0.63 & $0.29-1.39$ & \\
\hline Calcium channel blockers & 9 & $(16)$ & 86 & (13) & 1.31 & $0.64-2.66$ & \\
\hline ACE inhibitors & 9 & $(16)$ & 90 & $(14)$ & 1.31 & $0.64-2.66$ & \\
\hline Other vasodilators & 11 & (19) & 119 & (18) & 1.29 & $0.67-2.48$ & \\
\hline Other antidysrhythmics ${ }^{1}$ & 7 & $(12)$ & 111 & $(17\rangle$ & 0.82 & $0.37-1.81$ & \\
\hline - digoxin & 7 & (12) & 101 & $(15)$ & 0.91 & $0.41-2.00$ & \\
\hline - membrane stabilisers & 0 & (0) & 5 & $(<1)^{*}$ & & & \\
\hline - amiodarone & 0 & (0) & 15 & $(2)^{* *}$ & & & \\
\hline Histamine antagonists & 11 & (19) & 54 & (8) & 2.77 & $1.44-5.34$ & 0.002 \\
\hline - $H_{1}$-receptor antagonists & 2 & (3) & 13 & (2) & 7.68 & $0.41-6.88$ & \\
\hline - $\mathrm{H}_{2}$-receptor antagonists & 9 & $(16)$ & 47 & (6) & 3.04 & $1.49-6.18$ & 0.002 \\
\hline Antidiabetic agents ${ }^{2}$ & 11 & $(19)$ & 89 & (14) & 1.57 & $0.81-3.02$ & \\
\hline - insulin & 6 & $(10)$ & 35 & (5) & 2.48 & $1.06-5.77$ & 0.035 \\
\hline - oral antidiabetes drugs & 8 & $(74)$ & 68 & (10) & 1.3 .3 & $0.63-2.80$ & \\
\hline Corticosteroids & 5 & (9) & 29 & (4) & 2.56 & $1.02-6.41$ & 0.044 \\
\hline Vitamin B complex & 11 & (19) & 54 & (8) & 4.37 & $2.27-8.43$ & 0.000 \\
\hline Antibacterial drugs ${ }^{3}$ & 16 & $(28)$ & 105 & $(16)$ & 3.00 & $1.69-5.34$ & 0.000 \\
\hline - Beta-lactams & 9 & $(76)$ & 65 & $(10)$ & 3.15 & $1.55-6.41$ & 0.002 \\
\hline - Penicillins & 7 & $(12)$ & 34 & (5) & 4.06 & $1.84-8.94$ & 0.001 \\
\hline - Cephalosporins & 2 & (3) & 31 & (5) & 1.51 & $0.37-6.20$ & \\
\hline - Aminoglycosides & 2 & (3) & 17 & (3) & 2.54 & $0.62-10.40$ & \\
\hline - Sulphonamides & 6 & $(10)$ & 48 & (7) & 1.81 & $0.78-4.22$ & \\
\hline - Tetracyclines & 1 & (2) & 3 & $(<1)$ & 5.36 & $0.74-38.71$ & \\
\hline - Azoles or Quinolones & 0 & $(0)$ & 0 & (0) & & & \\
\hline - Macrolides & 0 & $(0)$ & 7 & $(<7)^{*}$ & & & \\
\hline - Others & 0 & (0) & 1 & $(<1)^{*}$ & & & \\
\hline
\end{tabular}

= ten patients had a combination of drugs from different subgroups

= seventeen patients had both insulin and oral antidiabetics

$=$ twenty-nine patients had a combination of antibacterial drugs from different subgroups

$=$ Two tailed Fisher Exact test $p$-value $=1.000$

$=$ Two tailed Fisher Exact test $p$-value $=0.62$ 
Figure 6.1: Medication use as a risk factor for the occurrence of post-stroke seizures

Benzodiazepines

$\mathrm{BDZ}$ withdrawal

Ncuroleptics

Antidepressants

Xanthines

Central antihypertensives

Diuretics

B-adrenoceptor blockers

Calcium channcl blockers

ACE inhibitors

Other vasodilators

Other antidysrhythmics

Digoxin

Membrane stabilisers

Histamine antagonists

HI-rcceptor antagonists

H2-rcceptor antagonists

Antidiabetic agents

Insulin

Oral antidiabetes drugs

Corticosteroids

Vitamin B complex

Antibacterial drugs

Beta-lactams

Penicillins

Cephalosporins

Aminoglycosides

Sulphonamides

Tetracyclines

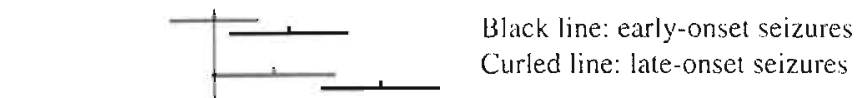

Curled line: late-onsel seizures
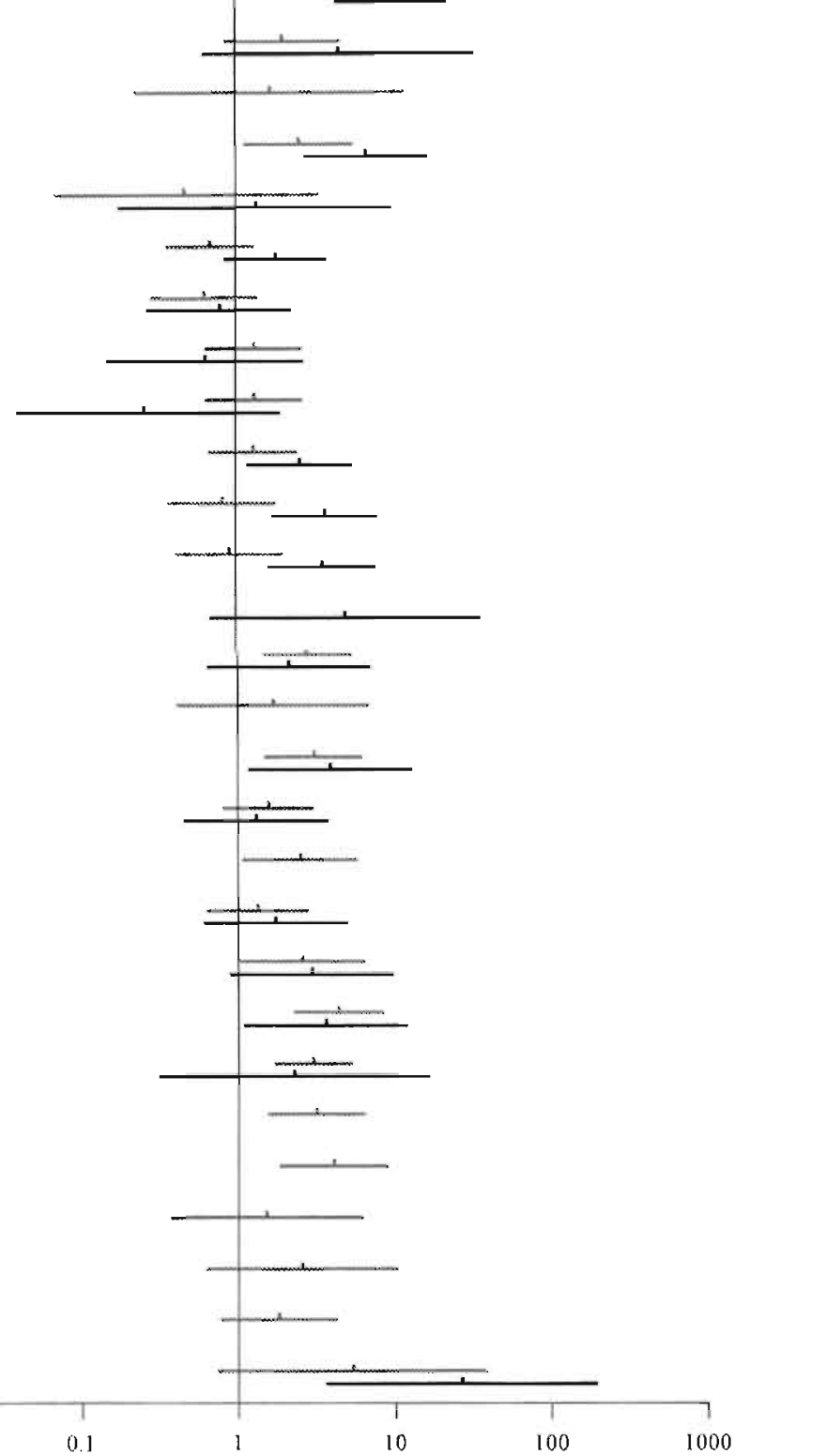

Diagram of IRR's with $95 \% \mathrm{Cl}$ 's on a logarithmic scale; IRR>1 means an increased risk of seizures when this type of medication has been used (compared with medication not used); $95 \% \mathrm{Cl}$ not including the value 1 means that the difference in risk is statistically significant with $p<0.05$ 
the distribution of these already discovered risk factors. Five patients without late-onset seizures (two males, three females, aged 76-88 years, four with a cortical syndrome and all five with a Rankin score $\geq 3$ ) were excluded from the Cox regression analysis as they were censored before the earliest event occurred, because they died (three on day 15, one on day 16 and one on day 17 poststroke) before the first late seizure among the patients with late seizures (day 18). As these five patients together were at risk for developing late-onset seizures for just eight days, excluding these five patients unlikely affected the final results. Consequently Cox regression analysis was performed on 711 patients.

\section{Administration of drugs during the first 48 hours after stroke-onset}

Cox regression analysis was performed with the variables age, sex, Rankin score, clinical syndrome, cardiac source of embolism, and drug-class in the model. Every single drug-class was included in the model one by one. The presence of a cortical syndrome and a Rankin score $\geq 3$ remained significantly associated with the occurrence of late-onset seizures in all analyses, with HR's closely varying around 4.8 and 4.6 , respectively, in the various models. Results of the Cox regression analyses are shown in table 6.7. Two drug-classes were significantly associated with the occurrence of late seizures: histamine $\mathrm{H}_{2}$-receptor antagonists $(\mathrm{HR}=2.96)$ and corticosteroids $(\mathrm{HR}=3.18)$. However, when these two drug-classes were analysed together in one model, none of them remained significantly associated with the occurrence of late-onset seizures (table 6.7). Overall, drugs administered during the first 48 hours after strokeonset hardly affected the risk of late-onset seizures.

\section{Administration of drugs during the first week after stroke-onsct}

Cox regression analysis was performed with the same model as described above. Every single drug-class was included in the model one by one. The presence of a cortical syndrome and a Rankin score $\geq 3$ remained significantly associated with the occurrence of late-onset seizures in all analyses, with HR's closely varying around 4.8 and 4.6. respectively, in the various models. Results of the Cox regression analyses are shown in table 6.8. Four drug-classes were significantly associated with the occurrence of late-onset seizures: histamine $\mathrm{H}_{2}$-receptor antagonists ( $\mathrm{HR}=3.40)$; corticosteroids $(\mathrm{HR}=2.85)$; vitamin $\mathrm{B}(\mathrm{HR}=2.19)$; and penicillins $(H R=3.19)$. When these four drug-classes were analysed together in one model, only histamine $\mathrm{H}_{2}$-receptor antagonists and penicillins used during the first week following stroke onset remained significantly associated with the occurrence of late-onset seizures (table 6.8). 
Table 6.7: Cox regression analysis, risk of late-onset seizures

Risk factors from chapter 4 , basic model for late-onset seizures

\begin{tabular}{llcl}
\hline & HR & $95 \% \mathrm{Cl}$ & p-value \\
\hline Age young vs middle & 1.35 & $0.66-2.75$ & \\
Age old vs middle & 1.59 & $0.85-2.97$ & \\
Male sex & 1.11 & $0.65-1.90$ & \\
Rankin $\geq 3$ & 4.61 & $1.40-15.19$ & 0.012 \\
Cortical syndrome & 4.81 & $2.15-10.75$ & 0.000 \\
Cardioembolic cause & 0.86 & $0.47-1.57$ & \\
\hline
\end{tabular}

Drugs used during the first 48 hours after stroke-onset and the risk of late-onset seizures Various models as described in this chapter: Drugs used during the first 48 hours after stroke-onset and the already discovered risk factors from chapter 4

\begin{tabular}{|c|c|c|c|c|c|c|c|c|c|}
\hline & $H R$ & $95 \% \mathrm{Cl}$ & pivalue & HP & $95 \% \mathrm{Cl}$ & prabe & धंते & $35 \% \mathrm{Cl}$ & p-value \\
\hline Age young vs middle & 1.31 & $0.64 \cdot 2.67$ & & 1.45 & $0.70-2.99$ & & 1.43 & $0.69-2.95$ & \\
\hline Age old vs middle & 1.61 & $0.86 \cdot 3.00$ & & 1.74 & $0.92 \cdot 3.28$ & & 3.76 & $0.93-3.33$ & \\
\hline Male sex & 1.13 & $0.66 \cdot 1.94$ & & 1.04 & $0.61-1.79$ & & 1.07 & $0.62-1.84$ & \\
\hline Rankin $\geq 3$ & 4.59 & $1.39 \cdot 15.13$ & 0.012 & 4.52 & $1.37-14.88$ & 0.013 & 4.47 & $1.35-14.74$ & 0.014 \\
\hline Cortical syndrome & 4.99 & $2.23 \cdot 11.18$ & 0.000 & 4.93 & $2.21-11.02$ & 0.000 & 5.02 & $2.24-11.24$ & 0.000 \\
\hline Cardioembolic cause & 0.82 & $0.45 \cdot 1.51$ & & 0.83 & $0.45-1.51$ & & 0.81 & $0.44-1.48$ & \\
\hline $\mathrm{H}_{2}$-receptor antagonists & 2.96 & $1.06-8.27$ & 0.038 & & & & 2.32 & $0.80-6.79$ & \\
\hline Corticosteroids & & & & 3.18 & $1.23-8.24$ & 0.017 & 2.68 & $0.99-7.26$ & \\
\hline
\end{tabular}


Table 6.8: Cox regression analysis, risk of late-onset seizures Drugs used during the first week after stroke-onset: Various models as described in this chapter

\begin{tabular}{|c|c|c|c|c|c|c|c|c|c|}
\hline & $\mathrm{HR}$ & $95 \% \mathrm{Cl}$ & p-value & $H R$ & $95 \% \mathrm{Cl}$ & p-value & HR & $95 \% \mathrm{Cl}$ & p-value \\
\hline Age young vs middle & 1.35 & $0.66-2.76$ & & 1.38 & $0.67-2.82$ & & 1.31 & $0.64-2.67$ & \\
\hline Age old vs middle & 1.59 & $0.85-2.98$ & & 1.57 & $0.84-2.92$ & & 1.77 & $0.94-3.33$ & \\
\hline Male sex & 1.14 & $0.67 \cdot 1.96$ & & 1.07 & $0.63-1.84$ & & 1.21 & $0.71-2.07$ & \\
\hline Rankin $\geq 3$ & 4.55 & $1.38 \cdot 15.00$ & 0.013 & 4.45 & $1.35-14.68$ & 0.014 & 4.30 & $1.30-14.22$ & 0.017 \\
\hline Cortical syndrome & 4.68 & $2.09-12.50$ & 0.000 & 4.77 & $2.13-10.68$ & 0.000 & 4.82 & $2.15-10.80$ & 0.000 \\
\hline Cardioembolic cause & 0.84 & $0.46-1.54$ & & 0.86 & $0.47-1.58$ & & 0.80 & $0.44 \cdot 1.47$ & \\
\hline Early BDZ withdrawal & 1.55 & $0.66-3.66$ & & & & & & & \\
\hline Theophylline & & & & 2.03 & $0.91 \cdot 4.52$ & & & & \\
\hline $\begin{array}{l}\mathrm{H}_{2} \text {-receptor antagonists } \\
\text { Insulin }\end{array}$ & & & & & & & 3.40 & $7.63-7.09$ & $0.00 \%$ \\
\hline \multicolumn{10}{|l|}{ Corticosteroids } \\
\hline \multicolumn{10}{|l|}{ Vitamin B } \\
\hline Penicillins & & & & & & & & & \\
\hline
\end{tabular}

\begin{tabular}{|c|c|c|c|c|c|c|c|c|c|}
\hline & $\mathrm{HR}$ & $95 \% \mathrm{Cl}$ & $p$-value & $H R$ & $95 \% \mathrm{Cl}$ & p-value & $H R$ & $95 \% \mathrm{Cl}$ & p-value \\
\hline Age young vs middle & 1.31 & $0.64-2.68$ & & 1.42 & $0.69-2.92$ & & 1.45 & $0.71-2.99$ & \\
\hline Age old vs middle & 1.57 & $0.84-2.92$ & & 1.73 & $0.92-3.26$ & & 1.64 & $0.88-3.05$ & \\
\hline Male sex & 1.16 & $0.68-1.98$ & & 1.05 & $0.61-1.80$ & & 1.05 & $0.62-1.81$ & \\
\hline Rankin $\geq 3$ & 4.54 & $1.38-14.94$ & 0.013 & 4.43 & $1.34-14.62$ & 0.015 & 4.32 & $1.31 \cdot 14.29$ & 0.016 \\
\hline Cortical syndrome & 4.90 & $2.19-10.97$ & 0.000 & 4.93 & $2.20-11.02$ & 0.000 & 4.56 & $2.03-10.23$ & 0.000 \\
\hline Cardioembolic cause & 0.90 & $0.49 \cdot 1.64$ & & 0.83 & $0.45-1.52$ & & 0.83 & $0.46-1.52$ & \\
\hline \multicolumn{10}{|l|}{$\mathrm{H}_{2}$-receptor antagonists } \\
\hline Insulin & 2.20 & $0.86 \cdot 5.59$ & & & & & & & \\
\hline Corticosteroids & & & & 2.85 & $1.10-7.39$ & 0.032 & & & \\
\hline Vitamin B & & & & & & & 2.19 & $1.05-4.54$ & 0.036 \\
\hline Penicillins & & & & & & & & & \\
\hline
\end{tabular}

\begin{tabular}{lllllll}
\hline & HR & $95 \% \mathrm{Cl}$ & $\mathrm{p}$-value & HR & $95 \% \mathrm{Cl}$ & $\mathrm{p}$-value \\
\hline Age young vs middle & 1.37 & $0.67-2.81$ & & 1.52 & $0.73-3.18$ & \\
Age old vs middle & 1.57 & $0.84-2.94$ & & 1.90 & $0.99-3.63$ & \\
Male sex & 1.11 & $0.65-1.90$ & & 1.06 & $0.62-1.84$ & \\
Rankin $\geq 3$ & 4.36 & $1.32-14.40$ & 0.016 & 3.77 & $1.13-12.57$ & 0.031 \\
Cortical syndrome & 4.60 & $2.05-10.31$ & 0.000 & 4.44 & $1.97-10.01$ & 0.000 \\
Cardioembolic cause & 0.81 & $0.44-1.49$ & & 0.73 & $0.39-1.34$ & \\
H2-receptor antagonists & & & & 2.88 & $1.35-6.13$ & 0.006 \\
Corticosteroids & & & & 2.42 & $0.91-6.46$ & \\
Vitamin B & & & & 1.85 & $0.87-3.91$ & \\
Penicillins & 3.19 & $1.35-7.56$ & 0.008 & 3.25 & $1.35-7.80$ & 0.009 \\
\hline
\end{tabular}


Table 6.9: Cox regression analysis, risk of late-onset seizures

Drugs used during the first two weeks after stroke-onset:

Various models as described in this chapter

\begin{tabular}{|c|c|c|c|c|c|c|c|c|c|}
\hline & HR & $95 \% \mathrm{Cl}$ & p.value & HR & $95 \% \mathrm{Cl}$ & p-value & $\mathrm{HR}$ & $95 \% \mathrm{Cl}$ & $p$-value \\
\hline Age young vs middle & 1.32 & $0.65-2.70$ & & 1.30 & $0.64-2.67$ & & 1.42 & $0.69-2.92$ & \\
\hline Age old vs middle & 1.76 & $0.94 \cdot 3.29$ & & 1.54 & $0.82 \cdot 2.87$ & & 1.73 & $0.92 \cdot 3.26$ & \\
\hline Male sex & 1.20 & $0.70-2.06$ & & 1.15 & $0.68-1.97$ & & 1.05 & $0.61-1.80$ & \\
\hline Rankin $\geq 3$ & 4.29 & $1.30-14.19$ & 0.017 & 4.52 & $1.37-14.88$ & 0.013 & 4.43 & $1.34 \cdot 14.62$ & 0.015 \\
\hline Cortical syndrome & 5.01 & $2.24-11.22$ & 0.000 & 4.89 & $2.18-10.94$ & 0.000 & 4.93 & $2.20-11.02$ & 0.000 \\
\hline Cardioembolic cause & 0.81 & $0.44-1.48$ & & 0.91 & $0.50-1.68$ & & 0.83 & $0.45-1.52$ & \\
\hline $\mathrm{H}_{2}$-receptor antagonists & 3.09 & $1.49 \cdot 6.43$ & 0.003 & & & & & & \\
\hline Inșulin & & & & 2.42 & $1.02 \cdot 5.72$ & 0.045 & & & \\
\hline Corticosteroids & & & & & & & 2.85 & $1.10-7.39$ & 0.032 \\
\hline \multicolumn{10}{|l|}{ Vitamin B } \\
\hline Penicillins & & & & & & & & & \\
\hline
\end{tabular}

\begin{tabular}{|c|c|c|c|c|c|c|c|c|c|}
\hline & $H R$ & $95 \% \mathrm{Cl}$ & p-value & HR & $95 \% \mathrm{Cl}$ & $p$-value & HR & $95 \% \mathrm{Cl}$ & $\rho$-value \\
\hline Age young vs middle & 1.49 & $0.72-3.07$ & & 1.38 & $0.68-2.83$ & & 1.46 & $0.70-3.05$ & \\
\hline Age old vs middle & 1.61 & $0.87-3.01$ & & 1.51 & $0.81 \cdot 2.84$ & & 1.74 & $0.91-3.33$ & \\
\hline Male sex & 1.03 & $0.60-1.76$ & & 1.11 & $0.65-1.90$ & & 1.09 & $0.63-1.89$ & \\
\hline Rankin $\geq 3$ & 4.23 & $1.28-14.00$ & 0.018 & 4.42 & $1.34 \cdot 14.60$ & 0.015 & 3.60 & $1.08-12.04$ & 0.037 \\
\hline Cortical syndrome & 4.46 & $1.98 \cdot 10.01$ & 0.000 & 4.62 & $2.06-10.35$ & 0.000 & 4.56 & $2.02-10.29$ & 0.000 \\
\hline Cardioembolic cause & 0.83 & $0.46-1.52$ & & 0.86 & $0.47-1.57$ & & 0.84 & $0.46-1.55$ & \\
\hline $\mathrm{H}_{2}$-receptor antagonists & & & & & & & 2.93 & $1.37-6.25$ & 0.005 \\
\hline Insulin & & & & & & & 2.86 & $1.17-6.94$ & 0.021 \\
\hline Conticosteroids & & & & & & & 2.14 & $0.80-5.69$ & \\
\hline Vitamin B & 2.58 & $1.31 \cdot 5.09$ & 0.006 & & & & 2.08 & $1.01-4.28$ & 0.047 \\
\hline Penicillins & & & & 2.34 & $1.05 \cdot 5.25$ & 0.039 & 2.19 & $0.92 \cdot 5.21$ & \\
\hline
\end{tabular}

Drugs used during the first two weeks adjusted for diabetes mellitus

\begin{tabular}{llcl}
\hline & HR & $95 \% \mathrm{Cl}$ & p-value \\
\hline Age young vs middle & 1.46 & $0.70-3.04$ & \\
Age old vs middle & 1.73 & $0.90-3.32$ & \\
Male sex & 1.09 & $0.62-1.89$ & \\
Rankin $\geq 3$ & 3.62 & $1.08-12.08$ & 0.037 \\
Cortical syndrome & 4.56 & $2.02-10.28$ & 0.000 \\
Cardioembolic cause & 0.84 & $0.46-1.55$ & \\
H2-receptor antagonists & 2.94 & $1.38-6.27$ & 0.005 \\
Insulin & 3.02 & $1.00-9.13$ & 0.050 \\
Corticosteroids & 2.15 & $0.80-5.73$ & \\
Vitamin B & 2.09 & $1.01-4.34$ & 0.047 \\
Penicillins & 2.17 & $0.91-5.20$ & \\
Diabetes mellitus & 0.93 & $0.43-2.04$ & \\
\hline
\end{tabular}




\section{Administration of drugs during the first two weeks after stroke-onset}

Using the same Cox regression model, and including every single drug-class one by one. the presence of a cortical syndrome and a Rankin score $\geq 3$ remained significantly associated with the occurrence of late-onset seizures in all analyses, with HR's varying around 4.8 and 4.6 , respectively, in the different models. Results of the Cox regression analyses are shown in table 6.9. Five drug-classes were significantly associated with the occurrence of late-onset seizures: histamine $\mathrm{H}_{2}$-receptor antagonists $(\mathrm{HR}=3.09)$; insulin $(\mathrm{HR}=2.42)$; corticosteroids ( $\mathrm{HR}=2.85)$; vitamin $\mathrm{B}(\mathrm{HR}=2.58)$; and penicillins $(\mathrm{HR}=2.34)$. When these five drug-classes were analysed together in one model, histamine $\mathrm{H}_{2}$-receptor antagonists. insulin and vitamin $\mathrm{B}$ used during the first two weeks following stroke onset remained significantly associated with the occurrence of late-onset seizures (table 6.9). Insulin even remained significantly associated when diabetes mellitus was added to the model (table 6.9). Diabetes was not a risk factor and had no influence on the other variables in the model (table 6.9).

By combining the results from the above described separate analyses, the high risk group for developing late-onset seizures were patients with a cortical syndrome and a Rankin score $\geq 3$, who subsequently, during the first two weeks following their stroke, used at least one of the following four drugs: histamine $\mathrm{H}_{2}$-receptor antagonists, insulin. vitamin $\mathrm{B}$, or penicillins. According to this definition there were 119 high risk patients ( $17 \%$ of all patients at risk) of whom 23 patients experienced late-onset seizures ( $40 \%$ of all late-onset seizures; four patients died, ten had non-recurrent seizures, nine had recurrent seizures). Consequently, those high risk patients had a risk of late-onset seizures of $19 \%$ (95\% CI: 12-26), whereas the remaining 597 patients of whom 35 experienced late-onset seizures, had a risk of late-onset seizures of $6 \%(95 \% \mathrm{CI}: 4-8)$. The IRR for this high risk group is 6.01 (95\% CI: 3.55-10.16; $\mathrm{p}=0.000)$.

\section{Discussion}

Our findings show that certain drugs, administered just before or shortly after stroke-onset, strongly influence the risk of post-stroke seizures. There were obvious differences between early-onset and late-onset seizures, which suggest a toxic effect of drugs in early seizures, and an interference with epileptogenesis in late-onset seizures facilitating the occurrence of those late seizures. 


\section{Early-onset seizures}

Univariate analysis showed several drugs possibly related to the development of early-onset seizures. Cox regression analysis showed that, adjusted for interactions between the different possible risk factors. only the use of theophylline and benzodiazepines shortly before stroke-onset remained significantly associated with early-onset seizures. Digoxin was not associated any more when accounted for interactions; it was frequently used in patients with a possible cardiac source of embolism. Vitamin B, tetracyclines and vasodilators were more frequently used in older patients and therefore interacted with the risk factor high age. Two of the three patients who used histamine $\mathrm{H}_{2}$-receptor antagonists also used theophylline.

It was not surprising to find that theophylline increased the risk of early-onset seizures, as this drug is known to be able to cause seizures especially in elderly patients, in patients receiving long term theophylline therapy, and in patients with neurological disease. ${ }^{10,18,40,98,138,139,169}$ The fact that all six patients, who were treated with theophylline and subsequently developed early-onset seizures, experienced their first seizure at stroke-onset argues in favour of a direct toxic effect on the brain. probably by a local increased brain level of theophylline as a result of the $B B B$ damage. As most COPD patients who are treated with theophylline really are in need for this drug, and as there is no proper alternative drug available, ${ }^{1.15}$ it will be very difficult. if not impossible, to prevent this kind of seizures.

The finding that the usc of benzodiazepines shortly before stroke-onset significantly increased the risk of arly-onset seizures was rather contradictory. as it is very unlikely that benzodiazepines cause seizures, for diazepam is nota bene administered as an anticonvulsant in status epilepticus. Therefore, the patients who had been using benzodiazepines at home before stroke-onset (probably chronic benzodiazepine users), were further analysed. Then it appeared that it was not the early use of benzodiazepines that increased the risk of early-onset seizures, but the sudden withdrawal early after stroke-onset in patients accustomed to use these drugs at home, that was strongly associated with the occurrence of early-onset seizures, with a consequent increased risk of more than eight times. Seizures related to benzodiazepine withdrawal following prolonged administration, even when low dusis benzodiazcpines were used. have been described before. ${ }^{65.103}$ Such seizures are most common after withdrawal of short-acting hypnotic drugs, and usually occur within 48 hours. as was the case in six of our eight patients who developed curly-onset seizures following benzodiazepine withdrawal. Chronic ben /odiarcpine use may produce decreased sensitivity of the receptors to GABA. " The sudden decrease in benzodiazepine level probably deteriorates the binding of the neurotransmitter GABA at the benzodiazepinereceptor, resulting in an extra decreased neuronal inhibition and leading to seizures, especially in the acute phase after a stroke when not only GABA. but also massive amounts of excitatory amino acids, such 
as glutamate, are spilled from damaged cells into the interstitium.78,120,180 As receptor affinity for the inhibitory neurotransmitter GABA may be decreased also by these high concentrations of $\mathrm{GABA}, 4.186$ a relative $\mathrm{GABA}$-ergic deficiency may result in the cerebral cortex, thalamus, and striatum, ${ }^{190}$ disturbing the delicate balance between excitation and inhibition in favour of excitation. Therefore. we recommend to continue the use of benzodiazepines in patients with a brain infarct. especially in those patients with one or more other risk factors for post-stroke seizures.

Our results indicate that almost one third of early-onset post brain infarct seizures could have been prevented by continuation of benzodiazepine use after acute brain infarction!

\section{Late-onset seizures}

Medication administered during the first 48 hours after stroke-onset hardly affected the occurrence of late-onset seizures. However, several drugs administered during the first week or the first two weeks post-stroke were, in similar degree, significantly associated with the occurrence of late-onset seizures, increasing the risk of seizures substantially. These results suggest that the formation of an epileptic focus after a brain infarct probably takes place later than 48 hours after stroke-onset. Furthermore, that if prophylactic anti-epileptic drug treatment for high risk patients is considered. this should be initiated within 48 hours. However. the strategy of lowering the risk of late-onset post-stroke seizures by interfering with the development of an epileptic focus has not been tested so far. but may constitute a possible therapeutical option. As early benzodiazepine withdrawal after stroke-onset increased (but just under the level of statistical significance, table 6.4) the risk of late-onset seizures, early BDZ administration following stroke may possibly decrease the risk of epileptic focus development.

Univariate analysis showed several drugs related to late-onset seizures, that were not associated any more after Cox regression analysis. As corticosteroids were often administered in combination with histamine $\mathrm{H}_{2}$-receptor antagonists there was an interaction between these variables, explaining why the use of corticosteroids was not significant in the Cox regression analysis. Theophylline was not statistically significant any more, probably due to an interaction with age. However, once theophylline treatment is initiated it will probably be used for the rest of the patients' lift. and when time goes by theophylline treatment is started in more and more stroke patients with COPD. Therefore, at the time of the first late scizure more patients were using theophylline than in the first weeks pust-stroke, suggesting that theophylline increases the risk of late-onset seizures not by interfering with epileptogenesis, but by a toxic effect leading to seizures in combination with other predisposing factors in stroke patients.

Four drug classes were significantly associated with the occurrence of late-onset 
seizures after Cox regression analysis: histamine $\mathrm{H}_{2}$-receptor antagonists, insulin, vitamin B and penicillins. Beta-lactam antibiotics, especially penicillins, are known to be able to cause seizures by antagonizing neuronal inhibition by $\gamma$-aminobutyric acid (GABA), both via the GABA receptor and the benzodiazepine receptor. ${ }^{7}$ Penicillin is a competitive GABA $_{A}$ receptor antagonist, that causes "open channel blockade" of the GABA receptor by interacting with positively charged proteins within the channel, and then physically blocking chloride ion flow through the channel. 186 Probably this mechanism does not necessarily cause acute seizures, but may merely cause more structural damage to some neurons (probably those already affected by the results of the brain infarct) leading to the formation of an epileptic focus. As patients with COPD are especially sensitive to pulmonary infections, they have a high risk to be treated with penicillins after stroke. In addition, as COPD is a chronic disease with an increased risk of worsening, stroke patients with COPD are likely to be treated with theophylline at some time. Theophylline treatment then may further increase the risk of seizures in penicillin enhanced epileptic potential. Therefore, restricting the use of penicillins in stroke patients during the first weeks after stroke-onset may prevent seizures. Preferably, antibiotics from another class should be prescribed.

Vitamin $B$ and multivitamins containing vitamin $B$ are most likely not epileptogenic by themselves, but the underlying reason to prescribe vitamin $B$ may explain their association with the occurrence of late-onset seizures. Vitamin B is not routinely prescribed, but only in thuse patients with a supposed vitamin deficiency, and usually for only a few wecks. Stroke patients with a likely vitamin deficiency, and consequently a vitamin B prescription, may be vitamin $B$ deficient again some time after discharge if vitamin supplements are not taken regularly. Thus the fact that vitamins $B$ were prescribed in the patients of our series likely indicates their risk of a chronic deficiency of these vitamins. Especially pyridoxine (vitamin $\mathrm{B}_{6}$ ) deficiency may increase the risk of seizures in vulnerable people such as stroke patients. ${ }^{117}$ Pyridoxine defïciency may lead to a decreased level of pyridoxal phosphate, the active form of pyridoxine which is an important factor in the production of GABA. ${ }^{65.66 .123}$ Reduced GABA brain levels may in turn lead to decreased neuronal inhibition with consequent seizures. Testing for vitamin $B_{6}$ deficiency and adequate treatment may therefore prevent late-onset seizures in patients who sustained a brain infarct.

The explanation for the finding that insulin treatment is associated with the occurrence of late-onset seizures may be that insulin therapy considerably increases the risk of hypoglycaemia and consequently of seizures. Diabetic patients who undergo hypoglycaemic episodes are known to have an increased risk of seizures, probably because decreased blood glucose levels may activate ATP-regulated potassium channels in the substantia nigra (they open when ATP levels decrease). leading to hyperpolarization and a consequent decrease in GABA release. ${ }^{185}$ Furthermore, hypoglycaemia causes an increase of the extracellular concentrations of EAA. ${ }^{30}$ disturbing the delicate balance between 
excitatory and inhibitory neural mechanisms in favour of excitation. One example in our series is a 57 year old male, known with diabetes mellitus treated with insulin, who was admitted to our hospital with a CT proven lacunar infarct. During his two weeks hospitalization insulin dose was significantly increased because of post-stroke hyperglycaemia. Seventeen days after discharge the patient experienced an epileptic scizure. He had a severe hypoglycaemia of $1.5 \mathrm{mmol} / \mathrm{l}$. Insulin dose was adjusted and the patient remained seizure free without AED treatment for the rest of his follow-up (almost one year). Careful monitoring of blood glucose lavels in parients treated with insulin, in order to prevent severe hypoglycaemia, may prevent late-onset seizures in patients who sustained a brain infarct.

The finding that histamine $\mathrm{H}_{2}$-receptor antagonists significantly increase the risk of late-onset seizures is interesting. Histamine acts as a neurotransmitter in certain brain areas and is locally synthesized. ${ }^{31.164}$ Besides the already known $\mathrm{H}_{1}$ and $\mathrm{H}_{2}$ histamine receptors, in the brain a new subclass of histamine receptors $\left(\mathrm{H}_{3}\right)$ has been identified, that can be antagonised by certain histamine $\mathrm{H}_{1}$ - as well as certain histamine $\mathrm{H}_{2}$-receptor antagonists. 31.164 .165 One of the responses in the brain to histamine is an inhibition of neuronal firing with both fast onset and fast recovery, especially in the hippocampus and the cerebral cortex, mediated by $\mathrm{H}_{2}$-receptors. ${ }^{164}$ On the other hand, increased neuronal firing and even epileptiform bursts induced by histamine, may sometimes occur, mediated by $\mathrm{H}_{1}$-receptors and $\mathrm{H}_{2}$-receptors. 1.10 : Generally, however, the regular effect of histamine on the brain is depressant on spontaneously firing cortical cells. ${ }^{164}$ As histamine $\mathrm{H}_{2}$-receptor antagonists antagonise this normal action of histamine. they increase neuronal firing, and may be epileptogenic. This knowledge is based on experiments in rats and does not necessarily apply to humans, although it has been reported in man that small doses of antihistamines can lead to epileptic seizures in patients with focal epilepsy. ${ }^{122}$ Interestingly, our results confirm that the above described findings in rats also apply to humans, and that peripherally acting histamine $\mathrm{H}_{2}-$ receptor antagonists also act on histamine receptors in the brain, as they increase the risk of post-stroke seizures.

As histamine $\mathrm{H}_{2}$-receptor antagonists usually are prescribed for only a few weeks, most patients were not using those drugs any more when they experienced their first epileptic seizure. Therefore, histamine $\mathrm{H}_{2}$-receptor antagonists do not have a direct toxic epileptogenic effect, but more likely they interfere with epileptogenesis in the first weeks after stroke-onset. Our patients used several $\mathrm{H}_{2}$-receptor antagonists, however only the use of ranitidine (Zantac) was associated with the occurrence of seizures, suggesting that this drug antagonises the $\mathrm{H}_{2}$-receptors in the brain, whereas other peripherally acting histamine $\mathrm{H}_{2}$-receptor antagonists may not antagonise these centrally $\mathrm{H}_{2}$-receptors. Therefore we recommend not to prescribe histamine $\mathrm{H}_{2}$-receptor antagonists in patients with a brain infarct, but to choose a gastric acid secretion inhibitor with a different mode of action. 


\section{Chapter conclusions and recommendations}

- The results of this chapter again justify the distinction between early-and late-onset seizures, and confirm that early- and late-onset seizures represent two different types of epilepsy with different pathogenesis and specific risk factors. Results suggest a toxic effect of certain drugs in early seizures, and an interference with epileptogenesis in late-onset seizures facilitating the occurrence of those late seizures

- The risk of developing carly scizures is almost 24 limes higher in patients of 65 years or older who have a cortical syndrome, a Rankin score $\geq 3$. ánd a potential cardiac source of embolism, ánd who have been using theophylline before stroke or in whom the use of benzodialepines has been abruptly discontinued early after struke onset.

In comparison with the high risk group from chapter 4 (twenty per cent of all patients belonged to the high risk group with an eight times increased risk), theophylline use and benzodiazepine withdrawal added a substantial extra value to the prectiction of the risk of early-onset seizures: the risk group was reduced to only $2 \%$ of all patients, whereas $25 \%$ of the early seizures could be predicted

- The risk of late-onset seizures is six times higher in patients with a cortical syndrome and a Rankin score $\geq 3$. who subsequently, during the first two weeks following their stroke, used at least one of the following four drugs: histamine $\mathrm{H}_{2}$-receptor antagonists, penicillins, insulin, or vitamin $\mathrm{B}$. Histamine $\mathrm{H}_{2}$-receptor antagonists and penicillins may be epileptogenic and interfere with epileptogenesis, whereas the use of insulin was related to the increased risk of hypoglycaemias, and vitamin B use to vitamin deficiency. especially of pyridoxine (vitamin $\mathrm{B}_{6}$ ).

In comparison with the high risk group from chapter 4 (fifty-three per cent of all patients belonged to the high risk group with a more than eight times increased risk), the use of one of these four drugs was very helpful in reducing the high risk group from more than half of all patients. to only $17 \%$ of all patients. whereas $40 \%$ of the late-onset seizures could be predicted. In addition, these results also gave more insight in the possible pathogenesis and "prophylactic treatment" of late-onset seizures 
Although the number of patients that used drugs from a certain drug-class were relatively small, and our results should therefore be interpreted with caution, the associations we found were so strong that the following recommendations can be given:

- continue the use of benzodiazepines in patients with a brain infarct who had been using these drugs at home, not only to reduce the risk of early seizures, but possibly also to decrease the risk of epileptic focus development and late seizures

- be reluctant with the administration of theophylline in general but especially in stroke patients. and use the lowest possible doses when no alternative drugs for theophylline are possible

- restrict the use of penicillins in stroke patients during the first weeks after stroke-onset and prefer an antibiotic from a different class of antibiotics

- be alert for vitamin $B_{6}$ deficiency in elderly stroke patients; regular $B_{6}$ measurements may be indicated and deficiency should be adequately treated

- be alert for hypoglycaemia in diabetics who are treated with insulin

- do not prescribe ranitidine in patients with a brain infarct; a different histamine $\mathrm{H}_{2}$-receptor antagonist is preferred, or even better, use a gastric acid secretion inhibitor with a different mode of action

When these actions had been taken in our patients eight of the 28 early-onset seizures might have been prevented $(29 \%)$, and 23 of the 58 late-onset seizures $(40 \%)$. 



\title{
CHAPTER 7
}

\author{
General discussion
}

Can seizures following a first cerebral infarct be predicted. and should high risk brain infarct patients be treated prophylactically with anti-epileptic drugs? 
As stated in the general introduction. post-stroke epilepsy is an important health care problem, concerning approximately twelve per cent of all epilepsy patients. with many questions still unanswered. Therefore this prospective study in adult patients with a first-ever supratentorial brain infarct was performed.

Epileptic seizures occurred in eleven per cent of our patients and one of the most important findings was the clear distinction between early-onset and late-onset seizures, justifying separate analyses. We found that early-onset and late-onset seizures represent two different types of epilepsy, with different pathogenesis, different prognosis, and specific risk factors. Early seizures may be merely secondary to a variety of non-cerebral disarrangements in the early phase following stroke, older patients being more sensitive for such disarrangements than younger patients. The presence of a cardiac source of embolism increases this risk, as cardiac emboli may disintegrate, and reperfusion damage may cause seizures. Such mechanism probably occurs only shortly after stroke onset, and therefore does not play a role in the development of late-onset seizures, which may be regarded as "real" post-stroke epilepsy caused by epileptic disturbances in cerchral "scar" tissue remaining from large territorial infarcts, leading to recurrent seizures that are often difficult to treat. Late seizures may be due to membrane instability of the injured brain cells, disturbances in the GABA-ergic inhibitory system, or in the action of receptors involved in excitatory brain activity, all disturbing the delicate balance between excitatory and inhibitory neural mechanisms in favour of excitation in such "scarred" brain foci.

\section{Prediction of early-onset seizures}

Early-onset seizures occurred in 4 per cent of our patients after a very short delay: they occurred mainly in the first 48 hours after stroke. Early-onset seizures only occurred in patients of 65 years and older. and had a good prognosis: they were non-recurrent and easy to treat with current AED's in 80 per cent of the patients with early scizures who survived the first two weeks after their first seizure.

In chapter 4 the high risk group with an eight times increased risk for developing carly-onset seizures appeared to be the patients of 65 years or older, who had a corlical syndrome, a Rankin score $\geq 3$, and a potential cardiac source of embolism. Ninetien per cent of all patients at risk belonged to this high risk group that predicted 61 per cent of all patients with early-onset seizures. In chapter 5 only patients with a CT-confirmed territorial infarct involving the cerebral cortex were studied, using CT-scan features to define the high risk group: patients of 65 years or older with a cardioembolic brain infarct involving the middle temporal or post-central gyrus (21\% of the patients at risk), predicting 64 per cent of all patients with early-onset seizures. They had an eight times increased risk. Finally. in chapter 6 the high risk group with an almost 24 times increased risk appeared to be patients of 65 yiurs or older who had a 
cortical syndrome, a Rankin score $\geq 3$, ánd a potential cardiac source of embolism, ánd who had been using theophylline shortly before stroke-onset, ór in whom the use of benzodiazepines has been abruptly discontinued early after stroke-onset. Only two per cent of the patients at risk belonged to this high risk group, predicting 25 per cent of all early-onset seizures.

Early-onset seizures can be predicted rather reliable, sixty per cent of all earlyseizures occur in the high risk group, and prophylactic treatment with AED's shortly after stroke-onset could be considered in such high risk patients. However, it is highly questionable whether this treatment can be started soon enough after stroke onset to prevent the occurrence of the very early seizures, which occur within 48 hours after stroke-onset and comprise more than half of all the early-onset seizures. Besides, the prognosis of early-onset seizures was good. they were non-recurrent in 80 per cent of the patients who survived the first two weeks following their first seizure, and tended to resolve spontaneously (confirming our presumed pathogenesis) or, when treatment was indicated, responded well to AED's. Therefore, a second or even a third seizure may be awaited before AED treatment is started. This prognosis corresponds with the general observation that 70 to 80 per cent of epilepsy patients becomes seizurefree. 145.147 Therefore. it is questionable whether prophylactic treatment with AED's is indicated in these patients. In our opinion it is not. Yet. there is another "prophylactic" treatment possible: continuation of the use of benzodiazepines in patients with a brain infarct using these drugs, especially in those patients with one or more other risk factors for early-onset seizures. Almost one third of the early-onset seizures may possibly be prevented by this measure alone!

\section{Prediction of late-onset seizures}

Late-onset seizures occurred in 8 per cent of the patients who survived the first two weeks after stroke-onset. They occurred at all ages. They were recurrent in 48 per cent of the patients who survived the first two weeks following their first seizure, and were difficult to treat with the current AED's.

The high risk group with a more than eight times increased risk for developing late-onset seizures appeared to be patients with a cortical syndrome and a Rankin score $\geq 3$ (chapter 4). Fifty-three per cent of all patients at risk belonged to this high risk group that predicted 86 per cent of all patients with late-onset seizures, and 92 per cent of the recurrent seizures. When CT-scan features were used to define the high risk group, it appeared that patients with a large infarct involving the supramarginal or superior temporal gyrus, irrespective of stroke cause and patient's age ( $24 \%$ of the patients at risk), had a five times increased risk. This risk group predicted 49 per cent of all patients with late-onset seizures, including half of the recurtent seizures. Finally, the high risk group with a six times increased risk were patients with a cortical syndrome and a Rankin score $\geq 3$, who subsequently, during the first two weeks following their stroke, used at 
least one of the following four drugs: histamine $\mathrm{H}_{2}$-receptor antagonists, insulin, vitamin B, or penicillins. Seventeen per cent of the patients at risk belonged to this high risk group, predicting 40 per cent of all late-onset seizures, including 36 per cent of the recurrent seizures.

As late-onset seizures were recurrent and difficult to treat with current AED's, especially in the younger patients, prevention of these recurrent late-onset seizures following a brain infarct would be of significant clinical importance. Fortunately, late-onset seizures could be predicted almost perfectly: 86 per cent of all late-onset seizures (including $92 \%$ of the recurrent seizures). However, more than fifty per cent of the patients with a first-ever supratentorial brain infarct belong to this high risk group. and consequently are all candidates for prophylactic AED treatment. This means that $38 \mathrm{I}$ patients should be treated prophylactically with AED's and be exposed to possible side-effects, especially cognitive function disturbances in elderly patients, ${ }^{89,108,144.147}$ to prevent the occurrence of the lirst late-onset seizure in 50 of them $(13 \%)$. It seems unjustified to treat this rather large number of patients to prevent a first seizure in only ten per cent of them. Besides it would be very difficult to determine when prophylactic treatment with AED's should be started and how long it should be given, as late seizures occurred somewhere between 18 and 1848 days after stroke-onset. In addition it remains questionable if prophylactic AED treatment works, as in trials in the prevention of post-traumatic epilepsy the results were very poor. ${ }^{196,197,201}$ In conclusion, prophylactic treatment with AED's seems not feasible. Treatment after a first late seizure would therefore be a more preferable policy, but even then advantages and possible drawbacks of antiepileptic drug use in elderly stroke patients should be carefully counterbalanced. However, concerning the high number of recurrent seizures we prefer to start AED treatment after the first seizure in a sufficient high dose and advise strongly not to wait for an eventual second seizure to occur.

Fortunately there are other "prophylactic" treatment possibilities to prevent the occurrence of late-onset seizures:

- reluctance with the administration of theophylline in general is advisable. especially in stroke patients, and the lowest possible doses should be used when no alternative drugs for theophylline are possible

- the usc of penicillins in stroke patients during the first wecks after strokeonset should be restricted; antibiotics from different classes are preferred

- the possibility of vitamin $B_{6}$ deficiency in elderly stroke patients deserves attention: $\mathrm{B}_{6}$ should be measured regularly and deficiency treated adequately

- be aware of hypoglycaemia, especially in diabetics who are treated with insulin 
- histamine $\mathrm{H}_{2}$-receptor antagonists, especially ranitidine, should not be prescribed in patients with a brain infarct; a gastric acid secretion inhibitor with a different mode of action is preferred.

When these "prophylactic actions" had been taken in our patients forty' per c'ent of the late-onset seizures could have possibly been prevent'd.

\section{In conclusion:}

Early-onset and late-onset seizures represent two different types of epilepsy, with different pathogenesis, different prognosis, specific risk lactors and epileptogenic cortical areas. Early-onset seizures were non-recurrent in 80 per cent, whereas late-onset seizures were recurrent in 48 per cent of the patients who survived the first two weeks after their first seizure. Early- and late-onset seizures can be predicted rather reliable with the help of clinical features. Patients' medical history and neurological examination early after stroke-onset provide sufficient information to predict 60 per cent of the early-onset seizures and 86 per cent of the late-onset seizures. Prophylactic treatment with antiepileptic drugs seems not feasible. However, not withdrawing benzodiazepine's early after stroke-onset, the avoidance of the use of theophylline, penicillin and histamine $\mathrm{H}_{2}$-receptor antagonists during the first weeks following stroke-onset, and the avoidance of hypoglycaemia and the treatment of vitamin $B_{6}$ deficiency later on, are important prophylactic measures and, when taken in our patients, might possibly have prevented almost 30 per cent of the early-onset seizures and 40 per cent of the late-onset seizures.

The data from this thesis do not lend support to the feasibility of a controlled clinical trial to assess the value of prophylactic anti-epileptic drug treatment in patients who suffered a first supratentorial brain infarct. 



\title{
CHAPTER 8
}

\author{
Summary \\ Samenvatting
}




\section{Seizures following a first cerebral infarct}

\section{Risk factors and prognosis}

Post-stroke epilepsy is an important health care problem. concerning approximately twelve per cent of all epilepsy patients. Its importance will likely increase in the future, as the number of stroke victims will rise due to the ageing of the population. Post-stroke epilepsy is not a modern concept, the relationship between cerebrovascular disease and seizures has been recognized since 1864 , and many reports have been published since then. However, due to discrepancies in the literature many questions on post-stroke epilepsy still remain unanswered. Therefore this prospective study in adult patients with a first-ever supratentorial brain infarct was performed. to establish the frequency and prognosis of poststroke seizures, to identify clinical and CT-scan features increasing the risk of those seizures, and to provide rational guide-lines to lower the risk of post-stroke seizures.

In chapter 2 the frequency of supratentorial brain infarction as the cause of lateonset epilepsy in 680 patients with a first seizure after the age of twenty. registered in an epilepsy registry was studied retrospectively: $65(10 \%)$ had seizures following a symptomatic supratentorial brain infarct. Brain infarction as presumed cause of epilepsy was related with age at first seizure. First seizure occurred within one year after brain infarction in 62 per cent, and later than two years in 19 per cent. Eight of 14 patients $(57 \%)$ with an early seizure (within two weeks), and 28 of 41 patients $(68 \%)$ with a first seizure later than two weeks post-stroke had seizure recurrences despite anti-epileptic treatment. Of 38 patients who underwent computed tomography head scan (CT). $32(84 \%)$ had a cortical infarct, whereas six $(16 \%)$ had one or more lacunar infarcts. This may indicate that lacunar infarction may be associated with post-stroke epilepsy. Using a detailed topographic brain atlas to localize the cortical infarcts, it appeared that some gyri were more frequently involved, but "specific epileptogenic" gyri could not be identified. What factors predict future epilepsy in stroke patients has to be studied in prospective series of well-defined stroke subgroups.

Chapter 3 describes the "Patients and methods" of such a prospective study. During a five year intake period. 770 adult patients with a first-ever symptomatic supratentorial brain infarct were included in the study. They were followed for a median of almost two years. and 84 patients $(11 \%)$ developed post-stroke seizures (PSS) during follow-up. The first seizure occurred within two weeks following stroke-onset in one third of the patients, and in ninety per cent within the first two years. There was no predominance of one of the two sexes in developing PSS. however patients 75 years or older developed PSS significantly 
more often than younger patients. When seizures were divided in early-onset (within two weeks following stroke-onset) and late-onset seizures, these two seizure types seemed to represent two different types of epilepsy. Early-onset seizures occurred in 4 per cent of our patients after a very short delay: they occurred mainly in the first 48 hours after stroke. Late-onset seizures occurred in 8 per cent of the patients who survived the first two weeks after stroke-onset. Patients younger than 65 years developed only late-onset seizures, whereas in patients from 65 years and older the frequency of early-onset seizures increased with increasing age. Prognosis between early- and late-onset seizures was also different: early- onset seizures had a good prognosis, they were non-recurrent in 80 per cent, whereas late-onset seizures had a bad prognosis, they were recurrent in 48 per cent of the patients who survived the first two weeks after their first seizure, and especially in those younger than 65 years. However, seizures were not related to a higher mortality rate

In chapter 4 clinical features were studied in order to define "risk factors" that increase the risk of post-stroke seizures. All possible risk factors mentioned in the literature were studied in the 770 patients included in our prospective register. Because of various lengths of 'xposure time. Incidence Risk Ratio's were used to estimate the relative risk, and Cox regression analyses were performed to define the high risk groups. Early-onset and late-onset seizures represented two different types of epilepsy with different pathogenesis and risk factors. Early-onset seizures may be merely secondary to a variety of noncerebral disarrangements in the early phase following stroke, older patients being more sensitive for such disarrangements than younger patients. The presence of a cardiac source of embolism increases this risk, as cardiac emboli may disintegrate. and reperfusion damage may cause seizures. Such mechanism occurs shortly after stroke onset, and therefore probably does not play a role in the development of late-onset seizures, which may be regarded as "real" poststroke epilepsy caused by epileptic disturbances in cerebral "scar" tissue remaining from large territorial infarcts. Membrane instability of the injured brain cells, disturbances in the GABA-ergic inhibitory system, or in the action of receptors involved in excitatory brain activity, all disturbing the delicate balance between excitatory and inhibitory neural mechanisms in favour of excitation in such "scarred" brain foci. may be involved. The high risk group for developing early-onset seizures, with an eight times increased risk, were patients of 65 years or older, who had a cortical syndrome, a Rankin score $\geq 3$, and a potential cardiac source of embolism. Nineteen per cent of all patients at risk belonged to this high risk group. and 61 per cent of all patients with early-onset seizures could be predicted. The risk of late-onset seizures was more than eight times higher in patients with a cortical syndrome and a Rankin score $\geq 3$. Fifty-three per cent of all patients at risk belonged to this high risk group, and 86 per cent of all patients with late-onset seizures could be predicted, including 92 per cent of the patients with recurrent, difficult to treat seizures. 
In chapter 5 a sub-group of the patients registered in our register was studied. The occurrence of seizures in 322 patients with a first-ever $C T$-confirmed symptomatic territorial brain infarct involving the cortex was studied prospectively. Clinical and CT-scan features were studied to see whether infarction in certain brain areas would increase the risk of post-stroke seizures. Special attention was given to cortical infarct location. Fifty-four patients (17\%) developed post-stroke seizures. A distinction was made between early- and lateonset seizures, occurring within two weeks following stroke-onset, or later than two weeks, respectively. We found that paticnts of 65 years or older with a cardioembolic brain infarct involving the middle temporal or post-central gyrus. had an almost six times increased risk of early-onset scizures. Twenty-one per cent of all patients at risk belonged to this high risk group. and 64 per cent of all patients with early-onset seizures could be predicted. In the previous chapter a similar risk was found. Infarct location secmed to add no extra value to the prediction of the risk of early-onset seizures: early-onset seizures can be predicted from clinical fiatures alone. However the data showed that some brain areas are more epileptogenic than others. The high risk group for late-onset seizures. with a five times increased risk, were patients with a large brain infarct involving the supramarginal or superior temporal gyrus. Twenty-four per cent of all patients at risk belonged to this high risk group. and 49 per cent of all patients with late-onset seizures could be predicted. including half of the patients with recurrent seizures. In comparison with the high risk group from the previous chapter, infarct location reduced the high risk group from more than half to only one quarter of all patients, and is therefore useful in predicting the risk of lateonset seizures. Risk factors and epileptogenic cortical areas for post brain infarct seizures can be identified. however, they differ between early- and late-onset seizures. These data may influence treatment decisions in stroke patients.

In chapter 6 the influence of medication, other than anti-epileptic drugs, on the occurrence of post-stroke seizures is explored in all 770 patients. Theophylline use before stroke, and benzodiazepine withdrawal carly after stoke, increased the risk of early-onset seizures, whereas the occurrence of late-onset seizures was increased by the use of penicillins and histamine $\mathrm{H}_{2}$-receptor antagonists during the first weeks following stroke, by insulin induced hypoglycaemia and by vitamin $B_{6}$ deficiency. The high risk group with an almost 24 times increased risk for early-onset seizures appeared to be patients of 65 y'ears or older who had a cortical syndrome. a Rankin score $\geq 3$. ánd a potential cardiac source of embolism, and who had been using theophylline shortly before stroke-onset. or in whom the use of benzodiazepines had been abruptly discontinued early after stroke-onset. Only two per cent of the patients at risk belonged to this high risk group, and 25 per cent of all early-onset seizures could be predicted. The high risk group for late-onset seizures, with a six times increased risk. were patients with a cortical syndrome and a Rankin score $\geq 3$. who subsequently, during the 
first two weeks following their stroke. used at least one of the following four drugs: histamine $\mathrm{H}_{2}$-receptor antagonists, insulin, vitamin $\mathrm{B}$, or penicillins. Seventeen per cent of the patients at risk belonged to this high risk group, and 40 per cent of all late-onset seizures could be predicted, including 36 per cent of the patients with recurrent seizures. Although these findings may not be useful to predict a large number of patients that will develop post-stroke seizures, they provide us with some practical guide-lines to lower the risk of post-stroke seizures:

- benzodiazepines in patients with a brain infarct who had been using these drugs at home should not be withdrawn. Almost one third of the early-onset seizures may possibly be prevented by this measure alone!

- reluctance with the administration of theophylline in general is advisable, especially in stroke patients, and the lowest possible doses should be used when no alternative drugs for theophylline are possible

- the use of penicillins in stroke patients during the first weeks after strokeonset should be restricted; antibiotics from different classes are preferred

- the possibility of vitamin $B_{6}$ deficiency in elderly stroke patients deserves attention; $\mathrm{B}_{6}$ should be measured regularly and deficiency treated adequately

- be aware of hypoglycaemia, especially in diabetics who are treated with insulin

- histamine $\mathrm{H}_{2}$-receptor antagonists, especially ranitidine, should not be prescribed in patients with a brain infarct: a gastric acid secretion inhibitor with a different mode of action is preferred

When these "prophylactic actions" had been taken in our patients forty per cent of the late-onset seizures could have possibly been prevented.

In chapter 7, the general conclusion, it was concluded that early-onset and lateonset seizures represent two different types of epilepsy, with different pathogenesis, different prognosis, specific risk factors, and epileptogenic cortical areas. Early- and late-onset seizures can be predicted rather reliably with the help of clinical features. Patients' medical history and neurological examination early after stroke-onset provide sufficient information to predict 60 per cent of the carly-onset seizures and 86 per cent of the late-onset seizures. However. prophylactic treatment with anti-epileptic drugs seems not feasible. Early-onset seizures occur too early, and have a tendency to resolve spontaneously. A sccond or even a third seizure may be awaited before AED treatment is started. In late-onset seizures however, AED treatment has to be started after the first seizure in a sufficient high dose. The administration of AED's should not be delayed until an eventual second seizure, because this sccond seizure is likely to occur. Fortunately, other "prophylactic measures" can be taken: continuation of benzodiazepine use early after stroke-onset, the avoidance of the use of theophylline, penicillin and histamine $\mathrm{H}_{2}$-receptor antagonists during the first weeks following stroke-onset, and the avoidance of hypoglycaemia and the treatment of vitamin $\mathrm{B}_{6}$ deficiency later on. 


\title{
Epileptische insulten na een eerste herseninfarct
}

\author{
Risicofactoren en prognose
}

Ongeveer twaalf procent van alle epilepsie patiënten heeft epilepsie gekregen na een beroerte (de zogenaamde post-CVA epilepsie). Omdat door de vergrijzing van de bevolking het aantal patiënten dat getroffen wordt door een beroerte zal toenemen, zal het belang van post-CVA epilepsie in de toekomst hoogstwaarschijnlijk ook toenemen. Post-CVA epilepsie is geen modern begrip, de relatie tussen cerebrovasculaire aandoeningen en epileptische insulten is al bekend sinds 1864 en sindsdien zijn vele artikelen over dit onderwerp gepubliceerd. Echter, als gevolg van de tegenstrijdigheden in de literatuur blijven er nog veel vragen betreffende post-CVA epilepsie onbeantwoord. Daarom werd deze prospectieve studie onder volwassenen met een eerste supratentorieel herseninfarct uitgevoerd. De doelstellingen waren: 1) de frequentie en de prognose van epileptische insulten na een herseninfarct vast te stellen, 2) te bepalen welke klinische en radiologische kenmerken het risico op deze insulten verhogen. 3) te komen tot bruikbare richtlijnen ter verlaging van het risico op epileptische insulten na een herseninfarct.

In hoofdstuk 2 werd het vórkomen van een supratentorieel herseninfarct als oorzaak voor epilepsie op latere leeftijd retrospectief bestudeerd in 680 epilepsie patiënten, geregistreerd in een epilepsie register, die hun eerste insult hadden doorgemaakt na het twintigste levensjaar: 65 (10\%) van hen hadden insulten na een symptomatisch supratentorieel herseninfarct. De frequentie van het herseninfarct als veronderstelde oorzaak van de epileptische insulten nam toe naarmate de leeftijd waarop het eerste insult optrad hoger werd. Bij 62 procent van de patiënten trad het eerste insult binnen een jaar na het herseninfarct op en bij 19 procent pas na meer dan twee jaar. Ondanks een behandeling met antiepileptica bleven acht van de 14 patiënten ( $57 \%$ ) met een eerste vroeg-optredend insult (binnen twee weken na het herseninfarct), en 28 van de $41(68 \%)$ met een eerste laat-optredend insult (later dan twee weken na het herseninfarct) epileptische aanvallen houden. Van de 38 patiënten bij wie een CT-scan werd verricht, hadden 32 patiënten $(84 \%)$ een corticaal infarct, terwijl zes patiënten (16\%) één of meerdere lacunaire infarcten hadden. Dit zou kunnen betekenen dat lacunaire infarcten ook geassocieerd kunnen zijn met post-CVA epilepsie. Met behulp van een gedetailleerde typografische hersenatlas werden de corticale infarcten gelokaliseerd; sommige gebieden waren weliswalar vaker aangedaan. maar "specifieke epileptogene" gebieden konden niet worden ontdekt. De conclusie is dat de vraag welke factoren het optreden van epileptische insulten na een beroerte kunnen voorspellen. moet worden bestudecrd in wn prospectieve studie met een goed gedefinieerde patiëntengroep. 
Hoofdstuk 3 beschrijft de methodologie van een dergelijke prospectieve studie. Gedurende een periode van vijf jaar werden 770 volwassenen met een eerste symptomatisch supratentorieel herseninfarct ingesloten in de studie. Zij werden bijna twee jaar gevolgd (mediane follow-up duur) en 84 van hen (11\%) kregen epilepsie gedurende deze periode. Een derde van hen kreeg het eerste insult binnen twee weken na het herseninfarct, 90 procent binnen twee jaar. Mannen en vrouwen hadden een gelijke kans op post-CVA epilepsie. Leeftijd was echter wel een risicofactor: patiënten van 75 jaar en ouder kregen significant vaker epileptische insulten na hun herseninfarct dan patiënten die jonger waren. Nadat de epileptische aanvallen werden verdeeld in vroeg-optredende (binnen twee weken na het herseninfarct) en laat-optredende insulten (later dan twee weken na het herseninfarct), bleken dit twee verschillende soorten epilepsie te zijn. Vier procent van de patiënten maakte vroege insulten door na hun herseninfarct; deze insulten traden met name in de eerste 48 uur na het herseninfarct op. Acht procent van de patiënten die langer dan twee weken na hun herseninfarct overleefden, kreeg late insulten. De patiënten jonger dan 65 kregen alleen late insulten, terwijl van de patiënten van 65 jaar en ouder het percentage dat vroege insulten kreeg, toenam met het stijgen van de leeftijd. Ook de prognose van vroege en late insulten was verschillend: vroege insulten hadden een goede prognose: 80 procent van de patiënten was binnen twee weken na het eerste insult aanvalsvrij. Late insulten hadden een slechte prognose: van de patiënten die de eerste twee weken na het eerste epileptisch insult hadden overleefd, bleef 48 procent aanvallen houden, met name de patiënten jonger dan 65 jaar. Patiënten met insulten hadden geen verhoogde kans om te overlijden.

In hoofdstuk 4 werd onder de klinische kenmerken van de patiënten gezocht naar factoren die het risico op epileptische insulten na een herseninfarct verhogen. Alle risicofactoren die in de literatuur genoemd zijn, werden bestudeerd in de 770 patiënten uit onze prospectieve registratie. Omdat in deze studie de lengte van de tijd gedurende welke een patiënt rísico liep op het krijgen van epileptische insulten na een herseninfarct (duur blootstelling) varieerde, werden Incidence Risk Ratio's gebruikt om het relatief risico te berekenen, en Cox regressie analyses om de risicofactoren te identificeren. Vroeg-optredende en laat-optredende insulten bleken twee verschillende soorten epilepsie te vertegenwoordigen met verschillende pathogenese en risicofactoren. Vroege insulten zijn waarschijnlijk een gevolg van allerlei niet-cerebrale ontregelingen die in de vroege fase na een herseninfarct optreden en waarvoor oudere patiënten veel gevoeliger zijn dan jonge patiënten. De aanwezigheid van een cardiale emboliebron als mogelijke oorzaak voor het herseninfarct vergroot het risico extra, omdat cardiale emboliën uiteen kunnen vallen, waarna reperfusie-schade optreedt met als gevolg epileptische insulten. Omdat dit mechanisme kort na het optreden van het herseninfarct plaatsvindt. speelt het waarschijnlijk geen rol bij het ontstaan van de late insulten. Late insulten mocten ecrder worden beschouwd als "echte" epilepsie, veroorzaakt door epileptixthe ontladingen in cerebrale 
littekens die ontstaan zijn na grote corticale infarcten. Hierbij moet gedacht worden aan membraan-instabiliteit van de beschadigde hersencellen, stoornissen in het GABA-gestuurde remmende systeem en stoornissen in de werking van de receptoren die betrokken zijn bij neuronale excitatie, waardoor de gevoelige balans tussen neuronale excitatie en inhiberende neurale mechanismen wordt verstoord ten gunste van de neuronale excitatie. Patiënten van 65 jaar of ouder met een corticaal syndroom, een Rankin score $\geq 3$, en een potentiële cardiale emboliebron, vormden de risicogroep voor het krijgen van vroege insulten, met een acht maal verhoogde kans. Negentien procent van alle patiënten behoorde tot deze risicogroep. Deze combinatie van risicofactoren voorspelde 61 procent van alle patiënten met vroege insulten. Het risico op late insulten was meer dan acht maal hoger voor patiënten met een corticaal syndroom en bij opname een Rankin score $\geq 3$. Drieënvijftig procent van alle patiënten behoorde tot deze risicogroep. Deze combinatie van risicofactoren voorspelde 86 procent van alle patiënten met late insulten, onder wie 92 procent van de patiënten met recidiverende, moeilijk te behandelen insulten.

In hoofdstuk 5 werd het optreden van epileptische insulten in 322 patiënten met een eerste, CT-bevestigd, symptomatisch cortical herseninfarct beschreven. Klinische en radiologische kenmerken werden bestudeerd met de vraag of infarcering van bepaalde hersengebieden het risico op epileptische insulten na een herseninfarct verhoogde. Speciale aandacht werd besteed aan de exacte corticale lokalisatie van de infarcten. Vierenvijftig patiënten (17\%) kregen epileptische insulten na hun herseninfarct. Er werd onderscheid gemaakt tussen vroege en late insulten, respectievelijk optredend binnen twee weken na het herseninfarct, of later dan twee weken na het herseninfarct. We vonden dat patiënten van 65 jaar of ouder met een cardioembolisch herseninfarct, waarbij de gyrus temporalis medius of de gyrus postcentralis was betrokken. een bijna zes maal verhoogd risico hadden op het krijgen van vroege insulten. Eenentwintig procent van alle patiënten behoorde tot deze risicogroep. Deze combinatie van risicofactoren voorspelde 64 procent van alle patiënten met vroege insulten. In het vorige hoofdstuk werd ongeveer hetzelfde risico gevonden. Infarctlokalisatie bleek geen extra bijdrage te leveren aan de voorspelbaarheid van het risico op vroege insulten: vroege insulten kunnen worden voorspeld aan de hand van klinische kenmerken. De uitkomst van deze studie toonde echter wel aan dat sommige hersengebieden epileptogener zijn dan andere. De risicogroep met een vijf maal verhoogd risico op het krijgen van late insulten werd gevormd door de patiënten met een groot herseninfarct waarbij de gyrus supramarginalis of de gyrus temporalis superior betrokken was. Vierentwintig procent van alle patiënten behoorde tot deze risicogroep. Deze combinatie van risicofactoren voorspelde 49 procent van alle patiënten met late insulten. onder wie de helft van de patiënten met recidiverende aanvallen. In vergelijking met de risicogroep uit het vorige hoofdstuk. werd de groep met een hoog risico verkleind van meer dan de helft van alle patiënten tot slechts een kwart van hen. Het kenmerk "infarct- 
lokalisatie" is derhalve bruikbaar voor het voorspellen van het risico op late insulten. Risicofactoren en epileptogene corticale gebieden voor het optreden van epileptische insulten na een herseninfarct kunnen worden aangewezen, maar zijn verschillend voor de vroege en voor de late insulten.

In hoofdstuk 6 werd in alle 770 geregistreerde patiënten onderzocht of andere medicijnen dan anti-epileptica invloed hebben op het optreden van epileptische insulten na cen herseninfarct. Patiënten die vóor het herseninfarct theofylline gebruikten, hadden meer kans op het krijæren van vroege insulten. Patiënten die vóór het herseninfarct benzodiazepinen grcbruikt hadden, waarvan de toediening kort na het herseninfarct gestaakt wils, hadden eveneens een verhoogde kans op vroege insulten. Het risico op late insulten bleek te worden verhoogd door het gebruik van penicillines en histamine $\mathrm{H}_{2}$-receptor antagonisten gedurende de eerste twee weken na het herseninfarct, door hypoglycaemie bij insuline gebruik en door vitamine $\mathrm{B}_{6}$-deficiëntie. Patiënten van 65 jaar of ouder met een corticaal syndroom, een Rankin score $\geq 3$ en een cardiale emboliebron, die theofylline gebruikt hadden voor hun herseninfarct, of benzodiazepinen waarvan de toediening plotseling gestaakt was na het herseninfarct, hadden een bijna 24 maal verhoogd risico op het krijgen van vroege insulten. Slechts twee procent van alle patiënten behoorde tol deze risicogroep. Deze combinatie van risicofactoren voorspelde 25 procent van alle patiënten met vroege insulten. De risicogroep met een zes maal verhoogd risico op het krijgen van late insulten werd gevormd door de patiënten met een corticaal syndroom en een Rankin score $\geq 3$. die gedurende de eerste twee weken na hun herseninfarct behandeld werden met tenminste één van de volgende vier medicamenten: histamine $\mathrm{H}_{2}$-receptor antagonisten, insuline, vitamine $\mathrm{B}$, of penicillines. Zeventien procent van alle patiënten behoorde tot deze risicogroep. Deze combinatie van risicofactoren voorspelde 40 procent van alle patiënten met late insulten, onder wie 36 procent van de patiënten met recidiverende aanvallen.

Deze bevindingen geven enkele praktische richtlijnen ter verlaging van het risico op epileptische insulten na icn eerste herseninfarct:

- benzodiazepine-gebruik bij patiënten met een herseninfarct, die deze middelen thuis gebruikten. dient te worden gecontinueerd. Bijna een derde van de vroege insulten had mogelijk voorkomen kunnen worden door deze maatregel!

- terughoudendheid is geboden bij het voorschrijven van theofylline in het algemeen, maar met name bij patiënten die een herseninfarct hebben doorgemaakt. Indien er geen alternatief voor theolylline is, dient de laagst mogelijke dosering te worden voorgeschreven

- het gebruik van penicillines gedurende de eerste weken na een herseninfarct dient zoveel mogelijk te worden vermeden; de voorkeur moet worden gegeven aan antibiotica met een ander werkingsmechanisme 
- de mogelijkheid van een vitamine $\mathrm{B}_{6}$-deficiëntie in oudere patiënten met een herseninfarct dient overwogen te worden; $\mathrm{B}_{6}$ moet regelmatig worden bepaald en een gevonden deficiëntie dient adequaat te worden behandeld

- de mogelijkheid van een hypoglycaemie dient te worden overwogen, met name bij diabetici die behandeld worden met insuline

- histamine $\mathrm{H}_{2}$-receptor antagonisten, met name ranitidine. dienen niet te worden voorgeschreven aan patiënten die een herseninfarct hebben doorgemaakt; bij voorkeur dient gebruik gemaakt te worden van een maagzuur secretie remmer met een ander werkingsmechanisme

Wanneer deze "profylactische maatregelen" bij on « patiënten waren genomen. zou mogelijkerwijs veertig procent van de late insulten voorkomen hebben kunnen worden.

Hoofdstuk 7: Vroege en late insulten vertegenwoordigen twee verschillende soorten epilepsie met een verschillende pathogenese. een verschillende prognose. specifieke risicofactoren en verschillende epileptogene corticale gebieden. Vroege en late insulten kunnen redelijk betrouwbaar worden voorspeld met behulp van klinische kenmerken. De medische voorgeschiedenis van de patiënt, de anamnese en het neurologisch onderzoek kort na het optreden van het herseninfarct leveren voldoende informatie op om 60 procent van de vroege en 86 procent van de late insulten te kunnen voorspellen. Desondanks is w'n profylactische behandeling met anti-epileptica niet aangewezen. Vroege insulten treden te snel na het herseninfarct op en verdwijnen spontaan. Een lucede of zelfs een derde insult kan worden afgewacht voordat een behandeling met anti-epileptica wordt gestart. Na een laat insult is het echter aangewezen behandeling met anti-epileptica direct na het optreden van het eerste insult in een voldoende hoge dosering te starten, omdat een tweede insult zeer waarschijnlijk zal optreden.

Gelukkig kunnen er een aantal andere maatregelen worden genomen om het risico op epileptische insulten na een herseninfarct te verkleinen: continueren van de behandeling met benzodialzepinen na het ontstaan van een herseninfarct, het vermijden van het gebruik van theofylline. penicillines en histamine $\mathrm{H}_{2}$-receptor antagonisten gedurende de esrste weken na het herseninfarct. het voorkomen van hypoglycaemicën. en het behandelen van vitamine $\mathrm{B}_{6}$-deficiënties na het herseninfarct. 


\section{APPENDIX}

\section{The "Modified Rankin Scale"}

Grade $0=$ No symptoms

Grade $1=$ Minor symptoms which do not interfere with lifestyle

Grade 2 = Minor handicap - symptoms which lead to some restriction in lifestyle but do not interfere with the patient's capacity to look after himself

Grade 3 = Moderate handicap - symptoms which significantly restrict lifestyle and prevent totally independent existence

Grade $4=$ Moderately severe handicap - symptoms which clearly prevent independent existence though not needing constant attention

Grade 5 = Severe handicap - totally dependent requiring constant attention night and day

Grades 0,1 , and 2 are considered: Functionally totally independent Grades 3, 4, and 5 are considered: Functionally dependent 



\section{REFERENCES}

I. Ahrens RC. Theophylline - Down but not yet out. J Asthma 1995; 32: 8587.

2. Ahuja GK, Mohanta A. Late onset epilepsy. A prospective study. Acta Neurol Scand 1982; 66: 216-226.

3. Aird RB, Masland RL, Woodbury DM. Neurobiologic substrates of epilepsy. In: Aird RB, Masland RL, Woodbury DM. The Epilepsies. A critical review. Raven Press, New York, 1984; pp 1-42.

4. Akaike N, Inomata N, Tokutomi N. Contribution of chloride shifts to the fade of $\gamma$-aminobutyric acid-gated currents in frog dorsal root ganglion cells. J Physiol 1987; 391: 219-234.

5. Allen CMC. Clinical diagnosis of the acute stroke syndrome. Q J Med, New Series LII 1983; 208: 515-523.

6. Ang RT, Utterback RA. Seizures with onset after forty years of age; role of CVD. Southern Medical Journal 1966; 59: 1404-1408.

7. Antoniadis A. Müller WE. Wollert U. Benzodiazepine receptor interactions may be involved in the neurotoxicity of various penicillin derivatives. Ann Neurol 1980; 8: 71-73.

8. Aring $\mathrm{CD}$, Merritt $\mathrm{HH}$. Differential diagnosis between cerebral hemorrhage and cerebral thrombosis. A clinical and pathologic study of 245 cases. Arch Int Med 1935: 56: 435-456.

9. Avrahami E. Drory VE, Rabey MJ, Cohn DF. Generalized epileptic seizures as the presenting symptom of lacunar infarction in the brain. J Neurol 1988; 235: 472-474.

10. Bahls FH, Ma KK, Bird TD. Theophylline-associated seizures with "therapeutic" or low toxic serum concentrations: Risk factors for serious outcome in adults. Neurology 1991; 41: 1309-1312.

11. Bamford J, Sandercock P, Jones L. Warlow C. The natural history of lacunar infarction: The Oxfordshire Community Stroke Project. Stroke 1987; 18: 545-551.

12. Bamford J, Sandercock P. Dennis M. Warlow C, Jones L, McPherson K, Vessey M, Fowler G, Molyneux A, Hughes T, Burn J, Wade D. A prospective study of acute cerebrovascular disease in the community: The Oxfordshire Community Stroke Project 1981-86. 1. Methodology, demography and incident cases of first-ever stroke. J Neurol Neurosurg Psychiatry 1988: 51: 1373-1380.

13. Bamford JM, Sandercock PAG. Warlow CP. Slattery J. Interobserver agreement for the assessment of handicap in stroke patients. Stroke 1989; 20: 828 .

14. Bamford J, Sandercock P, Dennis M, Burn J, Warlow C. A prospective study of acute cerebrovascular disease in the community: The Oxfordshire 
Community Stroke Project 1981-86. 2. Incidence, case fatality rates and overall outcome at one year of cerebral infarction. primary intracerebral and subarachnoid haemorrhage. J Neurol Neurosurg Psychiatry 1990; 53: 16-22.

15. Banner AS. Theophylline: should we discard an old friend? Lancet 1994; 343: 618 .

16. Barry E, Hauser WA. Status epilepticus: The interaction of epilepsy and acute brain disease. Neurology 1993; 43: 1473-1478.

17. Berger AR, Lipton RB, Lesser ML, Lantos G. Portenoy RK. Early seizures following intracerebral hemorrhage: implications for therapy. Neurology 1988: 38: 1363-1365.

18. Bertino JS, Walker JW. Reassessment of theophylline toxicity. Serum concentrations, clinical course, and treatment. Arch Intern Med 1987; 147: 757-760.

19. Black SE, Norris JW, Hachinski VC. Post-stroke seizures. Stroke 1983; 14: 134.

20. Bladin CF, Johnston PJ, Norris JW for the Seizures after Stroke Study Group. Scizures after stroke. Stroke 1993; 24: 172.

21. Bladin CF. Seizures in the elderly. Neurology 1994: 44: 194.

22. Bladin CF. Chaudhari P. Black S, Norris JW for the Scizures after Stroke Study Group. The cortical localisation of seizure after ischemic stroke. Stroke 1995; 26: 159.

23. Bogounslarsky J, Van Melle G. Regli F. The Lausanne stroke registry: analvsis of 1.000 consecutive patients with first stroke. Stroke 1988: 19: $1083-1092$.

24. Boguusslarsky J. Martin R. Regli F. Despland PA, Bolyn S. Persistent worsening of stroke sequelae after delayed seizures. Arch Neurol 1992; 49: 385-388.

25. Boiten J, Lodder J. Lacunar infarcts. Pathogenesis and validity of the clinical syndromes. Stroke 1991; 22: 1374-1378.

26. Boon A, Lodder J. Heuts-ran Raak L, Kessels F. Silent brain infarcts in 755 consecutive patients with a first-ever supratentorial ischemic stroke. Relationship with index-stroke subtype, vascular risk factors, and mortality. Stroke 1994; 25: 2384-2390.

27. Bories J. Derhy S, Chiras J. CT in hemispheric ischaemic attacks. N.uroladiology 1985: 27: 468-483.

28. Brailowsky S. Knight RT. Etron R. Phenytoin increases the severity of cortical hemiplegia in rats. Brain Research 1986; 376: $71-77$.

29. Burdette DF., Foulkes MA. Wolf PA. Kase CS. Hier DB. Price TR. Mohr IP. The incidence of post-stroke seizures in the NINDS stroke data bank. In: Abstracts from the International Stroke Society Second World Congress of Stroke. Wilshington. September 8-12, 1992: S46.

30. Butcher SP, Sandberg M, Hagberg H. Hamberger A. Cellular origins of endogenous amino acids released into the extracellular fluid of the rat 
striatum during severe insulin-induced hypoglycemia. J Neurochem 1987; 48: $722-728$.

31. Calcutt CR. The role of histamine in the brain. Gen Pharmac 1976; 7: 1525.

32. Caplan LR. Carotid artery disease. N Engl J Med 1986; 315: 886-888.

33. Caveness WF. Epilepsy. a product of trauma in our time. Epilepsia 1976; 17: 207-215.

34. Cazzato G, Zorzon M, Masè G, Iona LG. Hyperglycemia at ischemic stroke onset as prognostic factor. Ital J Neurol Sci 1991; 12: 283-288.

35. Celesia GG. Modern concepts of status epilepticus. JAMA 1976; 235: $1571-1574$.

36. Cocito L, Favale E. Reni L. Epileptic seizures in cerebral arterial occlusive disease. Stroke 1982; 13: 189-195.

37. Cocito L, Favale E, Reni L. The frequency, characteristics and prognosis of epileptic seizures at the onset of stroke. J Neurol Neurosurg Psychiatry 1989; 52: 292.

38. Cocito L, Anfosso S, Nizzo R, Favale E. Hypertension and seizures. Neurology 1994; 44: 780 .

39. Commission on classification and terminology of the International League Against Epilepsy. Proposal for revised clinical and EEG classification of epileptic seizures. Epilepsia 1981; 22: 489-501.

40. Covelli HD, Knodel AR. Heppner BT. Predisposing factors to apparent theophylline-induced seizures. Ann Allergy 1985; 54:411-415.

41. Cristostomo EA, Duncan PW, Propst M. Dawson DV, Davis JN. Evidence that amphetamine coupled with physical therapy promotes recovery of motor function in stroke patients. Ann Neurol 1988; 23: 94-97.

42. Daly LE, Bourke GJ, McGilvray J. Interpretation and uses of medical statistics. Fourth Edition. Blackwell Scientific Publications, Oxford, 1992.

43. Daniele O, Mattaliano A, Tassinari CA, Natalè E. Epileptic seizures and cerebrovascular disease. Acta Neurol Scand 1989; 80: 17-22.

44. Daras M, Tuchman AJ, Strobos RJ. Computed tomography in adult-onset epileptic seizures in a city hospital population. Epilepsia 1987: 28: 519522.

45. Dávalos A, Cendra de E, Molins A, Ferrandiz M, Lopez-Pousa S, Genís D. Epileptic seizures at the onset of stroke. Cerebrovasc Dis 1992, 2: 327-331.

46. De Carolis P, D'Alessandro R, Ferrara R, Andreoli A, Sacquegna T, Lugaresi E. Late seizures in patients with internal carotid and middle cerebral artery occlusive disease following ischaemic events. J Neurol Neurosurg Psychiatry 1984:47: 1345-1347.

47. De Reuck J, Krahel N, Sieben G, Orban L, de Coster W, vander Eecken H. Epilepsy in patients with cerebral infarcts. J Neurol 1980; 224: 101-109.

48. Dennis MS. Bamford JM. Molyncux AJ. Warlow CP. Rapid resolution of signs of primary intracerebral haemorrhage in computer tomograms of the brain. Br Med J 1987: 295: 379-381. 
49. Dodge PR, Richardson EP Jr, Victor M. Recurrent convulsive seizures as a sequel to cerebral infarction: a clinical and pathological study. Brain 1954; 77: 610-638.

50. Douglas EF, White PT, Nelson JW. Three per second spike-wave in digitalis toxicity. Report of a case. Arch Neurol 1971; 25: 373-375.

51. Drury I, Beydoun A. Seizure disorders of aging: Differential diagnosis and patient management. Geriatrics 1993; 48: 52-58.

52. Ettinger AB, Shinnar $\mathrm{S}$. New-onset seizures in an elderly hospitalized population. Neurology 1993; 43: 489-492.

53. Ettinger AB. Structural causes of epilepsy. Tumors, cysts, stroke, and vascular malformations. Neurologic Clinics 1994; 12:41-56.

54. Faught E, Peters D. Seizures in intracerebral hemorrhage. Epilepsia 1984; 25: 666.

55. Faught E, Peters D, Bartolucci A. Moore L, Miller PC. Seizures after primary intracerebral hemorrhage. Neurology 1989; 39: 1089-1093.

56. Feeney DM, Walker AE. The prediction of posttraumatic epilepsy. A mathematical atpproach. Arch Neurol 1979; 36: 8-12.

57. Feeney DM. Gonzalez A, Law WA. Amphetamine, haloperidol, and experience interact to affect the rate of recovery after motor cortex injury. Science 1982; 217: 855-857.

58. Fentz V. Epileptic seizures in patients with cerebrovascular accidents. Nord Med 1971; 86:1023-1025.

59. Fine W. Epileptic syndromes in the elderly. Geront clin 1966: 8: 121-133.

60. Fine W. Post-hemiplegic epilepsy in the elderly. Br Med J 1967; 1: 199201.

61. Fish DR, Miller DH, Roberts RC. Blackie JD, Gilliatt RW. The natural history of late-onset epilepsy secondary to vascular disease. Acta Neurol Scand 1989; 80: 524-526.

62. Fisher CM. Lacunar strokes and infarcts: A review. Neurology 1982: 32: 871-876.

63. Foulkes MA. Wolf PA, Price TR, Mohr JP. Hier DB. The Stroke Data Bank: Design, methods, and baseline characteristics. Stroke 1988; 19: $547-$ 554.

64. Franke CL. Van Swieten JC, Van Gijn J. Residual lesions on CT after intracerebral hemorthage. Stroke 1991: 22: 1530-1533.

65. Garcia PA. Alldredge BK. Drug-induced seizures. Neurologic Clinics 1994: 12: 85-99.

66. Gilhotra R. Malik SK, Singh S. Sharma BK. Acute isoniazid toxicity. Report of 2 cases and review of literature. Int J Clin Pharmacol Ther Toxicol 1987: 25: 259-261.

67. Giroud M. Beuriat P. Vion P. D'Athis PH. Dusserre L. Dumas R. Stroke in a French prospective population study. Neuroepidemiology 1989: 8: 97 104.

68. Giroud M. Milan C. Beuriat P. Gras P. Essayagh E. Arveux P. Dumas R. 
Incidence and survival rates during a two-year period of intracerebral and subarachnoid haemorrhages, cortical infarcts, lacunes and transient ischaemic attacks. The Stroke Registry of Dijon: 1985-1989. Int J Epidemiol 1991; 20: 892-899.

69. Giroud M, Gras P, Fayolle H, André N, Soichot P, Dumas R. Early seizures after acute stroke: A study of 1,640 cases. Epilepsia 1994; 35: 959-964.

70. Goldstein LB, Davis IN. Physician prescribing patterns following hospital admission for ischemic cerebrovascular disease. Neurology 1988; 38: 1806-1809.

71. Goldstein LB. Amphetamine-facilitated functional recovery after stroke. In: Ginsberg MD, Dietrich WD, eds. Cerebrovascular diseases. Sixteenth Research (Princeton) Conference. Raven Press, New York, 1989; pp 303308.

72. Goldstein LB, Davis JN. Clonidine impairs recovery of beam-walking in rats. Brain Res 1990; 508: 305-309.

73. Goldstein LB, Matchar DB, Morgenlander JC, Davis JN. Drugs influence the recuvery of function after stroke. Stroke 1990; 21: 179.

74. Goldstein LB. Davis JN. Restorative Neurology. Drugs and recovery following stroke. Stroke 1990; 21: 1636-1640.

75. Goldstein LB, and the Sygen in Acute Stroke Study Investigators. Common drugs may influence motor recovery after stroke. Neurology 1995; 45: 865-871.

76. Goodridge DMG. Shorvon SD. Epileptic seizures in a population of 6000 . I Demography. diagnosis and classification, and role of hospital services. Br Med J 1983: 287: 641-644.

77. Gowers WR. Epilepsy and other chronic convulsive diseases: their causes, symptoms, and treatment. Wm Wood \& Co., New York, 1885. J and A Churchill. London. 1901. Dover Publications Inc., New York. 1964. Cited by: Kilpatrick (100), Lesser (107), Louis (113). Milandre (126) and Richardson ( 146).

78. Graham SH, Shiraishi K. Panter SS, Simon RP, Faden AI. Changes in extracellular amino acid neurotransmitters produced by focal cerebral ischemia. Neurosci Lett 1990: 110: 124-130.

79. Grondahl Tø. Langmoen IA. Epileptogenic effect of antibiotic drugs. J Neurosurg 1993: 78: 938-943.

80. Gupta SR. Naheedy MH, Elias D, Rubino FA. Postinfarction seizures. A clinical study. Stroke 1988; 19: 1477-1481.

81. Hankey GJ. Prolonged exacerbation of the neurological sequelae of stroke by post-stroke partial epileptic seizures. Aust NZ J Med 1993; 23: 306.

82. Hauser WA. Kurland LT. The epidemiology of epilepsy in Rochester, Minnesota. 1935 through 1967. Epilepsia 1975; 16: 1-66.

83. Hauser WA, Ramiru-Lasscpas M, Rosenstein R. Risk for seizures and epilepsy following curebrovascular insults. Epilepsia 1984; 25: 666.

84. Heinemann U, Jones RSG. Neurophysiology. In: Comprehensive 
Epileptology (Eds M. Dam and L. Gram). Raven Press, New York, 1990; pp 17-42.

85. Henny C, Despland PA, Regli F. Première crise épileptique après l'âge de 60 ans: étiologie, présentation clinique et EEG. Schweiz med Wschr 1990; 120: 787-792.

86. Herman B, Leyten ACM, van Luyk JH, Frenken CWGM, Op de Coul AAW, Schulte BPM. Epidemiology of stroke in Tilburg, the Netherlands. The population-based stroke incidence register: 2. Incidence, initial clinical picture and medical care. and three-week case fatality. Stroke 1982; 13: 629-634.

87. Heuts-van Raak EPM, Boellaard A, de Krom MCTFM, Lodder J. Supratentorial brain infarcts in adult-onset seizures; the Maastricht Epilepsy Case Register. Seizure 1993: 2: 221-227.

88. Hildick-Smith M. Epilepsy in the elderly. Age Ageing 1974; 3: 203-208.

89. Hirtz DG, Nelson KB. Cognitive effects of antiepileptic drugs. In: Pedley TA, Meldrum BS, eds. Recent advances in epilepsy. Churchill Livingstone, New York, 1985; pp 161-181.

90. Holmes GL. The electroencephalogram as a predictor of seizures following cerebral infarction. Clin Electroencephalogr 1980; I I: 83-86.

91. Homer D, Groothuis DR. Stroke and the blood-brain barrier. Current Opinion in Neurology and Neurosurgery 1991; 4: 891-895.

92. Hornig CR, Büttner T, Hufnagel A, Schröder-Rosenstock K, Dorndorf W. Epileptic seizures following ischaemic cerebral infarction. Clinical picture. CT findings and prognosis. Eur Arch Psychiatr Neurol Sci 1990; 239: 379383.

93. Humphrey P. Stroke and transient ischaemic attacks. J Neurol Neurosurg Psychiatry 1994; 57: 534-543.

94. Hurwitz BE, Dietrich WD. McCabe PM. Alonso O, Watson BD, Ginsberg MD, Schneiderman N. Amphetamine promotes recovery from sensorymotor integration deficit after thrombotic infarction of the primary somatosensory rat cortex. Stroke 1991: 22: 648-654.

95. Inzitari D, Diaz F, Fox A, Hachinski VC, Steingart A. Lau C. Donald A, Wade J. Mulic H. Merskey H. Vascular risk factors and leuko-araiosis. Arch Neurol 1987: 44: 42-47.

90. Isaacson SH. Carr J. Rowan AJ. Ciprofloxacin-induced complex partial status epilepticus manifesting as an acute confusional state. Neurology $1993 ; 43$ : 1619-1621.

97. Jackson JH. Epileptiform convulsions from cerebral disease. In: Taylor J. Holmes G. Walshe FMR, eds. Selected writingrs of John Hughlings Jackson on epilepsy and epileptiform convulsion. Hodder and Stoughton Ltd. London. 1931, Volume 1. Cited by: Gupta (80). Holmes (90). Kilpatrick (101), Lesser (107) and Richardson (146).

98. Johnston IDA. Theophylline in the management of airflow obstruction. 2. Dilficult drugs to use. few clinical indications. Br Med J 1990; 300: 929-931. 
49. Juul-Jensen P. Epilepsy: A clinical and social analysis of 1020 adult patients with epileptic seizures. Chapter II: Pathogenesis and prognosis. Acta Neurol Scand 1964; 40 (suppl 5): 26-46.

100. Kilpatrick CJ, Davis SM, Tress BM, Rossiter SC, Hopper JL, Vandendriesen ML. Epileptic seizures in acute stroke. Arch Neurol 1990; 47: $157-160$.

101. Kilpatrick CJ. Davis SM. Hopper JL, Rossiter SC. Early seizures after acute stroke. Risk of late seizures. Arch Neurol 1992; 49: 509-511.

102. Kotila M. Waltimo O. Epilepsy after stroke. Epilepsia 1992; 33: 495-498.

103. Kuy van der A. editor. Farmacotherapeutisch Kompas 1995. Medische Farmaceutische Voorlichting. Uitgave van de Centrale Medisch Pharmaceutische Commissie van de ZiekenfondsRaad, Amstelveen, 1995.

104. Lancman ME. Golimstok A, Norscini J, Granillo R. Risk factors for developing seizures after a stroke. Epilepsia 1993; 34: 141-143.

105. Laurence DR, Bennett PN. Clinical Pharmacology. Seventh Edition. Churchill Livingstone, Lundon. 1992.

106. LeMay DR, Gehua L, Zelenock GB, D'Alecy LG. Insulin administration protects neurologic function in cerebral ischemia in rats. Stroke 1988; 19: 1411-1419.

107. Lesser RP, Lüders H, Dinner DS, Morris HH. Epileptic seizures due to thrombotic and embolic cerebrovascular disease in older patients. Epilepsia 1985: 26: 622-630.

108. Levy RH, Dreifuss FE, Mattson RH. Meldrum BS, Penry JK, eds. Antiepileptic Drugs. Third Edition. Raven Press, New York, 1989.

109. Lisdonk van de EH, Bosch van den WJHM, Huygen FJA, Lagro-Janssen ALM, eds. Ziekten in de huisartspraktijk. Wetenschappelijke Uitgeverij Bunge. Utrecht. 1990.

110. Lodder J. Bamford J. Kappelle J. Boiten J. What causes false clinica! prediction of small deep infarcts? Stroke 1994: 25: 86-91.

111. Loiseau J. Loiseau P. Duché B. Guyot M. Dartigues JF. Aublet B. A survey of epileptic disorders in Southwest France: Seizures in elderly patients. Ann Neurol 1990; 27: 232-237.

112. López JLP, Longo J. Quintana F. Diez C, Berciano J. Late onset epileptic seizures. A retrospective study of 250 patients. Acta Neurol Scand 1985; 72: $380-384$.

113. Louis $\mathrm{S}$, McDowell F. Epileptic seizures in nonembolic cerebral infarction. Arch Neurol 1967: 17: 414-418.

114. Lühdorf K, Jensen LK, Plesner AM. Epilepsy in the elderly: incidence, social function, and disability. Epilepsia 1986; 27: 135-141.

115. Lühdorf K. Jensen LK. Plesner AM. Etiology of seizures in the elderly. Epilepsia 1986; 27: 458-463

116. Majkowski J. Posttraumatic epilepsy. In: Comprehensive Epileptology (Eds M. Dam and L. Gram). Raven Press. New York. 1990: pp 281-288.

117. Marcus R, Coulston AM. Water-soluble vitamins. The Vitamin B complex 
and ascorbic acid. Pyridoxine. In: Goodman and Gilman's The Pharmacological Basis of Therapeutics. A Goodman Gilman, TW Rall, AS Nies, P Taylor, eds. Eight Edition, Pergamon Press Inc. New York, 1990; pp 1538-1540.

1 18. Marquardson J. The natural history of acute cerebrovascular disease. A retrospective study of 769 patients. Acta Neurol Scand 1969; 45 (suppl 38): 9-192.

119. Matthews DE, Farewell VT. Ising and understanding medical statistics. 2nd, revised edition. S. Karger AG, Bascl. 1988.

120. McCulloch J, Bullock R, Teasdale GM. Fixcitatory amino acid antagonists: opportunities for the treatment of ischaemic brain damage in man. Chapter 14 in: Excitatory Amino Acid Antagonists. BS Meldrum, ed. Blackwell Scientific Publications, Oxford, 1991: pp 287-326.

121. Meldrum BS. Anatomy, physiology, and pathology of epilepsy. Lancet 1990; 336: 23।-234.

122. Melville KI. Antihistamine drugs. In: Histamine and antihistamines. M. Schachter, ed. International encyclopedia of pharmacology and therapeutics, Section 74. Pergamon Press Ltd, Oxford, 1973; pp 127-173.

123. Messing RO, Closson RG, Simon RP. Drug-induced seizures: A I0-year experience. Neurology (Cleveland) 1984: 34: 1582-1586.

124. Meyer JS, Charney IZ. Rivera VM. Mathew NT. Cerebral embolization: Prospective clinical analysis of 42 cases. Stroke 1971:2:541-554.

125. Milandre L, Brocil P. Sambuc R, Khalil R. Les crises épileptiques au cours et au décours des accidents cérébrovasculaires. Analyse clinique de 78 cas. Rev Neurol (Paris) 1992: 148: 767-772.

126. Milandre L. Broca P, Gabriel B, Khalil R. Les crises épileptiques secondaires aux accidents cérébrovasculaires. Ann Med Interne 1993; 144: 28-34.

127. Mohr JP. Caplan I.R. Melski JW. Goldstein RJ. Duncan GW. Kistler JP. Pessin MS, Bleich HL. The Harvard cooperative stroke registry: A prospective registry. Neurology 1978; 28: 754-762.

128. Mouritzen Dam A. Fuglsang-Frederiksen A. Svarre-Olsen U, Dam M. Late-onset epilepsy: etiologies, types of seizure, and value of clinical investigation, EEG, and computerized tomography scan. Epilepsia 1985; 26: $227-231$.

129. Mouritzen Dam A, Dam M. Neuropathology. In: Comprehensive Epileptology (Eds M. Dam and L. Gram). Raven Press. New York, 1990; pp 43-55.

130. Ng SKC, Hauser WA, Brust JCM, Susser M. Hypertension and the risk of new-onset unprovoked seizures. Neurology 1993: 43: 425-428.

131. Niessen LW. Barendregt JJ, Bonneux L. Koudstaal PJ. for the Technology Assessment Methods Project Team. Stroke trends in an aging population. Stroke 1993: 24: 931-939.

132. Norris JW. Zhu CZ. Silent stroke and carotid stenosis. Stroke 1992; 23: 483-485. 
133. Norusis MJ / SPSS inc. SPSS ${ }^{\circledR}$ for Windows ${ }^{\text {TM }}$ Base System User's Guide. Release 6.0. SPSS Inc., Chicago, Illinois, 1993.

134. Norusis MJ / SPSS inc. SPSS ${ }^{\circledR}$ for Windows ${ }^{\mathrm{TM}}$ Advanced Statistics. Release 5. SPSS Inc., Chicago, Illinois, 1992.

135. Nunes B, Barros J, Correia M, Lopes JC. Epilepsy and cerebrovascular diseases in an outpatient clinic. Cerebrovase Dis 1994; 4: 96-100.

136. Olsen TS. Factors of importance for the development of epilepsy in patients with cerebral infarction. Acta Neurol Scand 1984; 69 (suppl): 9596.

137. Olsen TS, Høgenhaven H, Thage O. Epilepsy after stroke. Neurology 1987; 37: 1209-1211.

138. Olson KR, Benowitz NL. Woo OF, Pond SM. Theophylline overdose: Acute single ingestion versus chronic repeated overmedication. Am J Emerg Med 1985; 3: 386-394.

139. O'Riordan Jl. Hutchinson J, Fitz Gerald MX, Hutchinson M. Amnesic syndrome after theophylline associated seizures: iatrogenic brain injury. $\mathrm{J}$ Neurol Neurosurg Psychiatry 1994; 57: 643-645.

140. Pirttimäki R, Narva EV, Ruikka I. Epilepsy as a sequel to cerebrovascular accident. Scand J Soc Med 1977: 14: 134-140.

141. Primavera A, Giberti L. Cocito L. Focal inhibitory seizures as the presenting sign of ischemic cerebrovascular disease. Ital J Neurol Sci 1993; 14: 381-384.

142. Ramirez-Lassepas M, Hauser WA, Bundlie SR, Cleeremans BB. Epileptiform activity, acute seizures and epilepsy with acute cerebral vascular disease. In: Advances in epileptology: the Xth Epilepsy International Symposium (Eds J.A. Wade and J.K. Penry). Raven Press, New York, 1980; pp 188.

143. Rankin J. Cerebral vascular accidents in patients over the age of 60: II Prognosis. Scot med J 1957: 2: 200 215.

144. Reynolds EH, Trimble MR. Adverse neuropsychiatric effects of anticonvulsant drugs. Drugs 1985; 29: 570-581.

145. Reynolds EH. Do anticonvulsants alter the natural course of epilepsy? Treatment should be started as early as possible. Br Med J 1995; 310: 176177.

146. Richardson EP Jr, Dodge PR. Epilepsy in cerebral vascular disease. A study of the incidence and nature of seizures in 104 consecutive autopsyproven cases of cerebral infarction and hemorrhage. Epilepsia 1954; 3: 49. 74.

147. Richens A. Perucca E. Clinical pharmacology and medical treatment. Chapter 15 in: A Textbook of Epilepsy. J Laidlaw, A Richens, D Chadwick, eds. Fourth Edition. Churchill Livingstone, London, 1993; pp 495-559.

148. Riggs JE. The decline of mortality due to stroke: A competitive and deterministic perspective. Neurology 1991; 41: 1335-1338.

149. Roberts MA. Godfrey JW. Caird FI. Epileptic seizures in the elderly: I. 
Aetiology and type of seizure. Age Ageing 1982: 1 1: 24-28.

150. Roberts RC, Shorvon SD, Cox TCS, Gilliatt RW. Clinically unsuspected cerebral infarction revealed by computed tomography scanning in late onset epilepsy. Epilepsia 1988; 29: 190-194.

151. Rothman KJ. Analysis of crude data. In: Modern Epidemiology (Kenneth J. Rothman). Little. Brown and Company, Boston/Toronto, 1986; pp 153 176.

152. Ryglewicz D. Barańska-Gieruszczak M, Niedzielska K, KrystWid7gouska T. EEG and CT findings in poststroke epilepsy. Acta Neurol Scand 1990; 81: 488-490.

153. Sacco RL, Shi T, Zamanillo MC, Kargman DE. Predictors of mortality and recurrence after hospitalized cerebral infarction in an urban community: The Northern Manhattan Stroke Study. Neurology 1994: 44: 626-634.

154. Sacquegna T, De Carolis P, Pazzaglia P, Andrcoli A. Limoni P. Testa C, Lugaresi $E$. The clinical course and prognosis of carotid artery occlusion. J Neurol Neurosurg Psychiatry 1982: 45: 1037-1039.

155. Sacquegna T, De Carolis P. Epileptic seizures in patients with cerebral arterial occlusive disease. Stroke 1983; 14: 305.

156. Sacquegna T, De Carolis P, Andreoli A. Ferrara R, Limoni P. Testa C, Lugaresi $\mathrm{E}$. Long term prognosis after ucclusion of middle cerebral artery. Br Med J 1984; 288: 1490-149I.

157. Sadoshima S, Fujii K, Ooboshi H. Ibayashi S, Fujishima M. Angiotensin converting enzyme inhibitors attenuate ischemic brain metabolism in hypertensive rats. Stroke 1993; 24: 1561-1567.

158. Salo AA, Feeney DM. Reduction of morbidity, mortality, and lesion size in a rat model of cerebral infarction with amphetamine. Soc Neurosci Abs 1987: 13: 1268.

159. Sandercock P. The Odds Ratio: a useful tool in neurosciences. J Neurol Neurosurg Psychiatry 1989; 52: 817-820.

160. Sayette V de la, Cosgrove R. Melanson D. Ethier R. CT findings in lateonset epilepsy. Can J Neurol Sci 1987; 14: 286-289.

161. Schallert T. Hernandez TD, Barth TM. Recovery of function after brain danlage: severe and chronic disruption by diazepam. Brain Res 1986; 379: 104-111.

In 2. Schold C. Yarnell PR. Earnest MP. Origin of seizures in elderly patients. JAMA 1977: 238: 1177-1178.

163. Schousboe A. Neurochemical alterations associated with epilepsy or seizure activity. In: Comprehensive Epileptology (Eds M. Dam and L. Gram). Raven Press. New York, 1990: pp 1-16.

164. Schwartz JC. Garbarg M, Pollard H. Histaminergic transmission in the brain. Chapter 5 in: Handbook of Physiology (SR Geiger. ed.) Section 1: The Nervous Svitem (VB Mountcastle. ed.) Volume IV: Intrinsic Rigulatory Systems of the Brain (FE Bloom, ed.). American Physiological Society, Bethi:nda, Maryland, 1986: pp 257-316. 
165. Schwartz JC, Arrang JM, Garbarg M, Pollard H. A third histamine receptor subtype: Characterisation, localisation and functions of the $\mathrm{H}_{3}$ receptor. Agents and Actions 1990; 30: 13-23.

166. Shinton RA, Gill JS, Melnick SC, Gupta AK, Beevers DG. The frequency, characteristics and prognosis of epileptic seizures at the onset of stroke. J Neurol Neurosurg Psychiatry 1988; 51: 273-276.

167. Shorvon SD, Gilliatt RW, Cox TCS, Yu YL. Evidence of vaseular disease from CT scanning in late onset epilepsy. J Neurol Neurosurg Psychiatry 1984; $47: 225-230$.

168. Silverstein A, Hollin S. Internal carotid vs middle cerebral artery occlusions. Arch Neurol 1965; 12: 468-471.

169. Singer EP. Kolischenko A. Seizures due to theophylline overdose. Chest 1985: 87: 755-757.

170. Smith ML, Kalimo H, Warner DS, Siesjö BK. Morphological lesions in the brain preceding the development of postischemic seizures. Acta Neuropathol 1988: 76: 253-264.

171. Steingart A, Hachinski VC, Lau C, Fox AJ, Diaz F, Cape R, Lee D, Inzitari $D$, Merskey $H$. Cognitive and neurologic findings in subjects with diffuse white matter lucencies on computed tomographic scan (Leuko-Araiosis). Arch Neurol 1987: 44: 32-35.

172. Sundaram MBM. Etiology and patterns of seizures in the elderly. Neuroepidemiology 1989; 8: 234-238.

173. Sung CY, Chu NS. Status epilepticus in the elderly: etiology, seizure type and outcome. Acta Neurol Scand 1989: 80: 51-56.

174. Sung CY, Chu NS. Epileptic seizures in intracerebral haemorrhage. J Neurol Neurosurg Psychiatry 1989: 52: 1273-1276.

175. Sung CY. Chu NS. Epileptic seizures in elderly people: aetiology and seizure type. Age Ageing 1990; 19: 25-30.

176. Sung CY, Chu NS. Epileptic seizures in thrombotic stroke. J Neurol 1990; 237: 166-170.

177. Sutton-Tyrrell K, Alcorn HG, Wolfson SK Jr, Kelsey SF, Kuller LH. Predictors of carotid stenosis in older adults with and without isolated systolic hypertension. Stroke 1993; 24: 355-361.

178. Svedmyr N, Rodger IW. Xanthines. Chapter 34 in: Asthma. Basic mechanisms \& Clinical management. PJ Barnes, IW Rodger, NC Thomson, eds. 2nd Edition. Academic Press Limited, London, 1992; pp 567-587.

179. Swieten van JC, Koudstaal PJ, Visser MC, Schouten HJA, Gijn van J. Interobserver agreement for the assessment of handicap in stroke patients. Stroke 1988; 19: 604-607.

180. Takagi K, Ginsberg MD. Globus MY-T. Dietrich WD. Martinez E, Kraydieh S. Busto $R$. Changes in amino acid neurotransmitters and cerebral blood flow in the ischemic penumbral region following middle cerebral artery occlusion in the rat: Correlation with histopathology. J 
Cereb Blood Flow Metab 1993; 13: 575-585.

181. Tallis R. Epilepsy in old age. Lancet 1990; 336: 295-296.

182. Tallis R, Hall G, Craig I, Dean A. How common are epileptic seizures in old age? Age Ageing 1991; 20: 442-448.

183. Ticku MK. Mechanism of GABA agonists and modulators of GABA ergic transmission in anticonvulsant activity. Chapter 7 in: GABA Mechanisms in Epilepsy. G Tunnicliff, BU Raess, eds. Wiley-Liss Inc, New York, 1991; pp 149-164.

184. Tracey F, Crawford VLS, Lawson JT, Buchanan KD, Stout RW. Hyperglycaemia and mortality from acute stroke. Q J Med 1993; 86: 439446.

185. Tunnicliff G, Raess BU. GABA neurotransmitter activity in human epileptogenic brain. Chapter 5 in: GABA Mechanisms in Epilepsy. G Tunnicliff, BU Raess. eds. Wiley-Liss Inc, New York, 1991; pp 105-119.

186. Twyman RE, Macdonald RL. Antiepileptic drug regulation of $\mathrm{GABA}_{\mathrm{A}}$ receptor channels. Chapter 4 in: GABA Mechanisms in Epilepsy. G Tunnicliff, BU Raess, eds. Wiley-Liss Inc, New York, 1991; pp 89-104.

187. Vitanen M, Eriksson S, Asplund K, Wester PO. Winblad B. Determinants of long-term mortality after stroke. Acta Med Scand 1987: 221: 349-356.

188. Viitanen M. Jiriksion S, Asplund K. Risk of recurrent stroke, myocardial infarction and epilepsy during long-term follow-up after stroke. Eur Neurol 1988: 28: 227-231.

189. Voll CL. Auer RN. Insulin attenuates ischemic brain damage independent of its hypoglycumic effect. J Cereb Blood Flow Metab 1991; 11: 10061014.

190. Voll CL, Auer RN. Postischemic seizures and necrotizing ischemic brain damage: Neuroprotective effect of postischemic diazepam and insulin. Neurology 1991; 41: 423-428.

19l. Warner DS, Gionet TX. Todd MM, McAllister AM. Insulin-induced normoglycemia improves ischemic outcome in hyperglycemic rats. Stroke 1992; 23: 1775-1781.

192. Weaver MS, l:armer LJ, Feeney DM. Norepinephrine receptor agonists and antagonists influence rate and maintenance of recovery of function after sensorimotor cortex contusion in rat. Soc Neurosci Abs 1987: 13: 477.

193. Weisherg LA, Shamsnia M, Elliott D. Seizures caused by nontraumatic parenchymal brain hemorrhages. Neurology 1991: 41: 1197-1199.

194. Werner C. Hoflmann WE. Kochs E. Rabito SF. Miletich DJ. Captopril improvis neurologic outcome from incomplete cerebral ischemia in rats. Stroke 1991: 22: 910-914.

195. Wijdicks EFM. Sharbrough FW. New-onset seizures in critically ill patients. Neurology 1993: 43: 1042-1044.

196. Willmore LJ. Post-traumatic epilepsy: Cellular mechanisms and implications for treatment. Epilepsia 1990; 31 (Suppl 3): S67-S73.

197. Willmore LJ. Posttraumatic epilepsy. Neurologic Clinics 1992; 10: 869-878. 
198. Wolf PA, Belanger AJ, D'Agostino RB. Quantifying stroke risk factors and potentials for risk reduction. Cerebrovasc Dis 1993; 3 (suppl 1): 7-14.

199. Wolfe CDA, Taub NA. Woodrow EJ, Burney PGJ. Assessment of scales of disability and handicap for stroke patients. Stroke 1991; 22: 1242-1244.

200. Woodcock S, Cosgrove JBR. Epilepsy after the age of 50. A five-year follow-up study. Neurology 1964; 14: 34-40.

201. Yablon SA. Posttraumatic seizures. Arch Phys Med Rehabil 1993; 74: 9831001 . 


\section{PUBLICATIONS}

Lodder J, Dennis MS, van Raak L, Jones LN, Warlow CP. Cooperative study on the value of long term anticoagulation in patients with stroke and non-rheumatic atrial fibrillation. Br Med J 1988; 296: 1435-1438.

Lodder J, Boiten J, Heuts-van Raak L. Sensorimotor syndrome relates to lacunar rather than to non-lacunar cercbral infarction. J Neurol Neurosurg Psychiatry 1992: 55: 1097.

Heuts-van Raak EPM, Boellaard A, de Krom MCTFM, Lodder J. Supratentorial brain infarcts in adult-onset seizures; the Maastricht Epilepsy Case Register. Seizure 1993; 2: 221-227.

Hupperts RMM. Lodder J. Wilmink J, Boiten I, Heuts-van Raak EPM. Haemodynamic mechanism in small subcortical borderzone infarcts? Cerebrovasc Dis 1993; 3: 231-235.

Luijckx GJ, Ukachoke C, Limapichat K. Heuts-van Raak EPM. Lodder J. Brain infarct causes under the age of fifty: a comparison between an East-Asian (Thai) and a Western (Dutch) hospital series. Clin Neurol Neurosurg 1993; 95: 199203.

Boon A. Lodder J. Heuts-van Raak L, Kessels F. Silent brain infarcts in 755 consecutive patients with a first-ever supratentorial ischemic stroke; the relationship with index stroke sublype, vascular risk factors, and mortality. Stroke 1994: 25: 2384-2391.

Hupperts RMM, Lodder J. Heuts-van Raak EPM. Kessels F. Infarcts in the anterior choroidal artery territory. Anatomical distribution, clinical syndromes, presumed pathogenesis and early outcome. Brain 1994: 117: 825-834.

Luijckx GJ. Boilen J. Lodder J, Heuts-van Raak L, Wilmink J. Isolated hemiataxia following supratentorial brain infarcts. J Neurol Neurosurg Psychiatry 1994: 57: 742-744.

Van Zagten M. Lodder J, Franke C. Heuts-van Raak L, Claassens C. Kessels F. Different vascular risk factor profiles in primary intracerebral haemorrhage and small deep infarcts do not suggest similar types of underlying small vessel disease. Cerebrovasc Dis 1994: 4: 121-124. 
Hupperts R, Wetzelaer W, Heuts-van Raak L, Lodder J. Is haemodynamical compromise a specific cause of borderzone brain infarcts following cardiac surgery? Eur Neurol 1995: 35: 276-280.

Heuts-van Raak EPM. Lodder J, Kessels F. Late seizures following a first symptomatic brain infarct are related to large infarcts involving the posterior area around the lateral sulcus. Seizure: accepted for publication.

Luijckx GJ, Boiten J, Lodder J. Heuts-van Raak L. Kessels F. Cardiac and carotid embolism, and other rare definite disorders are unlikely causes of lacunar ischaemic stroke in young patients. Cerebrovasc Dis; in press. 


\section{DANKWOORD}

Wat ooit begon als een verplichtte wetenschapsstage tijdens het derde jaar van mijn studie geneeskunde, is uiteindelijk uitgegroeid tot het proefschrift dat nu voor u ligt.

Die ontmoeting, nu bijna 10 jaar geleden, met mijn toenmalige begeleider en huidige co-promotor Dr. J. Lodder, heeft niet alleen tot dit proefschrift geleid, maar ook gevolgen gehad voor mijn verdere carrière-planning. Beste Jan, jouw enthousiasme voor het verrichten van wetenschappelijk onderzoek bleek zeer aanstekelijk te werken en heeft mijn interesse voor deze andere kant van de geneeskunde gewekt. Bedankt voor de prettige samenwerking die ongetwijfeld niet zal eindigen met de voltooiing van dit proefschrift.

Mijn promotor Prof. Dr. J. Troost dank ik voor de mogelijkheid die hij mij geboden heeft om dit onderzoek af te ronden toen het langer duurde dan voorzien.

In de loop der jaren zijn vele mensen betrokken geweest bij dit onderzoek, zoals bij het verzamelen en beoordelen van de honderden CT-scans. Een ieder die op enigerlei wijze een bijdrage heeft geleverd aan de totstandkoming van dit proefschrift wil ik daarvoor op deze plaats hartelijk bedanken.

Fin aantal (groepen) personen zou ik met name willen noemen, zonder de bijdrage van anderen te onderschatten.

De med'werkern van het medisch archief die mij al die jaren van de benodigde klinische en poliklinische statussen hebben voorzien.

De midewerkiters van de polikliniek Neurologie die de poliklinische statussen steeds van een follow-up formulier voorzagen.

Alle neurologen en (oud) arts-assistenten voor het invullen van deze "Post-CVA epilepsie" follow-up formulieren, ook al had de betreffende patiënt geen epilepsie.

De verpleeghuisartsen en secretaresses van de diverse verpleeghlinieken en de huisartsen en hun assistentes uit de regio, voor hun hulp bij het verzamelen van de follow-up gegevens vian de patiënten die de polikliniek niet meer bezochten. 
Fons Kessels voor zijn hulp bij de statistische analyws en zijn issmiële bijdrage aan mijn inwijding in de geheimen van de statistick.

Mijn collega's van de AIO kamer dank ik voor de (soms te) gezellige werksfeer en hun steun in moeilijker tijden.

Mijn ouders ben ik zeer erkentelijk voor de mogelijkheden die ze mij geboden hebben om te studeren en hun niet aflatende interesse in mijn werkzaamheden. Lieve pap, helaas heb je de afronding van dit proefschrift niet meer mogen meemaken. maar ik weet dat je ontzettend trots geweest zou zijn.

Tot slot mijn echtgenoot Hans. Beste Hans, dank voor je computer-technische ondersteuning en je substantiële bijdrage aan de afronding van dit proefschrift. Hopelijk komt er na mijn promotie weer wat meer rust. 


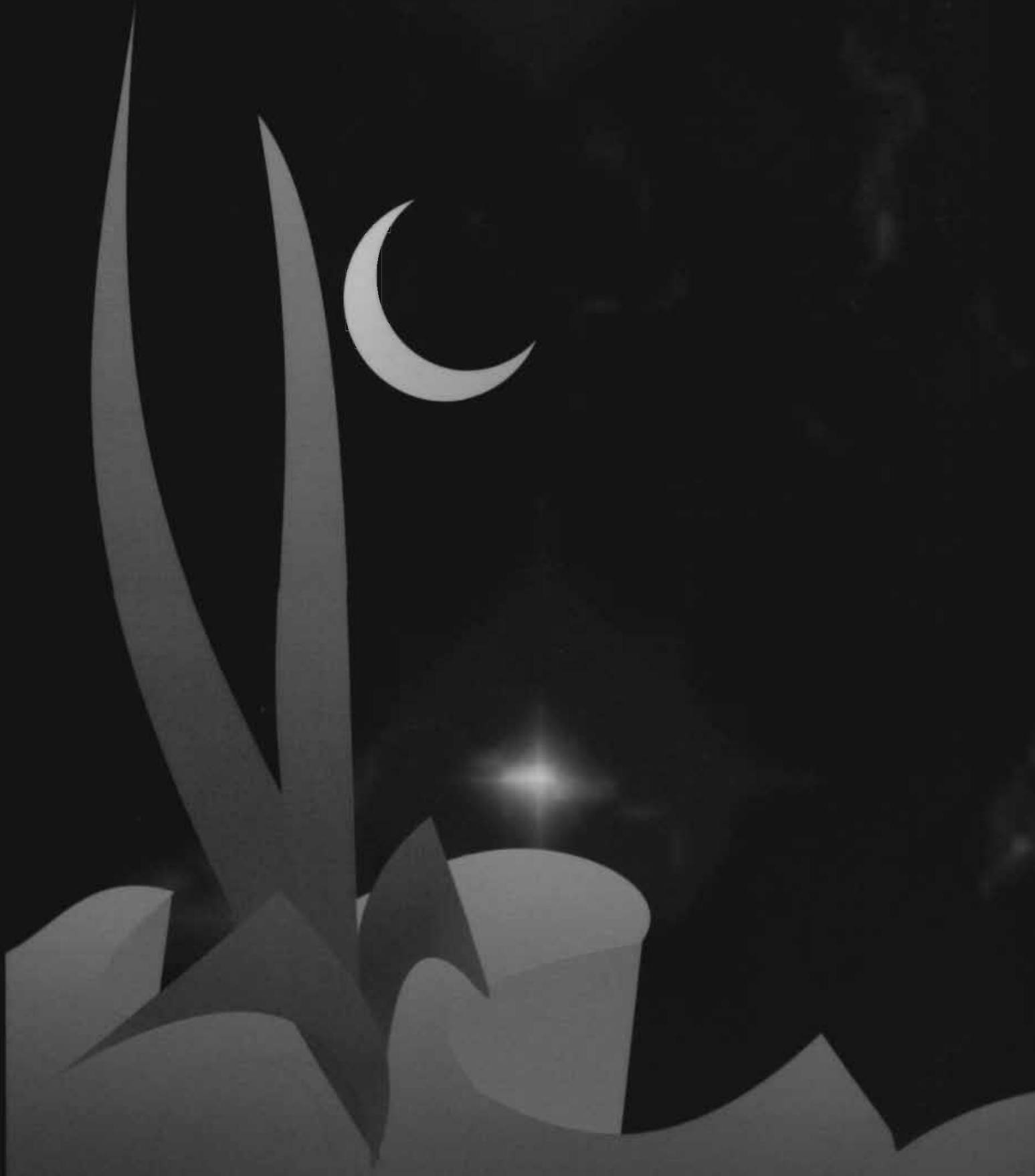

ISBN $90-9009220-\mathrm{X}$ 